\author{
UNIVERSIDADE DE SÃO PAULO \\ ESCOLA DE ENFERMAGEM DE RIBEIRÃO PRETO \\ UNIVERSIDADE NOVA DE LISBOA-PORTUGAL \\ ESCOLA NACIONAL DE SAÚDE PÚBLICA
}

DANIELLE TALITA DOS SANTOS

Os determinantes da mortalidade por Tuberculose e TB-HIV no Sul do Brasil: Da abordagem espacial à análise de sobrevida 


\section{Os determinantes da mortalidade por Tuberculose e TB-HIV no Sul do Brasil: Da abordagem espacial à análise de sobrevida}

Tese apresentada ao Programa Interunidades de Doutoramento em Enfermagem da Escola de Enfermagem da Universidade de São Paulo e Escola de Enfermagem de Ribeirão Preto da Universidade de São Paulo para obtenção do título de Doutor em Ciências.

Linha de pesquisa: Sociedade, Saúde e Enfermagem.

Orientador: Prof. Dr. Ricardo Alexandre Arcêncio

Tese apresentada sob regime de co-tutela para cumprimento dos requisitos necessários à obtenção do grau de Doutor em Saúde Pública, na Escola Nacional de Saúde Pública da Universidade Nova de Lisboa- Portugal.

Orientadora: $\operatorname{Prof}^{\mathrm{a}} \mathrm{Dr}^{\mathrm{a}}$ Carla do Rosário Delgado Nunes de Serpa

Ribeirão Preto

2019 
Autorizo a reprodução e divulgação total ou parcial deste trabalho, por qualquer meio convencional ou eletrônico, para fins de estudo e pesquisa, desde que citada a fonte.

\section{FICHA CATALOGRÁFICA}

Santos, Danielle Talita

Os determinantes da mortalidade por Tuberculose e TB-HIV no Sul do Brasil: Da abordagem espacial à análise de sobrevida. Ribeirão Preto-SP, 2019.

120. p. : il. ; $30 \mathrm{~cm}$

Tese de Doutorado, apresentada à Escola de Enfermagem de Ribeirão Preto e sob regime de co-tutela à Escola Nacional de Saúde Pública da Universidade Nova de Lisboa- Portugal.

Orientador nacional: Prof. Dr. Ricardo Alexandre Arcêncio

Orientadora estrangeira: Prof ${ }^{a}$ Dr $^{a}$ Carla do Rosário Delgado Nunes de Serpa

1. Tuberculose. 2. Análise espacial. 3. Determinantes sociais da saúde. 4. Mortalidade. 5. TB/HIV 
SANTOS, Danielle Talita

Os determinantes da mortalidade por Tuberculose e TB-HIV no Sul do Brasil: Da abordagem espacial à análise de sobrevida

Tese apresentada ao Programa Interunidades de Doutoramento em Enfermagem da Escola de Enfermagem da Universidade de São Paulo e Escola de Enfermagem de Ribeirão Preto da Universidade de São Paulo para obtenção do título de Doutor em Ciências da Saúde e sob regime de co-tutela com a Escola Nacional de Saúde Pública da Universidade Nova de Lisboa-Portugal

Aprovada em:

\section{Comissão Julgadora}

Prof. Dr.

Instituição:

Prof. Dr.

Instituição:

Prof. Dr.

Instituição:

Prof. Dr.

Instituição:

Prof. Dr.

Instituição: 
Ao Pai da Eternidade, por me conceder vida através de meus amados Pais, que me prepararam para ela. 


\section{Agradecimentos}

Em primeiro lugar, concedo honra e glória à Deus pela vida, pela existência que me levou a trilhar mais este caminho;

Agradeço

Ao Programa de pós-graduação Interunidades de Doutoramento em Enfermagem da Escola de Enfermagem da Universidade de São Paulo e Escola de Enfermagem de Ribeirão Preto;

À Escola Nacional de Saúde Pública e Universidade Nova de Lisboa- Portugal;

À coordenação de aperfeiçoamento de pessoa de nível superior (CAPES);

Ao Professor Ricardo Alexandre Arcêncio, pelas oportunidades proporcionadas, orientação e apoio; orientação;

À professora Carla Nunes pela acolhida, orientação e dedicação em minha

À professora Elma Mathias Dessunti, por ter acreditado e investido em mim, me proporcionando novos horizontes;

Aos colegas dos grupos de pesquisa: Grupo de Altos Estudos de Processos e Práticas de Atenção Primária à Saúde e Enfermagem (GAAPS) e Grupo de Estudos Epidemiológico-Operacional em Tuberculose (GEOTB);

Aos colegas e ao mesmo tempo instrutores do saber-fazer, com quem partilhamos experiências e aprendizados, um agradecimento carinhoso: Concy Garcia, Ana Angélica Rego, Aylana Belchior, Marcela Popolin, Juliane Crispim, Josylene Dalia, Luiz Arroyo, Miguel e Denise Fuentealba, Mellina Yamamura, Luana Seles, Marcos Arcoverde, Thais Berra, Clara Souza, Flavia Pieri, Antônio Ramos, Laura e todos os outros que não cito aqui os nomes, mas trocaram experiências e momentos de aprendizado ao longo desta jornada;

Àquelas que se tornaram minhas amigas e irmãs por dividir, partilhar e suportar, às "meia-patas" meu abraço carinhoso.

À minha família, meu pai Claudio, pelo suporte constante, pela força, por nunca desistir...

À minha mãe Rita, por seu afeto constante e infindavel, minha inspiração para vida

À minha irmã Karine, pelas risadas, momentos presentes e momentos distantes.

Ao meu marido Vinicius, por partilhar comigo uma jornada ainda mais elevada, que inclui todas as outras pequenas e grandes caminhadas, inclusive esta.

Minha sincera e profunda gratidão. 


\section{RESUMO}

SANTOS, Danielle Talita. Os determinantes da mortalidade por Tuberculose e TB-HIV no Sul do Brasil: Da abordagem espacial à análise de sobrevida. 2019. 120.f. Tese (Doutorado) - Escola de Enfermagem de Ribeirão Preto, Universidade de São Paulo sob regime de co-tutela Escola Nacional de Saúde Pública, Universidade Nova de Lisboa-Portugal. Ribeirão Preto, 2019.

O estudo teve como objetivo analisar os determinantes sociais da saúde associados à mortalidade por TB e verificar as mortes precoces ocorridas por TB e TB/HIV e seus fatores associados, por meio de duas abordagens: uma de base ecológica e uma de base individual, utilizando análise espacial e de sobrevida. O estudo foi realizado na capital do Paraná, Curitiba; e, para análise espacial, foram consideradas as 148 unidades de desenvolvimento humano (UDH). A população de estudo foi composta dos casos de mortes por TB como causa básica (CID 15-19). Para análise de sobrevida, foram acrescidos os casos de mortes pela coinfecção TB/HIV (CID 20.0). Os dados foram obtidos do Sistema de Informação sobre Mortalidade (SIM) e do Sistema de Informações sobre Doenças de Notificação (SINAN) referentes ao período 2008 a 2015. As Unidades de Desenvolvimento Humano foram caracterizadas de acordo com a mortalidade por TB e com as variáveis dos determinantes sociais da saúde. Inicialmente os casos de óbitos por TB foram geocodificados e calculadas taxas de mortalidade bruta, taxa Bayesiana e investigados quanto à autocorrelação espacial e existência de aglomerados de risco por meio da técnica de varredura espacial e obtidos riscos relativos espaciais. Para correlacionar as áreas de risco espacial para mortalidade por TB foi utilizada a regressão logística, tendo como variável dependente área de risco: sim e não, e após avaliado com uso da curva ROC, também foi elaborado um mapa de sobreposição de áreas de risco dos determinantes sociais da saúde e correlacionados com aglomerados de risco para mortalidade. Por último, para investigar as mortes precoces por TB e TB/HIV e fatores associados foi utilizada a técnica de Kaplan-Meier e Regressão de Cox. Foram identificados 131 óbitos por $\mathrm{TB}$, dos quais $126(96,2 \%)$ foram geocodificados e $05(4,8 \%)$ foram excluídos devido a endereços incompletos. Para a primeira fase, foram calculadas as taxas resultado em taxa média bruta de 1,07/100.000 habitantes. As mortes estiveram distribuídas de maneira difusa, porém, com maior concentração nas regiões periféricas e sul do município. Foi detectado um aglomerado espacial de risco na região sul para mortalidade por TB e para variáveis dos determinantes sociais da saúde, sendo onde as piores condições foram detectadas. O estudo confirmou a relação entre os determinantes sociais e as áreas de risco de mortes por TB quando relacionados com a Dimensão 1 extraída com ( $\mathrm{OR}=0,093$; IC95\% 0,34-0,25). O mapa de sobreposição dos aglomerados de risco relacionados com aglomerado para mortalidade por TB resultou em um OR= 5,98 (IC95\%: 2,41-14,49) e curva $\mathrm{ROC}=0,865 ;$ IC95\%=0,796-0,934. $\mathrm{Na}$ segunda fase, ao analisar as mortes precoces por TB, foi encontrada uma mediana de dias sobrevividos de 22 dias, sendo que $88(59,1 \%)$ dos pacientes morreram até 30 dias após o diagnóstico e 107 (72,5\%) após 60 dias (mínimo: 1, máximo: 349, D.P: 68,8 e média: 50 dias). Dentre os 179 óbitos analisados, 105 (58,6\%) óbitos tinham diagnóstico de TB (CID 15.0-19) e $74(41,4 \%)$ óbitos a coinfecção TB/HIV (CID 20.0). A maioria dos casos ocorreu em pessoas do sexo masculino, $138(77,1 \%)$, da raça/ cor branca predominante $120(67 \%)$ e a média de idade foi de 47 anos (mínimo:20, máximo: 94, mediana: 44, DP: 14). Os resultados corroboram com a necessidade de melhorias múltiplas nas condições de vida da população, com enfoque nas regiões mais vulneráveis (áreas de aglomerados de risco espacial) identificadas e políticas 
específicas para prevenção do uso de álcool, diante da identificação deste fator associado às mortes precoces.

Palavras chave: Tuberculose, TB/HIV, análise espacial, análise de sobrevivência, mortes precoces, mortalidade

\begin{abstract}
SANTOS, Danielle Talita. The determinants of tuberculosis and HIV-TB mortality in Southern Brazil: From the spatial approach to the survival analysis2019. 120.f. Tese (Doutorado) - Escola de Enfermagem de Ribeirão Preto, Universidade de São Paulo sob regime de co-tutela Escola Nacional de Saúde Pública, Universidade Nova de Lisboa-Portugal. Ribeirão Preto, 2019.
\end{abstract}

The objective of the study was to analyze the social determinants of health associated with TB mortality and to verify the early deaths caused by TB and TB / HIV and their associated factors, through two approaches: one based on an ecological basis and an individual basis using analysis spatial and survival The study was carried out in the capital of Paraná, Curitiba; and for spatial analysis, the 148 human development units (UDH) were considered. The study population was composed of cases of TB deaths as the underlying cause (ICD 15-19). Survival analysis included cases of TB / HIV coinfection deaths (ICD 20.0). Data were obtained from the Mortality Information System (SIM) and the Notification Disease Information System (SINAN) for the period 2008 to 2015. The Human Development Units were characterized according to TB mortality and the variables determinants of health. Initially the cases of TB deaths were geocoded and gross mortality rates, Bayesian taxa were calculated and investigated for spatial autocorrelation and existence of clusters of risk by means of the spatial scanning technique and obtained relative spatial risks. In order to correlate spatial risk areas with mortality from TB, logistic regression was used as a risk variable: yes and no and after being evaluated using the ROC curve, a map of overlapping risk areas of social determinants correlated with clusters of risk for mortality. A total of $131 \mathrm{~TB}$ deaths were identified, $126(96.2 \%)$ of which were geocoded and $05(4 \%)$ of the deaths were TB and HIV and associated factors were Kaplan-Meier and Cox Regression. A total of 131 TB deaths were identified, of which 126 (96.2\%) were geocoded and 05 (4.8\%) were excluded due to incomplete addresses. For the first phase, the results were calculated at a gross average rate of 1.07 / 100,000 inhabitants. The deaths were distributed in a diffuse way, however, with greater concentration in the peripheral and southern regions of the municipality. It was detected a spatial cluster of risk in the southern region for mortality by TB and for variables of the social determinants of health and where the worst conditions were detected. The study confirmed the relationship between social determinants and risk areas for TB deaths when related to Dimension 1 extracted with $(\mathrm{OR}=0,093$; IC95\% 0,34-0,25). The map of overlapping cluster-related risk clusters for TB mortality resulted in an $\mathrm{OR}=5.95$ IC95\% $=2.41-14.49$ and ROC curve $=0.865($ CI95\% $=0.796-0.934)$. In the second phase, when analyzing the early TB deaths, a median number of surviving days of 22 days was found, of which $88(59.1 \%)$ died within 30 days after diagnosis and 107 (72.5\%) after 60 days days (minimum: 1, maximum: 349, SD: 68.8 and average: 50 days). Among the 179 deaths analyzed, 105 (58.6\%) deaths had a diagnosis of TB (ICD 15.0-19) and 74 (41.4\%) had TB / HIV co-infection (ICD 20.0). The majority of the cases occurred in males, $138(77.1 \%)$, the predominant white race (67\%) and the mean age was 47 years (minimum: 20, maximum: 94, median: 44, DP: 14). The results corroborate the need for multiple improvements in the living conditions of the population, with a focus on the most vulnerable regions (areas of 
agglomerates of spatial risk) identified and specific policies to prevent alcohol use, in view of the identification of this factor associated with early deaths.

Key words: Tuberculosis, TB / HIV, spatial analysis, survival analysis, early deaths, mortality

\section{RESUMEN}

SANTOS, Danielle Talita. Los determinantes de la mortalidad por Tuberculosis y TB-VIH en el Sur de Brasil: Del abordaje espacial al análisis de supervivência. 2019. 118.f. Tese (Doutorado) - Escola de Enfermagem de Ribeirão Preto, Universidade de São Paulo sob regime de co-tutela Escola Nacional de Saúde Pública, Universidade Nova de Lisboa-Portugal. Ribeirão Preto, 2019.

El estudio tuvo como objetivo analizar los determinantes sociales asociados a la mortalidad por TB y verificar las muertes precoces ocurridas por TB y TB / VIH y sus factores asociados, por medio de dos abordajes: una de base ecológica y una de base individual utilizando análisis espacial y de supervivência. El estudio fue realizado en la capital de Paraná, Curitiba; y para el análisis espacial, se consideraron las 148 unidades de desarrollo humano (UDH). La población de estudio se compuso de los casos de muertes por TB como causa básica (CID 1519). Para el análisis de sobrevida se añadieron los casos de muertes por la coinfección TB / VIH (CID 20.0). Los datos fueron obtenidos del Sistema de Información sobre Mortalidad (SIM) y del Sistema de Información sobre Enfermedades de Notificación (SINAN) referentes al período 2008 a 2015. Las Unidades de Desarrollo Humano fueron caracterizadas de acuerdo con la mortalidad por TB y con los determinantes social. Inicialmente los casos de muertes por TB fueron geocodificados y se calcularon tasas de mortalidad bruta, tasa Bayesiana e investigados en cuanto a la autocorrelación espacial y la existencia de aglomerados de riesgo por medio de la técnica de exploración espacial y obtenidos riesgos relativos espaciales. Para correlacionar las áreas de riesgo espacial para mortalidad por TB se utilizó la regresión logística teniendo como variable dependiente área de riesgo: sí y no y después de evaluado con uso de la curva ROC. Por último, para investigar las muertes precoces por TB y TB / VIH y factores asociados se utilizó la técnica de Kaplan-Meier y Regresión de Cox. Se identificaron 131 muertes por TB de las cuales 126 (96,2\%) fueron geocodificados y $05(4,8 \%)$ fueron excluidos debido a la incompleta de la dirección. Para la primera fase, se calcularon las tasas resultantes en tasa media bruta de 1,07 / 100.000 habitantes. Las muertes estuvieron distribuidas de manera difusa, sin embargo, con mayor concentración en las regiones periféricas y sur del municipio. Se detectó un aglomerado de riesgo en la región sur para mortalidad por TB y para variables de los determinantes sociales de la salud siendo las peores condiciones fueron detectadas. El estudio confirmó la relación entre los determinantes sociales y las áreas de riesgo de muertes por TB en relación con la Dimensión 1 extraída con $(\mathrm{OR}=0,093$; $\mathrm{IC}=0,34-0,25)$. El mapa de superposición de los aglomerados de riesgo relacionados con el aglomerado de mortalidad por TB resultó en un $\mathrm{OR}=5,98(\mathrm{IC} 95 \%=2,41-14,49)$ y curva $\mathrm{ROC}=0,865$ (IC95\%=0,796-0,934). En la segunda fase, al analizar las muertes precoces por TB se encontró una mediana de días sobrevivientes de 22 días, siendo que $88(59,1 \%)$ de los pacientes murieron hasta 30 días después del diagnóstico y 107 (72,5\%) después de 60 días (mínimo: 1, máximo: 349, DP: 68,8 y media: 50 días). Entre los 179 muertes analizados, $105(58,6 \%)$ las muertes tenían diagnóstico de TB (CID 15.0-19) y 74 (41,4\%) muertes por la coinfección TB / VIH (CID 20.0). La mayoría de los casos ocurrieron en personas del sexo masculino, $138(77,1 \%)$, de la raza / color blanca predominante $120(67 \%)$ y la media de edad fue de 47 años (mínimo: 20, máximo: 94, 
mediana: 44, DP: 14). Los resultados corroboran con la necesidad de mejoras múltiples en las condiciones de vida de la población, con enfoque en las regiones más vulnerables (áreas de aglomerados de riesgo espacial) identificadas y políticas específicas para prevención del uso de alcohol, frente a la identificación de este factor asociado a las muertes precoces.

Palabras clave: Tuberculosis, TB / VIH, análisis espacial, análisis de supervivencia, muertes precoces, mortalidad 


\section{LISTA DE FIGURAS}

Figura 1 - Abrangência Projeto Multicêntrico - FAPESP - "A mortalidade por tuberculose e sua relação com as iniquidades sociais: um estudo multicêntrico" (2015-

2017)

Figura 2 - Fluxograma das fases e seleções dos artigos do mapeamento sistemático da literatura

Figura 3 - Determinantes Sociais da Saúde: modelo de Dahlgren e Whitehead

Figura 4 - Os Determinantes Sociais da Saúde (Solar e 52 Irvan).

Figura 5 - Localização geográfica das Unidades de Desenvolvimento Humano no município de Curitiba, Paraná, Brasil

Figura 6 - Síntese esquemática dos procedimentos analíticos segundo objetivo do estudo.

Curitiba,

Paraná,

Brasil

(20082015)

Figura 7 - Distribuição das taxas de mortalidade por tuberculose. Curitiba, Paraná,

Brasil (2008-2015)

Figura 8 - Aglomerado de risco espacial de mortes por tuberculose e risco relativo espacial atribuídos às unidades de desenvolvimento humano-UDH. Curitiba, Paraná, Brasil (2008-2015)

Figura 9 - Distribuição gráfica das variáveis dos determinantes sociais da saúde nas Unidades de desenvolvimento humano-UDH. Curitiba, Paraná, Brasil (200874 $2015) \ldots$

Figura 10 - Aglomerado de risco espacial das variáveis dos determinantes sociais da saúde. Curitiba, Paraná, Brasil (2008-2015)

Figura 11 - Sobreposição dos aglomerados de risco espacial das variáveis dos Determinantes sociais da saúde mais representativas e da mortalidade por TB. Curitiba, Paraná, Brasil (2008-2015)

Figura 12 - Fluxograma da inclusão dos casos de óbitos por TB e TB/HIV e as 
análises $\quad$ adotadas. $\quad$ Curitiba, $\quad$ Paraná, $\quad$ Brasil $\quad$ (2008- 83 2015)

Figura 13 - As Curvas obtidas pela análise de Kaplan-Meier para sobrevida em relação ao uso de álcool em pacientes que morreram por TB e de TB-HIV. Curitiba, Paraná, Brasil (2008-2015).

\section{LISTA DE QUADROS}

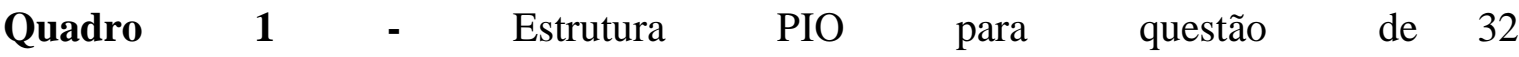
pesquisa.

Quadro 2 - Artigos originais publicados a partir de 2010 nas Bases de Dados: Pubmed e Scielo com os descritores: "tuberculosis" AND "mortality” OR "deaths" AND "determinants" OR "risk factors". Ribeirão Preto- SP, 34 2016

Quadro 3 - Formas clínicas consideradas no estudo, segundo a Classificação Internacional de Doenças versão 10 (CID 10)......................................................... 55

Quadro 4 - Variáveis consideradas para análise dos determinantes sociais da saúde. $\quad 58$

Quadro 5 - Variáveis individuais analisadas. Curitiba, Paraná, Brasil (2008-2015)... 61 


\section{LISTA DE TABELAS}

Tabela 1 - Índice de Desenvolvimento Humano de Curitiba, Paraná, Brasil.

Tabela 2 - Distribuição dos valores mínimo, máximo, médio, mediano e desviopadrão das variáveis dos determinantes sociais da saúde analisados. Curitiba, Paraná, Brasil

(2008- 73 2015)

Tabela 3 - Índice de Moran bivariado da associação dos determinantes sociais da saúde e a mortalidade por TB. Curitiba, Paraná (2008- 76 2018)

Tabela 4 - Informações sobre os aglomerados de risco das variáveis dos determinantes sociais da saúde. Curitiba, Paraná, Brasil (2008- 78 2015)

Tabela 5 - Teste de independência do Qui-quadrado entre as áreas dos aglomerados das variáveis dos determinantes sociais da saúde e áreas de risco de mortes por TB, Curitiba, Paraná, Brasil (2008-2015)

Tabela 6 - Dimensões dos determinantes sociais da saúde extraídas por meio da Análise de Componentes Principais Categórica. Curitiba, Paraná, Brasil (200880 2015)

Tabela 7 - Associação dos determinantes sociais às áreas de risco de mortes por TB, Curitiba, Paraná, Brasil (2008-2015).

Tabela 8 - Regressão logística Score da sobreposição dos aglomerados de risco das variáveis dos Determinantes Sociais da Saúde e as áreas de risco de mortes por TB, Curitiba, Paraná, Brasil (2008-2015)

Tabela 9 - Distribuição das características clínica e operacionais dos casos de óbitos. Curitiba, Paraná, Brasil $(2008-\quad 84$ 2015)

Tabela 10 - Análise de sobrevida: Kaplan-Meier e Cox bivariado entre pacientes que morreram por TB e TB/HIV e os determinantes individuais, Curitiba, Paraná, Brasil (2008- 
Tabela 11 - Regressão de Cox multivariada dos determinantes associados às mortes por tuberculose em Curitiba, Paraná, Brasil (20082015). 


\section{LISTA DE ABREVIATURAS}

BCG Bacille Calmette-Guerin

BRICS Brasil, Federação Russa, Índia, China e África do Sul

CID -10 Classificação Internacional de Doenças versão 10

CNDSS Comissão Nacional sobre os Determinantes Sociais da Saúde

DO Declaração de Óbito

DOTS Directly Observed Treatment Shiort-Course

EERP Escola de Enfermagem de Ribeirão Preto

End TB Estratégia para o fim da tuberculose

FAPESP Fundação de Amparo à Pesquisa do Estado de São Paulo

HIV Human Immuno deficiency Virus

IBGE Instituto Brasileiro de Geografia e Estatística

IC Intervalo de confiança

IDH Índice de Desenvolvimento Humano

LISA Índice de Moran local bivariado

Mvaccae Mycobacterium vaccae

OMS Organização Mundial de Saúde

ONU Organização das Nações Unidas

OR Odds Ratios

PNUD Programa das Nações Unidas para o Desenvolvimento

ROC Receiver Operating Characteristic Curve

RR Risco relativo

SIG Sistema de Informação Geográfica

SIM Sistema de Informações sobre Mortalidade

SIRGAS Sistema de Referência Geocêntrico para as Américas

SPSS Statistical Package for the Social Sciences

SUS Sistema Único de Saúde

TB Tuberculose

TB-MDR Tuberculose multidrogarresistente

TDO Tratamento Diretamente Observado

TxMTB Taxas de mortalidade por TB

UDH Unidade de Desenvolvimento Humano 
UDHs Unidades de Desenvolvimento Humano

USP Universidade de São Paulo

UTM Universal Transversa de Mercator

WHO World Health Organization 


\section{SUMÁRIO}

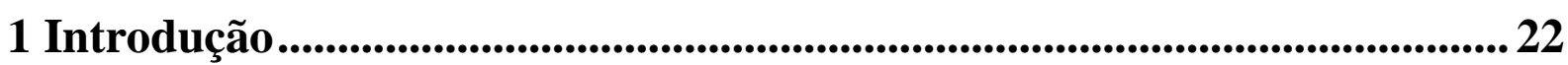

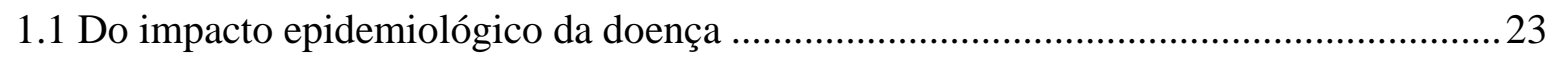

1.2 As políticas de Controle da TB ao longo do tempo e novas perspectivas diagnósticas e

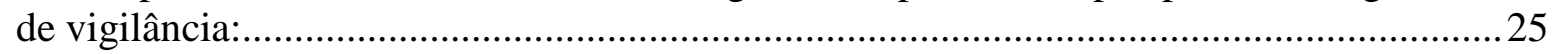

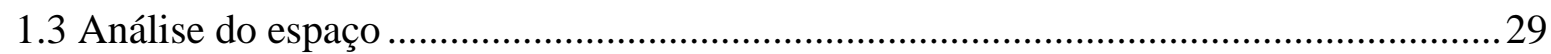

2 Mapeamento sistemático da literatura..................................................................... 33

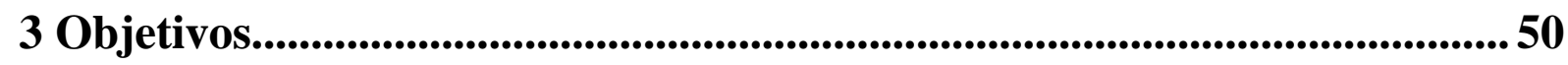

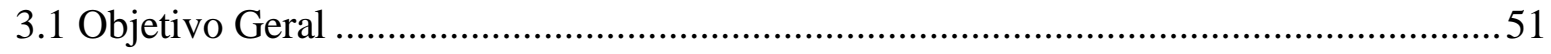

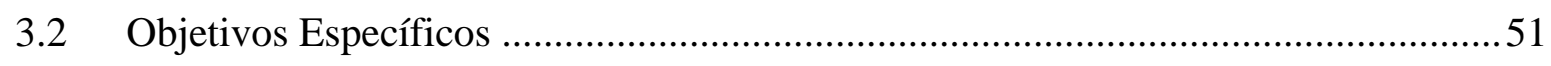

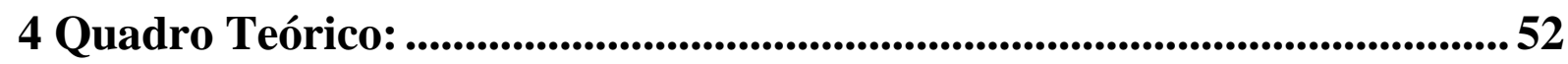

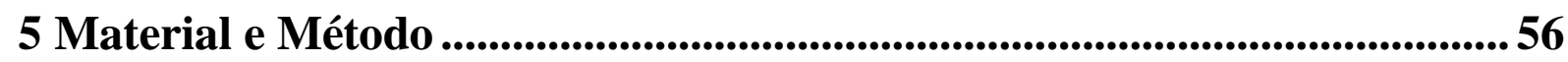

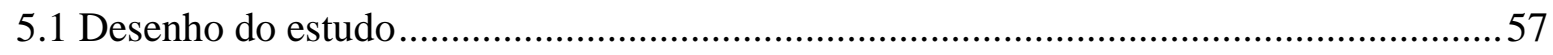

5.2 População de estudo, critérios de inclusão e unidades de observação ............................57

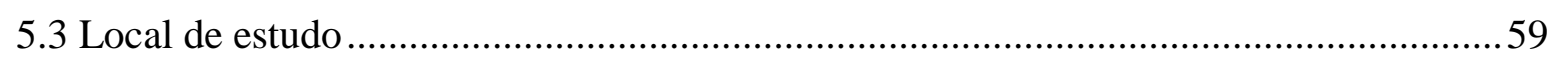

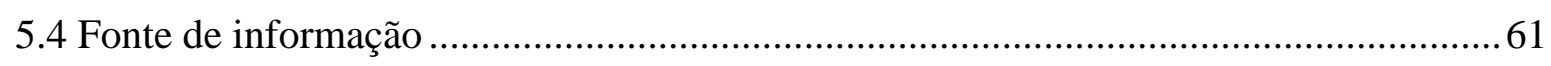

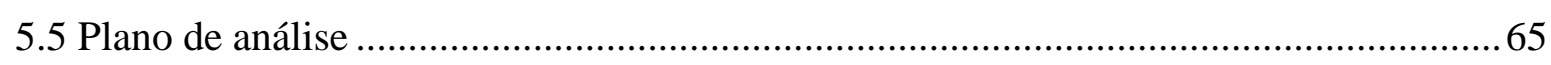

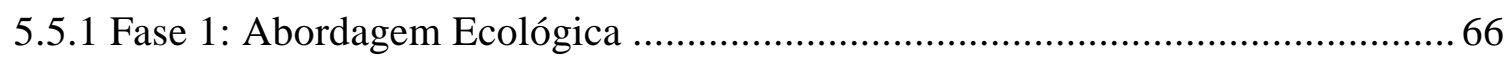

5.5.2 Fase 2: Análise de sobrevida: estudo de base individual, do tipo coorte

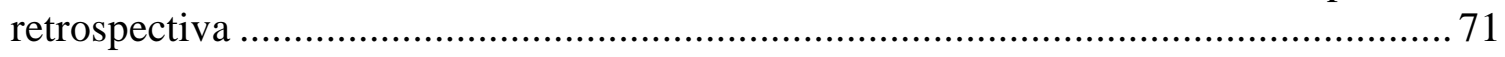

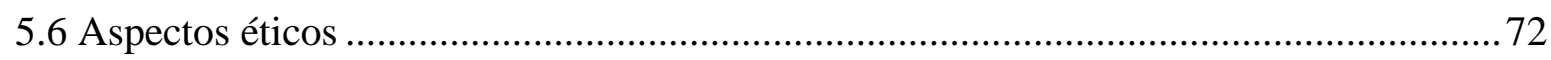

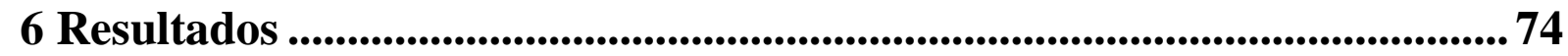

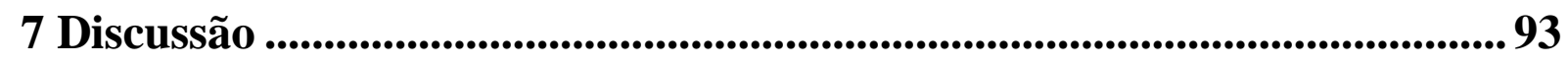

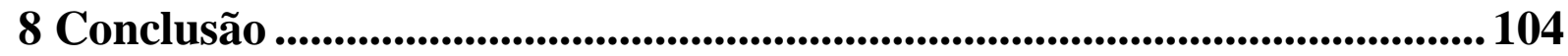

Referências ...................................................................................................106

Anexos...................................................................................................................................... 121 
Apresentação 
Meu interesse na realização do doutorado surgiu quando recém-formada e atuando como enfermeira assistencial e, diante das minhas inquietações e motivações, tive a oportunidade de acompanhar estágios e disciplinas teóricas em uma Faculdade da cidade de Londrina-PR.

Neste processo de ensino-aprendizagem, realizei duas especializações, Controle de Infecções em Serviços de Saúde e Biologia da Saúde, com intuito de desenvolver competências na área de ensino superior/docência; a monografia que desenvolvi nesta fase relacionava-se aos temas de infecção bacteriana e controle em serviços de saúde.

O interesse e compromisso de me envolver com a Academia só cresceu depois desse período, levando à realização do mestrado em Enfermagem na Universidade Estadual de Londrina- UEL, sob orientação da professora Elma Mathias Dessunti, com expertise na área de doenças infecciosas: HIV e Tuberculose.

No curso, me aprofundei nos assuntos envolvendo ambas as doenças, TB e HIV, que culminaram no tema da minha dissertação de mestrado. Na defesa do mestrado recebemos como convidado externo para a Banca Examinadora o Prof. Dr. Ricardo Alexandre Arcêncio, que trouxe grandes contribuições para o aprimoramento da pesquisa. Neste grato encontro, muitas oportunidades se abriram, inclusive com o auxílio do grupo de pesquisa do referido pesquisador para melhoria da qualidade dos resultados oriundos da dissertação e publicação em revista de seletiva política editorial e arbitragem (SANTOS et al., 2017). Desta parceira veio o convite para o doutorado, o que aconteceu com a entrada no Programa de PósGraduação Interunidades de Doutoramento em Enfermagem da Escola de Enfermagem (EEUSP) e Escola de Enfermagem de Ribeirão Preto (EERP/USP).

Após ingresso no programa, surgiu a oportunidade de realizar o doutorado sanduíche por meio do edital da Coordenação de Aperfeiçoamento de Pessoal de Nível Superior (CAPES) junto à Escola Nacional de Saúde Pública-ENSP da Universidade Nova de Lisboa (ENSP-UNL) sob a supervisão da Profa. Dra. Carla Nunes, que resultou em um estágio de Dupla Titulação. Essa experiência teve duração de um ano, em que foram possíveis grandes aprendizados nas áreas da estatística análise espacial, sob a orientação da pesquisadora e articulação com demais estudantes e pesquisadores da ENSP-UNL.

Oriundos da tese que ora apresentamos, tivemos um artigo publicado em revista de impacto internacional (SANTOS et al., 2018a) e mais dois artigos submetidos, que estão em 
fase de análise (SANTOS et al., 2018b; SANTOS et al., 2019b). Os resultados oriundos desta pesquisa também foram apresentados na 49th Union World Conference on Lung Health realizada em Haia em 2018, na Holanda (SANTOS et al., 2018c), que é a mais prestigiada Conferência Internacional na área da tuberculose, em que participam pesquisadores expoentes em todo o mundo, e foi um privilégio ter nossos resultados aceitos por esta Conferencia e publicados em anais pelo International Journal of Tuberculosis and Lung Disease (IJTLD).

Destacamos que a tese é decorrente de um projeto matriz intitulado "A mortalidade por tuberculose e sua relação com as iniquidades sociais: um estudo multicêntrico" (Processo 2015/17586-3- FAPESP), sob a liderança do Prof. Dr. Ricardo Alexandre Arcêncio, que está em desenvolvimento em municípios das cinco macrorregiões do país, que são Ribeirão Preto/SP (sudeste), Natal/RN (nordeste), São Luís/MA (nordeste), Manaus/AM (norte), Londrina/PR, Foz do Iguaçu/ PR, Curitiba/ PR (sul) e Cuiabá/MT (centro-oeste); na Figura 1 são trazidos estes cenários. Também faço parte do Grupo de Estudos EpidemiológicoOperacional em Tuberculose (GEOTB) da Rede Brasileira de Pesquisa em Tuberculose (REDE-TB), que inclui a investigação estudos de análise espacial e espaço-temporal da tuberculose e dos territórios em risco e ou vulneráveis; assim, nossos estudos estão alinhados à missão e objetivo deste grupo, que é produção de conhecimento nesta área, para avançar em termos de políticas e práticas de saúde. 
Figura 1 - Abrangência Projeto Multicêntrico - FAPESP- "A mortalidade por tuberculose e sua relação com as iniquidades sociais: um estudo multicêntrico" (2015-2017).

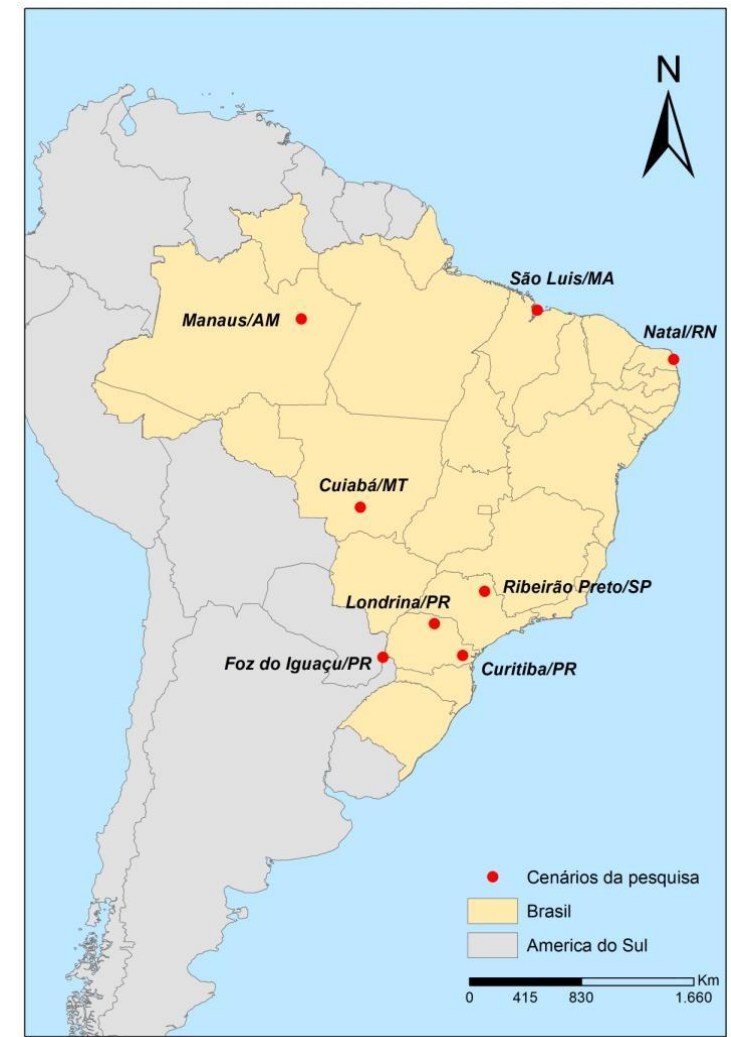

Fonte: Projeto Multicêntrico - FAPESP (2015/17586-3)

A tese está estruturada em introdução, revisão sistemática da literatura, objetivos da pesquisa, quadro teórico, metódos, resultados e discussão, ao final estão dispostas as referências e anexos, conforme regimento do Programa de Doutoramento Interunidades da EERP-USP. 


\section{Introdução}




\subsection{Do impacto epidemiológico da doença}

A tuberculose (TB) é um problema de saúde pública mundial, estando entre as dez doenças infecciosas que mais matam no mundo, inclusive à frente do HIV, em 2017 morreram cerca de 1,3 milhões de pessoas por TB, entre pessoas HIV-negativas, e mais cerca de 300 mil entre as pessoas vivendo com HIV/Aids (PVHIV) (WHO, 2018).

A carga da TB está diminuindo, apresentando redução de cerca de $2 \%$ ao ano, isso no mundo. O número de mortes por TB entre as pessoas HIV-negativas caiu cerca de $1,7 \%$ ao ano, com 1,8 milhões de óbitos no ano 2000 e 1,3 milhões em 2017. O número de mortes por tuberculose entre PVHIV reduziu 44\% entre os anos de 2000 e 2017, o que equivale a um decréscimo de 2,4\% ao ano (WHO, 2018).

Atualmente, 30 países concentram $87 \%$ dos casos de TB no mundo, estando estes classificados quanto à carga da $\mathrm{TB}$, ou número de casos registrados, número de $\mathrm{TB}$ multidroga-resistente (MDR) e coinfecção TB-HIV (WHO, 2018). O Brasil, nesta lista, ocupa a $20^{\mathrm{a}}$ posição em relação à carga da doença e a $19^{\mathrm{a}}$ posição em relação à coinfecção TB/HIV (BRASIL, 2018a). Vale destacar que Brasil, Rússia, Índia, China e África do Sul, que compõem os BRICS, são responsáveis por $50 \%$ dos casos de TB no mundo (WHO, 2018; BRASIL, 2018a).

Como no mundo, no Brasil houve uma redução da mortalidade, de 2,6/100.000 habitantes em 2008 para 2,1/100.000 habitantes em 2017, representando uma queda de 20\%, o que representa um decréscimo de 2,0\% ao ano (BRASIL, 2018a; BRASIL, 2018b). Quanto à incidência, passou-se de 39 mortes para cada 100.000 habitantes em 2008, para 33,5 mortes por 100.000 habitantes em 2017 (BRASIL, 2018a) o que tem sido significativo; todavia, nesse compasso, é pouco provável o alcance das metas de eliminação da doença até 2050 ( $<1$ caso para cada 100.000 habitantes); para tal, seria necessária uma redução das taxas de 4 a 5\% ao ano até 2020 e de 10\% ao ano, até 2025 (WHO, 2018; WHO, 2015).

É válido mencionar que, por um tempo, a TB foi considerada uma doença superada principalmente nos países desenvolvidos, depois do advento dos antibióticos; a doença reapareceu nestes países depois da pandemia do HIV, o que levou a OMS classificá-la como "doença reemergente". No Brasil, no entanto, a TB sempre foi "um problema presente e ficante a longo tempo" (RUFFINO-NETO, 2002). 
O país, apesar de ter apresentado uma queda de detecção próxima aos indicadores estabelecidos pela OMS da ordem de $70 \%$, o percentual de cura está aquém das metas esperadas, de $73 \%$ (quando o mínimo é de $85 \%$ ) e abandono de 10,3\% (máximo estabelecido de 5\%) (WHO, 2018). Isso é ainda mais grave quando considerados os casos de TB Multidroga-resistentes (TB-MDR), o que significa a resistência da microbactéria aos dois principais medicamentos usados no tratamento da $\mathrm{TB}$, a rifampicina e a isoniazida, ou monorresistência à rifampicina (TB-RR); o percentual de cura entre estes casos resistentes foi de apenas 61,4\% (BRASIL, 2018a; BRASIL, 2017a).

Quando há o abandono do tratamento do TB, o risco de desenvolvimento de TBMDR chega a aumentar em 4,5 vezes (ZHANG et al., 2016). Há estimativas que tenham ocorrido 558.000 casos no mundo, sendo que $17 \%$ dos casos de retratamento desenvolveram TB-RR ou TB-MDR, e entre os casos de TB-MDR, 8,5\% tiveram TB resistência extensiva aos medicamentos (TB-XDR), o que significa resistência, pelo menos, à rifampicina e à isoniazida, além de qualquer fluoroquinolona e, pelo menos, a uma das três seguintes drogas injetáveis usadas no tratamento da TB, que são a capreomicina, canamicina e amicacina (WHO, 2018). A TB-MDR aumenta o tempo de tratamento, exige uso de diferentes tipos de drogas e pode aumentar consideravelmente o risco da mortalidade por TB (ZURCHER et al., 2019).

Garantir a adesão do paciente ao tratamento é uma questão crucial quando se pretende melhorar as taxas de cura, sendo a estratégia DOTS, do inglês Directly Observed Therapy - Short Course (BRASIL, 2011a; BRASIL, 2011b; BERTOLOZZI et al., 2014) uma das estratégias mais custo-efetiva para o alcance deste objetivo.

Para que o controle da TB seja efetivado, se faz necessário fortalecimento das ações de detecção, diagnóstico e acompanhamento de forma descentralizada pela Atenção Primária à Saúde, cobertura diagnóstica universal e tratamento gratuito, políticas de proteção social e o envolvimento ativo da sociedade civil (MATTEELLI et al., 2018). Um desafio é qualificar e expandir as ações desenvolvidas de forma descentralizada para a Atenção Primária à Saúde, com vistas a diagnosticar mais precocemente e garantir a conclusão do tratamento, evitandose as mortes (BRASIL, 2017b; VIACAVA et al., 2012), haja vista a efetividade do tratamento comprovado em 99,9\%, quando o tratamento é regular/ininterrupto.

A redução em $95 \%$ das mortes por TB até 2035 deve estar alicerçada em políticas sensíveis aos determinantes sociais da saúde e um sistema de vigilância inteligente (WHO, 2018). Neste sentido, recentemente foi lançado um protocolo de vigilância de óbitos causados pela $\mathrm{TB}$, com a finalidade de identificar problemas no acompanhamento do paciente, 
melhorar os sistemas de notificação e promover ações de melhoria a partir da avaliação destes casos (BRASIL, 2017 Vigilância), incluindo as iniquidades sociais e disparidades.

A mortalidade por TB se associa a diversos determinantes sociais, como relacionados a moradia: superlotação nos domicílios, poucas janelas por cômodos com baixa incidência de luz solar no interior, (SAN PEDRO; OLIVEIRA, 2013; ZURCHER et al., 2019) índice de vulnerabilidade social e pobreza (BERRA et al., 2017; ÁLVAREZ-HERNÁNDEZ et al., 2010), além de determinantes ligados ao indivíduo como sexo, idade maior de 50 anos, presença de comorbidades, etilismo, tabagismo, drogadição, violência, imigração, adesão ao tratamento da TB (ZERBINI et al., 2017).

A ocorrência de óbitos por TB é considerada um evento sentinela (BRASIL, 2017c), pode estar relacionada ao não diagnóstico, ou diagnóstico tardio ocorrido em fase avançada da doença e também a um início de tratamento tardio, situações como estas podem levar a mortes precoces, ou seja, ocorridas na fase inicial do tratamento (WAITT et al., 2011) o que é muito preocupante e deve ser analisado com cautela, para definição de estratégias de enfrentamento e superação.

Entende-se que, ao analisar a mortalidade por TB, é necessário compreender o contexto social em que ocorreu, o meio em que o indivíduo está inserido e que determinantes sociais se relacionaram com o evento, além ainda de investigar e compreender as mortes em si, o momento em que ocorreram e quais fatores se relacionaram com a precocidade destas mortes.

Desta forma, a produção de conhecimento sobre os determinantes sociais das mortes por TB é estratégica no sentido de orientar políticas e ações direcionadas à eliminação da TB.

\subsection{As políticas de Controle da TB ao longo do tempo e novas perspectivas diagnósticas e de vigilância}

Em 1983, a Organização Mundial da Saúde (OMS) reconheceu a situação da TB no mundo como "estado de urgência", principalmente devido a pandemia do HIV; na atualidade outros fatores, como envelhecimento da população, movimentos migratórios, desigualdades sociais, ainda contribuem para sua permanência no cenário mundial (RUFFINO-NETO, 2002; WILLIAMS; MARUTHAPPU, 2013).

Depois do recrudescimento da TB como problema de saúde pública nos países desenvolvidos, a estratégia DOTS foi recomendada em 1994 e tinha como objetivo fortalecer os programas nacionais para controle da doença, buscando, sobretudo, a garantia da adesão e 
quebra da cadeia de transmissão da doença (WHO, 2015). A referida estratégia incluía cinco componentes: 1) Compromisso político financeiro das autoridades, 2) Identificação dos casos através de baciloscopia direta do escarro, 3) Tratamento Diretamente Observado, 4) Sistema de registro para monitorização e avaliação dos resultados, 5) Garantia do suprimento dos medicamentos anti-TB (WHO, 1999). No Brasil, a estratégia DOTS foi implantada em 1998, sob a gestão do Prof. Dr. Antonio Ruffino Netto, coordenador na ocasião do Programa Nacional de Controle da TB; sua expansão e sustentabilidade se deu mediante o estímulo financeiro repassado pelo governo federal diretamente aos municípios; sob estas circunstâncias, para cada caso curado por meio do DOTS, o município recebia em média $\mathrm{R} \$ 100,00$, o que foi extremamente relevante, em termos das políticas de controle da TB (RUFFINO -NETTO; VILLA, 2009).

Na primeira década do ano 2000, observa-se expansão da cobertura dos serviços que utilizam a estratégia DOTS e o Brasil passou a pertencer ao grupo de países que possuem entre $50 \%$ a $90 \%$ dos serviços com a estratégia já implantada; todavia, com o fim do incentivo financeiro para a estratégia, alguns municípios tiveram dificuldade para sua sustentabilidade (SÁ et al., 2011) o que acabou por prejudicar a expansão de maneira universal no país.

No cenário internacional, em 2006 foi criado o Programa Stop TB, que tinha como meta reduzir drasticamente a carga da TB mundial em consonância com os Objetivos do Milênio (OM), além de propor, até 2050, que a doença não fosse mais um problema de saúde pública ( $<1$ caso por milhão de habitantes por ano). Ela visava também fortalecer a estratégia DOTS e ampliá-la para alcance de outros objetivos respondentes a outros problemas como a TB-MDR, destacando seis componentes principais: 1) Expansão e aprimoramento da estratégia DOTS com elevada qualidade; 2) Enfoque para os casos de coinfecção TB/HIV e TB-MDR; 3) Fortalecimento do sistema de saúde; 4) Envolvimento de todos os profissionais de saúde; 5) Capacitação de pacientes e comunidades; 6) Capacitação e promoção para o desenvolvimento da pesquisa (WHO, 2015).

Uma vez que as metas de redução em $50 \%$ da mortalidade e da incidência foram atingidas no ano de 2015, imediatamente houve o lançamento da estratégia "End $T B$ ", que apresentou como campanha "Um mundo livre da tuberculose: zero mortes, doenças e sofrimento devido à TB”. Esta estratégia, mais ambiciosa, propõe uma redução de $90 \%$ no número absoluto de mortes por TB e de $80 \%$ na incidência de TB, em comparação com os índices de 2015 (WHO, 2018). Nesta estratégia estão destacados os três pilares para que as ações de eliminação da TB sejam alcançadas: 
Pilar 1: Cuidado integrado e prevenção centrada no paciente, sendo incluídos o diagnóstico precoce da $\mathrm{TB}$, com acesso universal aos testes de suscetibilidade às drogas e rastreamento sistemático dos contatos e de grupos de alto risco; o tratamento de todas as pessoas com TB, incluindo àqueles droga-resistentes e suporte aos pacientes; ações colaborativas entre os programas TB e HIV e gestão das comorbidades; tratamentos preventivos de pessoas em alto risco de adoecer por TB e vacinação contra a TB.

Pilar 2: Políticas ousadas e sistemas de informações integrados, incluindo ações de proteção social aos pacientes e recomendação de acesso universal à saúde. Além de prever a necessidade de comprometimento político com recursos adequados de atenção à TB e prevenção da doença, engajamento das comunidades, sociedade civil organizada, integração entre os sistemas públicos de saúde e privado, política de sistema universal, esquemas regulatórios/sistemáticos para notificação dos casos, qualidade dos registros, qualidade e uso racional dos medicamentos e controle da infecção, proteção social, alívio da pobreza e ações direcionadas aos determinantes sociais da TB.

Pilar 3: Intensificação das pesquisas e ações de inovação e incorporação de novas tecnologias, que incluem: descoberta, desenvolvimento e rápida implementação de novos instrumentos, intervenção e estratégias e pesquisas para otimizar a implementação destas ações ou estratégias.

A estratégia End $T B$ preconiza fortalecimento das atividades a fim de melhorar as ações a serem desenvolvidas rumo à eliminação da doença, além de estar alinhada com os Objetivos de Desenvolvimento Sustentável (ODS) mais especificamente com o Objetivo Número 3, que visa assegurar vida saudável e promover o bem-estar para todos, em todas as idades, e está intencionado em acabar com as epidemias de AIDS, tuberculose, malária e doenças tropicais negligenciadas até 2030.

Em 2017, foi lançado no Brasil o plano: "Brasil livre da tuberculose: Plano Nacional pelo fim da tuberculose como problema de saúde pública”, com objetivos e estratégias singularizados em dois tipos de cenários e oito subcenários de acordo com uma classificação baseada em características socioeconômicas, epidemiológicas e operacionais da TB (Brasil, 2017). Ainda incluem as atribuições de cada uma das esferas de gestão do SUS (federal, estadual, regional e municipal), além de sugerir quais indicadores de resultado e de processos para monitoramento dos Programas de Controle da TB; essa política representou marco regulatório na organização do sistema de saúde para a eliminação da doença.

A aceleração necessária para alcançar uma redução nas taxas de $10 \%$ até 2025 perpassa pelo desenvolvimento de novas ferramentas como vacina eficaz contra TB, 
tratamentos mais curtos e seguros, diagnóstico rápido e ações combinadas/sinérgicas em um sistema de saúde com prestação de cuidado resolutivo e integral (LIENHARDT et al., 2016).

O último alicerce da Estratégia End $T B$ propõe justamente a intensificação da pesquisa, assim reconhece-se por esta política a importância da ciência para encontrar caminhos para alcance da eliminação da TB.

Diversos são os estudos conduzidos com este objetivo, a exemplo, a existência de oito medicamentos novos ou reaproveitados em diferentes fases de pesquisa (LIENHARDT et al., 2016); duas novas drogas, nomeadamente diarilquinolina (ANDRIES et al., 2005) e delamanid (LIU, et al., 2018) que já são recomendadas pela OMS e foram aprovadas por autoridades reguladoras, incluindo a Agência de Medicamentos e Alimentos dos EUA e a Agência Europeia de Medicamentos. Cabe mencionar que novos esquemas estão em estudo para um tratamento mais curto, seguro e simplificado da TB, seja ela sensível ou resistente (ZUMLA et al., 2014).

Com relação às novas tecnologias de diagnóstico, existem atualmente cerca de 50 testes em desenvolvimento, em diferentes estágios de pesquisa, alguns já disponíveis para comercialização (LIENHARDT et al., 2016). Alguns testes moleculares e culturas rápidas permitem o diagnóstico em menor tempo, como é o caso do GeneXpert MTB/RIF, em uso no Brasil desde 2013 e que, por meio do material genético do complexo Mycobacterium tuberculosis, identifica a presença da microbactéria e a resistência à rifampicina ao mesmo tempo e com uso do mesmo material, permitindo um resultado em até duas horas; os métodos clássicos, como a baciloscopia e cultura bacteriológica continuam recomendados, todavia, estes levam muito mais tempo a depender da organização dos serviços de saúde para atendimento dos casos da tuberculose; sendo que a cultura continua a ser padrão ouro para o diagnóstico da TB e deve ser usada universalmente (BRASIL, 2018a; BRASIL 2017b).

Além dos medicamentos, há o desenvolvimento de vacinas, como a MTBVAC, que utiliza o Mycobacterium tuberculosis vivo atenuado para aplicação em recém-nascidos e tem conseguido sucesso na avaliação clínica (MARINOVA et al., 2017) e uma das vacinas mais estudadas é a Mycobacterium vaccae inativada, que é uma espécie não patogênica pertencente à mesma família do $M$. tuberculosis e tem sido utilizada e comercializada como um imunoterapêutico no tratamento da TB e alcançado bons resultados clínicos (HUANG; HSIEH, 2017).

Apesar da centralidade destas descobertas e avanços destacados no aspecto imunopatogênico da doença, é importante produzir ciência voltada ao contexto social em que o paciente de tuberculose está inserido e sua família; isto tem sumária importância quando o 
objetivo é melhoria do acesso ou acessibilidade aos serviços de saúde em um contexto de grande desigualdade. A desigualdade social faz com que as pessoas não tenham as mesmas oportunidades de acesso às tecnologias; portanto, apesar da importância da descoberta de novas tecnologias diagnósticas e de tratamento, se não compreendidos os determinantes que definem seu uso e utilização, elas por si só não serão suficientes para impactar na eliminação da $\mathrm{TB}$, isto porque se trata de uma doença socialmente determinada, que se relaciona com o modo de vida, habitação, cultura, ambientes, renda, políticas, entre outros (RUFFINO-NETO, 2002; CECILIO et al., 2013; QUEIROGA et al., 2012).

Por essa característica, é requerido mais do que medidas isoladas, seu enfrentamento não pode ser pontual, centrado em procedimentos médicos individuais e ou na tecnologia dura (QUEIROGA et al., 2012; LONNROTH et al., 2009; CARTER et al., 2018), são necessárias ações alargadas, de um diagnóstico situacional criterioso com vistas a propostas mais finas e com acurácia, com perspectivas de mudanças de uma realidade (LONNROTH, 2009; WINGFIELD et al., 2016).

Link e Phelan (1995) afirmaram que as condições sociais são a causa fundamental das doenças; nessa mesma linha, mais tarde, Rasanathan et al. (2011) destacam que a solução da TB perpassa pela compreensão e sensibilidade das ações direcionadas aos Determinantes Sociais da Saúde, sendo necessárias articulações entre o setor saúde e outros setores, como sociais, de justiça e direito, acadêmico, econômico, habitação e geração de renda. As ações clínicas e/ou assistenciais devem estar entrelaçadas a uma satisfatória compreensão do contexto e de sua organização, para então definição de políticas públicas, que sejam utilizadas efetivamente e alcancem o seu propósito (LONNROTH et al., 2009; CARTER et al., 2018).

Carter et al. (2018), em um estudo de predições, observou que a redução da pobreza provocou uma queda na incidência de tuberculose de 33,4\% e que a ampliação da cobertura de proteção social resultou em redução na incidência de $76,1 \%$ até 2035 . Desse modo, a compreensão dos determinantes sociais que favoreçam as mortes por TB poderá dar respostas relevantes para a meta de eliminação da TB.

\subsection{Análise do espaço}

Pela forte relação da TB aos determinantes sociais (LONNROTH, 2009), é relevante considerar o espaço ou a espacialização da doença, pois ao analisar a doença levando em conta o território, podem-se mensurar suas associações tendo em vista o seu aspecto clínicosocial (CÂMARA et al., 2004). Para Queiroga et al. (2012), um estudo que considere o 
espaço permite compreender os fenômenos sociais juntamente com as doenças endêmicas de forma profícua, possibilitando uma averiguação realista, que leva em conta o meio em que ocorre.

O espaço/território na presente tese está compreendido como uma localização geográfica e também como um campo de atuação, de expressão do poder público, privado, governamental ou não governamental e, sobretudo, populacional. Cada território tem uma determinada área, uma população e uma instância de poder; este último pode ser concebido como de domínio público ou privado, de caráter administrativo, cultural, político, religioso, entre outros; deste modo, os territórios são, ao mesmo tempo, espaços e lugares construídos socialmente; eles não estão restritos à noção de território-solo (processo estanque/estático), mas são muito variáveis e dinâmicos, e a sua peculiaridade mais importante é ser um espaço de transformação/mutável pelo poder público e pela sociedade, um espaço de atuação, de fazer, de responsabilidade (VENÂNCIO, 2004).

Sob esta perspectiva do território que é construído e reconstruído a todo o momento, que possui uma população, que por vezes não está distribuída de forma uniforme ou homogênea, que apresenta áreas mais densas que outras, com algumas regiões com condições sociais melhores que outras, deve-se considerar que a localização em que as pessoas se estabelecem nem sempre é consequência de uma escolha destas, mas sim devido ao processo histórico de ocupação, da apropriação do território e das desigualdades sociais; essas condições fazem com que pessoas com características semelhantes estejam mais próximas (VENÂNCIO, 2004).

As desigualdades sociais fazem com que em um mesmo município, os melhores lugares do ponto de vista ambiental, saneamento básico, transporte estejam juntas as famílias com maior renda, ao passo que os mais pobres se distribuam nos lugares de piores condições de urbanização, nas áreas mais distantes e mal servidas; o que autores classificam como segregação espacial. É importante frisar que esta segregação espacial decorre de um processo intensificado de desigualdade social, que ocorre de geração em geração e, na ausência de políticas públicas que façam essa correção, os problemas de saúde são mais frequentes nas populações desfavorecidas (MONKEN; BARCELLOS, 2005). Considerando esta complexidade para compreensão dos territórios, a epidemiologia vem se aproximando da geografia no sentido de encontrar ferramentas com acurácia/sensibilidade para mensurar e ou compreender o fenômeno.

A análise espacial vem sendo empregada no sentido de responder às questões sobre os territórios em sua interface com a saúde. Para Câmara et al. (2004), a distribuição espacial 
dos eventos é um grande desafio para elucidação de questões em diversas áreas do conhecimento, pois leva em conta a localização espacial do evento, permitindo uma análise que incorpora e considera o espaço.

A análise espacial envolve uma série de técnicas; dentre elas, podemos citar o geoprocessamento que permite a localização e distribuição espacial (CÂMARA et al., 2004) e a avaliação de eventos de saúde com simultânea relação de fatores do espaço, como aspectos estruturais, sócio econômicos, ambientais e presença de serviços (HINO et al., 2011; BARBOSA et al., 2014).

O geoprocessamento engloba diversas tecnologias de tratamento e manipulação de dados geográficos; dentre essas tecnologias, os Sistemas de Informações Geográficas (SIG) têm sido adotados para abordagem de eventos de saúde (PINA; SANTOS, 2000). Os SIGs são sistemas que realizam o tratamento computacional de dados geográficos e armazenam a geometria e os atributos dos dados que estão georreferenciados, isto é, localizados na superfície terrestre e representados em uma projeção cartográfica (CÂMARA et al.; 2004).

A modalidade da análise espacial permite que dados ambientais e socioeconômicos sejam considerados para que então se processe a análise no espaço onde ocorreu o evento. Parte-se inicialmente de uma fase exploratória, procedida de uma averiguação que identifique padrões de dependência espacial dos óbitos (CÂMARA, 2004) e que permite a associação de indicadores, índices ou variáveis das unidades geográficas onde estão localizados os eventos sob estudo, neste caso os óbitos por TB (SUN, et al, 2015; NG, et al, 2012; OLIVEIRA et al., 2012; SANTOS-NETO, et al, 2014).

Há ainda outras técnicas, como a detecção de aglomerados de risco por meio da técnica de varredura espacial (KURDOLF, 1997) e a mensuração das relações entre o desfecho estudado e fatores, com correlações bivariadas e regressão espacial (ANSELIN,2005).

Ao se analisar a mortalidade por TB, levando em conta o espaço, é possível diagnosticar indicadores sociais relacionados, além de expor áreas com maior vulnerabilidade social atrelada ao desfecho, o que permite definição de ações de reestruturação na saúde e dos territórios (ARCOVERDE et al., 2018; BERRA et al., 2017; SANTOS et al., 2018)

A análise espacial dos óbitos por TB permite um aprimoramento de ações de vigilância dos casos, além de revelar a acessibilidade aos serviços de saúde para diagnóstico precoce e acompanhamento dos casos já diagnosticados nos diferentes pontos de atenção; desta forma, verifica-se o comportamento da doença em meio a uma determinada população e se avalia se as intervenções em saúde já praticadas são efetivas (PINA; SANTOS, 2000). 
Diante do exposto, a análise espacial com suas técnicas permite a distribuição dos casos e medidas de relacionamento entre os determinantes sociais devidamente regionalizados. Alguns estudos realizados abordaram os determinantes sociais e a mortalidade por TB, considerando o espaço também como objeto de análise. Entre os estudos (SANTOS NETO et al., 2014; ARCOVERDE et al., 2018; SANTOS et al., 2018; YAMAMURA et al., 2017) este é o primeiro com este tipo de abordagem, realizado em uma capital brasileira do Sul do Brasil. Considerando a necessidade da condução de uma revisão sistemática para sustentar a originalidade e as lacunas de conhecimento do estudo, na próxima seção estão expostas todas as etapas lançadas para o alcance destes objetivos. 
2 Mapeamento sistemático da literatura 
A etapa de revisão de literatura é relevante para a execução de uma pesquisa já que se trata de um processo de busca, descrição e análise de um tema. Muitas definições existem quando se trata de revisão de literatura que pode variar conforme o método de elaboração utilizado e os objetivos que se pretende através dela. Alguns tipos comumente utilizados são revisão narrativa, revisão sistemática, revisão integrativa, revisão de escopo, mapeamento sistemático, entre outras (SAMPAIO; MANCINI 2007).

Os mapeamentos sistemáticos permitem identificar lacunas de conhecimento e fornecem uma visão geral estruturada das evidências científicas disponíveis diante de uma questão de pesquisa. Diferentemente das revisões sistemáticas, que utilizam resultados para estabelecer relações quantitavas ou metanálises, os mapas sistemáticos visam categorizar a literatura de acordo com os objetivos do estudo, o design ou outros fatores que possam ser de interesse. Além disso, podem ser aplicados às questões mais amplas, sintetizando estudos potencialmente díspares que não puderam ser diretamente comparados via metanálise (GRANT; BOOTH, 2009).

Pretende-se com esta revisão reunir os conhecimentos atuais sobre os determinantes da mortalidade por TB, de maneira a contribuir para discussão dos resultados, além de nortear a seleção das variáveis utilizadas nas análises propostas na presente pesquisa. Para orientar os pesquisadores na seleção dos manuscritos, foram considerados os artigos com enfoque ecológico e também aqueles de base individual que verificaram as mortes precoces por TB e TB-HIV e seus determinantes; houve preocupação em observar se haveria algum tipo de estudo "híbrido", com combinação destes objetos.

Para o alcance do objetivo ao considerar os determinantes sociais, foi elaborada uma pergunta baseada na estratégia PIO, de acordo com o Quadro 1:

Quadro 1 - Estrutura PIO para questão de pesquisa

\begin{tabular}{|l|l|}
\hline \multicolumn{1}{|c|}{ Elemento } & \multicolumn{1}{|c|}{ Componente da pergunta } \\
\hline P - População & Pacientes de tuberculose \\
\hline I - Intervenção ou fenômeno de interesse & Determinantes sociais de saúde \\
\hline O - Resultado & Mortes; Mortes precoces \\
\hline
\end{tabular}

Fonte: Elaborado pela autora. 
Foi formulada a seguinte pergunta de pesquisa: "Quais estudos abordam a mortalidade por tuberculose e sua relação com determinantes sociais da saúde? "As perguntas secundárias: "O enfoque é análise espacial? Há estudos que verificaram as mortes precoce por TB? Quais são os determinantes destas?"

Os critérios de inclusão foram: estudos primários quantitativos que apresentem em seu escopo a análise de Determinantes Sociais da Saúde (DSS) associados à mortalidade por TB, publicados após 2010, sem restrição de área geográfica. As buscas foram realizadas entre os meses de agosto de 2018 a janeiro de 2019. Foram excluídos estudos com população infantil, relatórios inconclusivos, em andamento e estudos de revisão.

Para a busca dos artigos de interesse foram adotados os seguintes termos Mesh (Medical Subject Headings): "tuberculosis"[Title/abstract] "mortality"[Title/abstract]; "social determinants of health" OR "determinants" [All fields] para busca na PubMed e para busca no Scielo, os DeCS (Descritores de Ciências da Saúde) "tuberculose", "mortalidade", "determinantes sociais da saúde" OR "determinantes". Ainda foram utilizados os filtros: literatura com seres humanos; nos idiomas, português e inglês; e sem restrição segundo o tipo de estudo. A sequência das etapas de identificação dos artigos, triagem, elegibilidade e seguindo o (Preferred Reporting Items for Systematic and Meta-Analyses) PRISMA está apresentado na Figura 2. 
Figura 2 - Fluxograma das fases e seleções dos artigos do mapeamento sistemático da literatura.
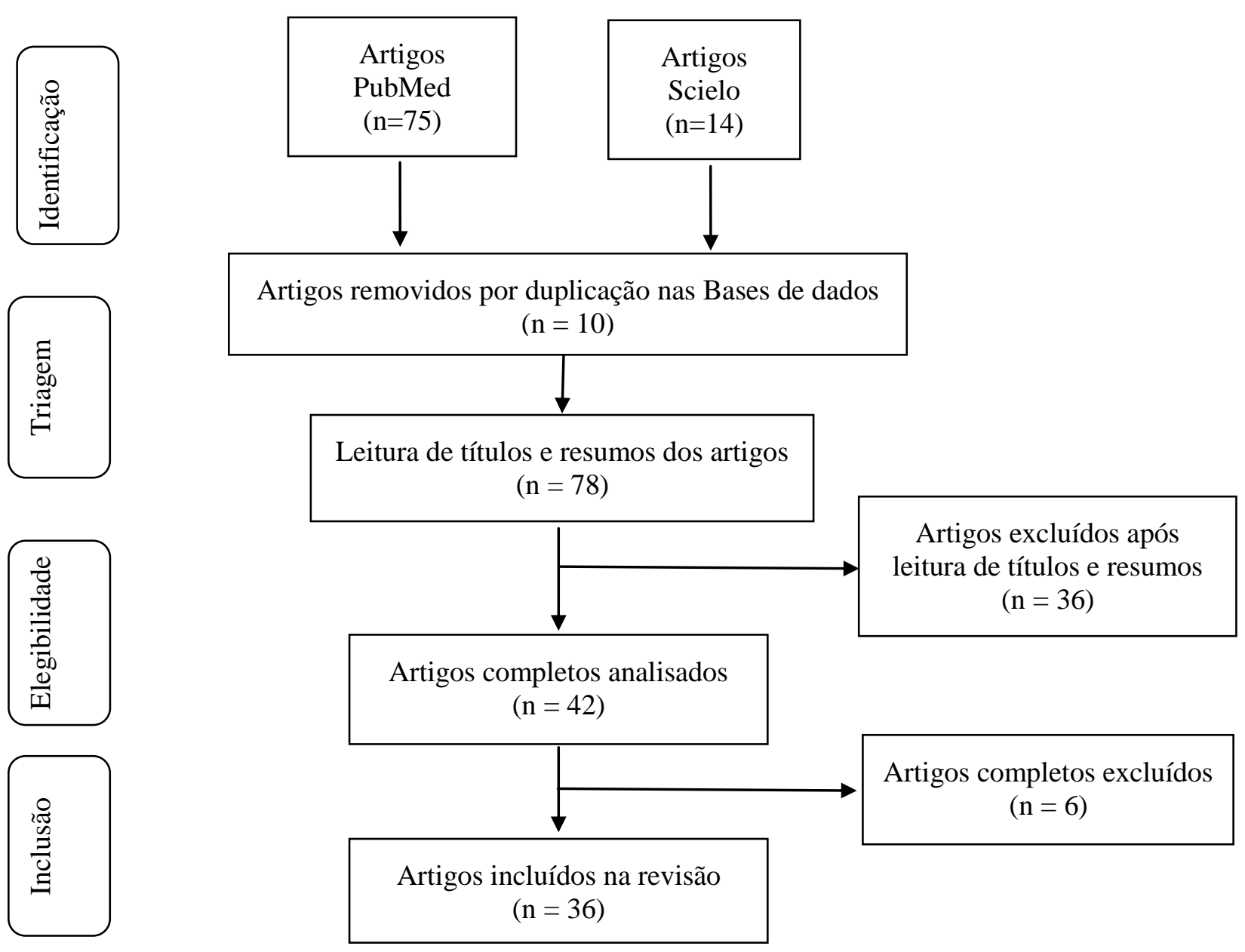
Quadro 2 - Artigos originais publicados a partir de 2010 nas Bases de Dados: Pubmed e Scielo com os descritores: "tuberculosis" AND "mortality" OR "deaths" AND "determinants" OR "risk factors". Ribeirão Preto- SP, 2016.

\begin{tabular}{|c|c|c|c|c|c|c|c|}
\hline & $\begin{array}{l}\text { Autores/ } \\
\text { Ano } \\
\text { Publicação }\end{array}$ & Título & Local & Tipo de Estudo & Tipo de Análise & Objetivos & Principais resultados \\
\hline E01 & $\begin{array}{c}\text { Oliveira et al., } \\
2019\end{array}$ & $\begin{array}{c}\text { Early death by tuberculosis as } \\
\text { the underlying cause in a state } \\
\text { of Southern Brazil: Profile, } \\
\text { comorbidities and associated } \\
\text { vulnerabilities }\end{array}$ & Brasil & Observacional & Regressão logística & $\begin{array}{l}\text { Identificar o perfil de } \\
\text { pessoas que morreram por } \\
\text { TB precocemente } \mathrm{e} \\
\text { tardiamente }\end{array}$ & $\begin{array}{c}\text { As mortes precoces corresponderam a } \\
74,6 \% \text { (705/944). Sexo masculino, } \\
\text { outras doenças do aparelho } \\
\text { respiratório e doenças mentais } \\
\text { estiveram associadas a mortes } \\
\text { precoces } \\
\end{array}$ \\
\hline E02 & $\begin{array}{c}\text { Arcoverde } \\
\text { et al., } \\
2018\end{array}$ & $\begin{array}{l}\text { How do socialeconomic } \\
\text { differences in urban areas affect } \\
\text { tuberculosis mortality in a city } \\
\text { in the tri-border region of } \\
\text { Brazil, Paraguay and Argentina }\end{array}$ & Brasil & Ecológico & $\begin{array}{l}\text { Espacial: Detecção de } \\
\text { cluster; análise } \\
\text { bivariada LISA e } \\
\text { temporal }\end{array}$ & $\begin{array}{c}\text { Analisar a mortalidade } \\
\text { espacial por TB e seus } \\
\text { determinantes } \\
\text { socioeconômicos na } \\
\text { população geral, nas } \\
\text { regiões limítrofes do } \\
\text { Brasil, Paraguai e } \\
\text { Argentina } \\
\end{array}$ & $\begin{array}{c}\text { A morte por TB foi associada à renda, } \\
\text { densidade de residentes nos } \\
\text { domicílios e condições demográficas } \\
\text { e sociais }\end{array}$ \\
\hline E03 & Santos et al., 2018 & $\begin{array}{l}\text { Is there association between } \\
\text { human } \\
\text { development index and } \\
\text { tuberculosis mortality } \\
\text { risk? Evidence from a spatial } \\
\text { analysis study in } \\
\text { the south of Brazil }\end{array}$ & Brasil & Ecológico & $\begin{array}{c}\text { Espacial: LISA } \\
\text { bivariado e detecção de } \\
\text { cluster }\end{array}$ & $\begin{array}{l}\text { Associar diferentes taxas } \\
\text { (medidas) da mortalidade } \\
\text { por TB com o Índice de } \\
\text { Desenvolvimento Humano } \\
\text { (IDH) global, renda, } \\
\text { longevidade, educação }\end{array}$ & $\begin{array}{l}\text { Foi encontrada associação entre a } \\
\text { mortalidade e o IDH renda para todas } \\
\text { as medidas (taxas). A taxa bayseana } \\
\text { global apresentou significância com } \\
\text { todos IDHs }\end{array}$ \\
\hline E04 & $\begin{array}{l}\text { Ferreira et al., } \\
\quad 2018\end{array}$ & $\begin{array}{c}\text { Predictors of mortality among } \\
\text { intensive care unit patients } \\
\text { coinfected with tuberculosis and } \\
\text { HIV. }\end{array}$ & Brasil & Coorte retrospectiva & $\begin{array}{l}\text { Análise de sobrevida: } \\
\text { Modelo de Cox }\end{array}$ & $\begin{array}{l}\text { Identificar fatores } \\
\text { preditivos de mortalidade } \\
\text { entre pacientes com a } \\
\text { coinfecção TB/HIV } \\
\text { internados em UTI }\end{array}$ & $\begin{array}{c}62(66 \%) \text { dentre } 94 \text { indivíduos } \\
\text { morreram na primeira semana após } \\
\text { admissão na UTI. Ventilação } \\
\text { mecânica invasiva }(\mathrm{p}=0,002), \\
\text { hipoalbunemia }(\mathrm{p}=0,0013) \mathrm{e} \\
\text { contagem de células TCD4 <200 } \\
\text { cel } / \mathrm{mm}^{3}(\mathrm{p}=0,002) \text { foram associados } \\
\text { com a mortalidade }\end{array}$ \\
\hline
\end{tabular}


- continuação-

\begin{tabular}{|c|c|c|c|c|c|c|c|}
\hline & $\begin{array}{c}\text { Autores/ } \\
\text { Ano } \\
\text { Publicação }\end{array}$ & Título & Local & Tipo de Estudo & Tipo de Análise & Objetivos & Principais resultados \\
\hline E05 & $\begin{array}{l}\text { Yamamura et al., } \\
2017\end{array}$ & $\begin{array}{l}\text { Areas with evidence of equity } \\
\text { and their progress on mortality } \\
\text { from tuberculosis in an } \\
\text { endemic municipality of } \\
\text { southeast Brazil }\end{array}$ & Brasil & Ecológico & $\begin{array}{c}\text { Espacial: } \\
\text { Regressão linear } \\
\text { múltipla; verificação de } \\
\text { dependência espacial } \\
\text { do resíduo (I Moran) e } \\
\text { regressão espacial }\end{array}$ & $\begin{array}{c}\text { Identificar áreas } \\
\text { geográficas que } \\
\text { apresentaram progresso } \\
\text { em termos de equidade } \\
\text { (de renda, escolaridade e } \\
\text { ocupação urbana) e testar } \\
\text { seu efeito na mortalidade } \\
\text { por tuberculose }\end{array}$ & $\begin{array}{c}\text { A equidade social teve uma } \\
\text { associação negativa com } \\
\text { mortalidade de TB; cada aumento } \\
\text { desta unidade (equidade) seria } \\
\text { equivalente a uma redução de } 8,8 \% \\
\text { na taxa de mortalidade. } \\
\text { Este indicador de equidade foi } \\
\text { composto por variáveis de renda, } \\
\text { escolaridade e condições de } \\
\text { ocupação do domicílio }\end{array}$ \\
\hline E06 & $\begin{array}{l}\text { Ceccon et al., } \\
2017 .\end{array}$ & $\begin{array}{l}\text { Tuberculosis mortality in } \\
\text { Brazilian capitals, 2008-2010 }\end{array}$ & Brasil & Ecológico & $\begin{array}{l}\text { Regressão linear } \\
\text { múltipla }\end{array}$ & $\begin{array}{l}\text { Analisar associação entre } \\
\text { as taxas de mortalidade } \\
\text { por tuberculose e } \\
\text { indicadores } \\
\text { sociodemográficos e de } \\
\text { saúde nas capitais dos } \\
\text { estados brasileiros e no } \\
\text { Distrito Federal }\end{array}$ & $\begin{array}{c}\text { As variáveis: desigualdade de renda } \\
\text { (índice Gini) } \beta=0,454 ; \text { IC } 95 \% \text { 6,21; } \\
\text { 28,51), proporção de migrantes no } \\
\text { município ( } \beta=0,537 \text { IC95\% 0,12; } \\
0,31 \text { ), indivíduos negros pobres ( } \beta= \\
0,302 \text { IC95\% } 0,004 ; 0,109 \text { ) e } \\
\text { coeficiente de coinfecção Tb/HIV ( } \beta \\
=0,449 \text { IC95\% } 0,05 ; 0,28 \text { ) foram } \\
\text { associados à mortalidade por TB }\end{array}$ \\
\hline E07 & $\begin{array}{l}\text { Santos-Neto et al., } \\
2016\end{array}$ & $\begin{array}{l}\text { The Impact of Social } \\
\text { Inequities on Mortality Due to } \\
\text { Pulmonary Tuberculosis in São } \\
\text { Luis, Maranhão, Brazil }\end{array}$ & Brasil & Ecológico & $\begin{array}{c}\text { Espacial: } \\
\text { Regressão linear com } \\
\text { análise de dependência } \\
\text { espacial do resíduo (I } \\
\text { de Moran) e regressão } \\
\text { espacial }\end{array}$ & $\begin{array}{c}\text { Identificar áreas com } \\
\text { desigualdade social e seu } \\
\text { impacto na mortalidade } \\
\text { por TB }\end{array}$ & $\begin{array}{c}\text { A desigualdade social foi } \\
\text { estatisticamente associada à } \\
\text { mortalidade }\left(\mathrm{R}^{2}=23,86 \%\right) \text {. Identificou } \\
\text { as maiores taxas de mortalidade nas } \\
\text { áreas com alta desigualdade social } \\
\text { classificada como intermediária. } \\
\text { A desigualdade social foi representada } \\
\text { por variáveis referentes a condições } \\
\text { insalubres de moradia, maior } \\
\text { aglomeraçãa humana e baixa renda }\end{array}$ \\
\hline
\end{tabular}

- continua- 
- continuação-

\begin{tabular}{|c|c|c|c|c|c|c|c|}
\hline & $\begin{array}{l}\text { Autores/ } \\
\text { Ano } \\
\text { Publicação }\end{array}$ & Título & Local & $\begin{array}{l}\text { Tipo de } \\
\text { Estudo }\end{array}$ & Tipo de Análise & Objetivos & Principais resultados \\
\hline E08 & $\begin{array}{l}\text { Yamamura et al., } \\
2015\end{array}$ & $\begin{array}{c}\text { Epidemiological } \\
\text { characteristics of cases of } \\
\text { death from tuberculosis and } \\
\text { vulnerable territories }\end{array}$ & $\begin{array}{l}\text { Ribeirão } \\
\text { Preto, } \\
\text { Brasil }\end{array}$ & Ecológico & $\begin{array}{l}\text { Espacial: análise } \\
\text { bivariada e de } \\
\text { densidade (Kernel) }\end{array}$ & $\begin{array}{l}\text { Caracterizar clínica e } \\
\text { epidemiologicamente os } \\
\text { casos de óbitos por TB } \\
\text { como causa básica e } \\
\text { associada }\end{array}$ & $\begin{array}{l}\text { As variáveis idade e setor ou } \\
\text { responsável pelo atestado de óbito } \\
\text { apresentaram associação estatística } \\
\text { com óbito }\end{array}$ \\
\hline E09 & $\begin{array}{l}\text { Santos-Neto et } \\
\text { al., } \\
2015\end{array}$ & $\begin{array}{l}\text { Pulmonary tuberculosis in } \\
\text { Sao Luis, State of Maranhão, } \\
\text { Brazil: space and space-time } \\
\text { risk clusters for death (2008- } \\
\text { 2012) }\end{array}$ & $\begin{array}{l}\text { São Luiz, } \\
\text { Brasil }\end{array}$ & Ecológico & $\begin{array}{l}\text { Espacial: cluster de } \\
\text { risco }\end{array}$ & $\begin{array}{l}\text { Identificar clusters de } \\
\text { risco espaço e espaço- } \\
\text { temporais para } \\
\text { ocorrência de mortes por } \\
\text { TB }\end{array}$ & $\begin{array}{l}\text { Foram identificados dois clusters } \\
\text { espaciais, um de alto risco e outro } \\
\text { com baixo risco. Identificado } \\
\text { também um cluster no tempo e } \\
\text { espaço }\end{array}$ \\
\hline E10 & $\begin{array}{l}\text { Santos-Neto et } \\
\text { al., } \\
2014\end{array}$ & $\begin{array}{l}\text { Spatial analysis of deaths } \\
\text { from } \\
\text { pulmonary tuberculosis in the } \\
\text { city of Sao Luis, Brazil }\end{array}$ & $\begin{array}{l}\text { São Luiz, } \\
\text { Brasil }\end{array}$ & Ecológico & $\begin{array}{l}\text { Espacial: descritiva e } \\
\text { densidade de pontos } \\
\text { (Kernel) }\end{array}$ & $\begin{array}{c}\text { Caracterizar os óbitos } \\
\text { por TB pulmonares de } \\
\text { acordo com variáveis } \\
\text { sociodemográficas e } \\
\text { operacionais } \\
\end{array}$ & $\begin{array}{l}\text { Encontra uma distribuição espacial } \\
\text { heterogênea por meio de mapa de } \\
\text { densidade por pontos }\end{array}$ \\
\hline E11 & $\begin{array}{l}\text { Yang et al., } \\
\quad 2013\end{array}$ & $\begin{array}{c}\text { Epidemiology of pulmonary } \\
\text { tuberculosis in Wenchuan } \\
\text { earthquake stricken area: } \\
\text { population-based study. }\end{array}$ & $\begin{array}{l}\text { Wenchuan, } \\
\text { China }\end{array}$ & Ecológico & $\begin{array}{l}\text { Modelo multinível e } \\
\text { detecção de Cluster }\end{array}$ & $\begin{array}{l}\text { Explorar a distribuição } \\
\text { espaço-temporal e } \\
\text { fatores associados a TB } \\
\text { pulmonar (incidência e } \\
\text { mortalidade) }\end{array}$ & $\begin{array}{l}\text { Revelaram clusters espaciais- } \\
\text { temporais de mortalidade por TB. } \\
\text { Um dos fatores associados foi região } \\
\text { afetada por terremoto }\end{array}$ \\
\hline
\end{tabular}


- continuação-

\begin{tabular}{|c|c|c|c|c|c|c|c|}
\hline & $\begin{array}{c}\text { Autores/ } \\
\text { Ano } \\
\text { Publicação }\end{array}$ & Título & Local & $\begin{array}{l}\text { Tipo de } \\
\text { Estudo }\end{array}$ & Tipo de Análise & Objetivos & Principais resultados \\
\hline E12 & $\begin{array}{l}\text { Houlihan et al., } \\
\qquad 2010\end{array}$ & $\begin{array}{c}\text { The tuberculosis challenge in } \\
\text { a rural South African HIV } \\
\text { programme. }\end{array}$ & $\begin{array}{l}\text { África do } \\
\quad \text { Sul }\end{array}$ & Ecológico & $\begin{array}{c}\text { Regressão logística } \\
\text { multivariada. Análise } \\
\text { de sobrevivência de } \\
\text { Kaplan-meier e } \\
\text { Regressão de Cox e } \\
\text { Análise de cluster } \\
\text { (Kurldolf) } \\
\end{array}$ & $\begin{array}{c}\text { Analisar diferenças } \\
\text { geográficas na } \\
\text { incidência da TB. } \\
\text { Identificar clusters e } \\
\text { fatores associados. A } \\
\text { taxa de mortalidade foi } \\
\text { avaliada como variável } \\
\text { independente } \\
\end{array}$ & $\begin{array}{c}\text { Foi identificado um cluster de } \\
\text { baixo risco para incidência da TB. } \\
\text { A mortalidade foi mais elevada } \\
\text { nas regiões com maiores taxas de } \\
\text { incidência e prevalência }\end{array}$ \\
\hline E13 & $\begin{array}{l}\text { Alvarez- } \\
\text { Hernandez et al., } \\
2010\end{array}$ & $\begin{array}{c}\text { An analysis of spatial and } \\
\text { socio-economic determinants } \\
\text { of tuberculosis in } \\
\text { Hermosillo, Mexico, 2000- } \\
2006\end{array}$ & $\begin{array}{l}\text { Hermosillo } \\
\text {, México }\end{array}$ & Ecológico & $\begin{array}{l}\text { Análise de } \\
\text { componentes } \\
\text { principais. } \\
\text { Moran } \\
\text { LISA bivariado }\end{array}$ & $\begin{array}{c}\text { Caracterizar a } \\
\text { distribuição geográfica } \\
\text { da prevalência e } \\
\text { mortalidade por TB e } \\
\text { comparar com índices de } \\
\text { privação social }\end{array}$ & $\begin{array}{l}\text { Não encontrou autocorrelação } \\
\text { espacial da mortalidade por TB, no } \\
\text { entanto identificou associação } \\
\text { entre taxa de mortalidade e o } \\
\text { Índice de privação criado com } 13 \\
\text { aglomerados detectados por meio } \\
\text { do LISA bivariado } \\
\end{array}$ \\
\hline E14 & Lee et al., 2017 & $\begin{array}{c}\text { Comparison of } \\
\text { Early and Late Tuberculosis } \\
\text { Deaths in Korea. }\end{array}$ & Coréia & Coorte & Análise de sobrevida & $\begin{array}{c}\text { Comparar causas de } \\
\text { mortes entre aquelas que } \\
\text { morreram precocemente } \\
\text { e tardiamente por TB na } \\
\text { Coreia }\end{array}$ & $\begin{array}{l}\text { O tempo mediano do início do } \\
\text { tratamento até a morte foi } 21 \text { dias } \\
(7-38) \text {. As mortes ocorreram entre } \\
\text { pacientes com idade avançada e } \\
\text { com comorbidades. As mortes } \\
\text { precoces ocorreram por causas } \\
\text { especificamente relacionadas a TB } \\
\text { enquanto que as tardias por outras } \\
\text { causas } \\
\end{array}$ \\
\hline E15 & Yen et al., 2017 & $\begin{array}{l}\text { Determinants of mortality in } \\
\text { Eelderly patients } \\
\text { with tuberculosis: a } \\
\text { population-based follow-up } \\
\text { study. }\end{array}$ & $\begin{array}{l}\text { Taipei, } \\
\text { Taiwan }\end{array}$ & $\begin{array}{l}\text { Coorte } \\
\text { retrospectiva }\end{array}$ & $\begin{array}{l}\text { Regressão logística } \\
\text { múltipla }\end{array}$ & $\begin{array}{l}\text { Identificar fatores } \\
\text { associados com a morte } \\
\text { por TB entre cidadãos } \\
\text { idosos de Taipei }\end{array}$ & $\begin{array}{c}\text { As variáveis sexo masculino, } \\
\text { doença renal, baciloscopia } \\
\text { positiva, derrame pleural no RX } \\
\text { foram associadas com maior risco } \\
\text { de morte, enquanto maior } \\
\text { escolaridade e TDO foram } \\
\text { associadas com menor risco de } \\
\text { mortes por TB }\end{array}$ \\
\hline
\end{tabular}


- continuação -

\begin{tabular}{|c|c|c|c|c|c|c|c|}
\hline & $\begin{array}{c}\text { Autores/ } \\
\text { Ano } \\
\text { Publicação }\end{array}$ & Título & Local & $\begin{array}{l}\text { Tipo de } \\
\text { Estudo }\end{array}$ & Tipo de Análise & Objetivos & Principais resultados \\
\hline E16 & $\begin{array}{l}\text { Kebede } \text { et al., } \\
2017\end{array}$ & $\begin{array}{l}\text { Tuberculosis and HIV are the } \\
\text { leading causes of adult death in } \\
\text { northwest Ethiopia: evidence } \\
\text { from verbal autopsy } \\
\text { data of Dabat health and } \\
\text { demographic surveillance } \\
\text { system, 2007-2013 }\end{array}$ & Ethiopia & Coorte & $\begin{array}{l}\text { Análise bivariada e } \\
\text { Regressão logística }\end{array}$ & $\begin{array}{c}\text { Analisar as principais } \\
\text { causas de morte entre a } \\
\text { população adulta do } \\
\text { nordeste da Etiópia (2007- } \\
\text { 2013) }\end{array}$ & $\begin{array}{c}\text { A TB foi a causa majoritária entre as } \\
\text { mortes ocorridas no período de estudo } \\
155(20,8 \%) \text { seguida do HIV/Aids } 55 \\
(7,4 \%)\end{array}$ \\
\hline E17 & $\begin{array}{l}\text { Santos Feltrin } \\
\text { et al., } 2016\end{array}$ & $\begin{array}{l}\text { Death in patients with } \\
\text { tuberculosis and diabetes: } \\
\text { Associated factors. }\end{array}$ & Brasil & Epidemiológico & Regressão logística & $\begin{array}{c}\text { Identificar fatores } \\
\text { associados com a morte de } \\
\text { pacientes com TB e } \\
\text { diabetes registrados no } \\
\text { DATAWEB (1996-2014) }\end{array}$ & $\begin{array}{c}\text { O DM apareceu como fator protetivo } \\
\text { para mortalidade. } 306(6,3 \%) \text { dentre } \\
4447 \text { casos tinham TB e DM. Fatores } \\
\text { de proteção para mortalidade foram } \\
\text { DM (OR: } 0,69 \text { ) seguimento por } \\
\text { serviço especializado de média e alta } \\
\text { complexidade (OR: } 0,51) \\
\end{array}$ \\
\hline E18 & $\begin{array}{l}\text { Gesesew et al., } \\
2016\end{array}$ & $\begin{array}{c}\text { Predictors } \\
\text { of mortality in a cohort of } \\
\text { tuberculosis/HIV co-infected } \\
\text { patients in Southwest } \\
\text { Ethiopia. }\end{array}$ & Etiópia & $\begin{array}{l}\text { Coorte } \\
\text { retrospectiva }\end{array}$ & Modelo de Cox & $\begin{array}{l}\text { Avaliar a incidência e os } \\
\text { preditores da mortalidade } \\
\text { pela coinfecção TB/HIV no } \\
\text { sudoeste da Etiópia }\end{array}$ & $\begin{array}{c}57(20,2 \%) \text { dos pacientes morreram } \\
\text { dentre } 272 \text { participantes do estudo. Os } \\
\text { preditores para a mortalidade foram } \\
\text { idade entre } 33-44 \text { anos (HR:2,9), ser } \\
\text { trabalhadora do sexo feminino } \\
\text { (H.R: } 9,1) \text {, ser acamado (HR: } 3,2) \text {. E } \\
\text { um achado incomum, pacientes com } \\
\text { HIV estágio } 1 \text { tiveram menor risco do } \\
\text { que pacientes no estágio } 2,3,4 \text { (WHO) }\end{array}$ \\
\hline
\end{tabular}


- continuação -

\begin{tabular}{|c|c|c|c|c|c|c|c|}
\hline & $\begin{array}{c}\text { Autores/ } \\
\text { Ano } \\
\text { Publicação }\end{array}$ & Título & Local & $\begin{array}{l}\text { Tipo de } \\
\text { Estudo }\end{array}$ & Tipo de Análise & Objetivos & Principais resultados \\
\hline E19 & $\begin{array}{l}\text { Pecego et al., } \\
2016\end{array}$ & $\begin{array}{l}\text { Six-month survival of } \\
\text { critically ill } \\
\text { patients with HIV-related } \\
\text { disease and tuberculosis: a } \\
\text { retrospective study. }\end{array}$ & Brasil & $\begin{array}{l}\text { Coorte } \\
\text { retrospectiva }\end{array}$ & $\begin{array}{c}\text { Análise de } \\
\text { sobrevivência: Kaplan } \\
\text { Meier e Regressão de } \\
\text { Cox }\end{array}$ & $\begin{array}{l}\text { Analisar fatores } \\
\text { associados com } \\
\text { mortalidade em pacientes } \\
\text { criticamente doentes com } \\
\text { HIV e TB atendidos em } \\
\text { uma unidade de terapia } \\
\text { intensiva (2007-2012) }\end{array}$ & $\begin{array}{c}48 \%(21) \text { dos } 44 \text { pacientes } \\
\text { morreram antes de } 6 \text { meses. Entre } \\
\text { as diferenças entre aqueles que } \\
\text { morreram e sobreviveram estão: } \\
\text { contagem de células TCd4, tempo } \\
\text { ente diagnóstico do HIV e } \\
\text { admissão na unidade e disfunções } \\
\text { neurológicas } \\
\end{array}$ \\
\hline E20 & $\begin{array}{l}\text { Gaifer et al., } \\
\quad 2016\end{array}$ & $\begin{array}{c}\text { Risk factors for tuberculosis } \\
\text { mortality in a tertiary care } \\
\text { center } \\
\text { in Oman, 2006-2016 }\end{array}$ & Oman & $\begin{array}{l}\text { Transversal } \\
\text { retrospectivo }\end{array}$ & $\begin{array}{l}\text { Regressão logística } \\
\text { multivariada }\end{array}$ & $\begin{array}{l}\text { Explorar fatores de risco } \\
\text { associados com a } \\
\text { mortalidade por TB entre } \\
\text { pacientes admitidos num } \\
\text { hospital público de } \\
\text { Oman }\end{array}$ & $\begin{array}{l}31(15 \%) \text { dos } 205 \text { pacientes } \\
\text { morreram durante o tratamento da } \\
\text { TB. O tempo mediano entre início } \\
\text { do tratamento e morte foi } 30 \text { dias. } \\
\text { Os fatores associados foram: idade } \\
\text { avançada, baixo IMC, baciloscopia } \\
\text { negativa, coinfecção HIV e ser } \\
\text { estrangeiro (não cidadão local) }\end{array}$ \\
\hline E21 & $\begin{array}{c}\text { Zurcher et al., } \\
2016\end{array}$ & $\begin{array}{l}\text { Tuberculosis Mortality and } \\
\text { Living Conditions } \\
\text { in Bern, Switzerland, 1856- } \\
1950\end{array}$ & Suíça & Coorte & Regressão linear & $\begin{array}{l}\text { Analisar a mortalidade } \\
\text { por TB no período } 1856- \\
1950 \text { e fatores } \\
\text { relacionados }\end{array}$ & $\begin{array}{l}\text { A mortalidade foi maior no centro } \\
\text { da cidade }(327 / 100.000) . \mathrm{E} \\
\text { aumentou conforme o número de } \\
\text { pessoas por dormitório }(\mathrm{R}: 0,69, \\
\mathrm{p}=0,02) \text {, percentual de cômodos } \\
\text { com luz solar }(\mathrm{R}=0,79, \mathrm{p}=0,02), \mathrm{e} \\
\text { negativamente relacionada com } \\
\text { número de janelas por domicílio } \\
(\mathrm{R}=-0,79, \mathrm{p}=0,007)\end{array}$ \\
\hline
\end{tabular}


- continuação -

\begin{tabular}{|c|c|c|c|c|c|c|c|}
\hline & $\begin{array}{c}\text { Autores/ } \\
\text { Ano } \\
\text { Publicação }\end{array}$ & Título & Local & $\begin{array}{l}\text { Tipo de } \\
\text { Estudo }\end{array}$ & Tipo de Análise & Objetivos & Principais resultados \\
\hline E22 & Bigna et al., 2015 & $\begin{array}{c}\text { Early Mortality during Initial } \\
\text { Treatment of Tuberculosis in } \\
\text { Patients } \\
\text { Co-Infected with HIV at the } \\
\text { Yaoundé Central Hospital, } \\
\text { Cameroon: An 8-Year } \\
\text { Retrospective Cohort Study } \\
\text { (2006-2013) }\end{array}$ & Camarões & $\begin{array}{l}\text { Coorte } \\
\text { restrospectiva }\end{array}$ & $\begin{array}{l}\text { Regressão logística } \\
\text { binária }\end{array}$ & $\begin{array}{l}\text { Compreender os } \\
\text { contribuidores para } \\
\text { mortalidade de } \\
\text { pacientes em tratamento } \\
\text { (fase inicial) da TB com } \\
\text { a coinfecção HIV }\end{array}$ & $\begin{array}{l}\text { 49\% dos pacientes morreram na fase } \\
\text { intensiva do tratamento. A incidência da } \\
\text { mortalidade nesta fase foi } 32,2 / 100.000 . \\
\text { Os fatores associados com a morte } \\
\text { precoce foram não ter outra comorbidade } \\
\text { relacionada a AIDS (OR2,4), ter TB } \\
\text { extrapulmonar (OR: } 1,8) \text {, infecção do HIV } \\
\text { conhecida a um ano }(1,2) \\
\end{array}$ \\
\hline E23 & Miller et al., 2015 & $\begin{array}{l}\text { Mortality hazard and survival } \\
\text { after tuberculosis treatment. }\end{array}$ & $\begin{array}{l}\text { Estados } \\
\text { Unidos }\end{array}$ & Coorte & Regressão de Cox & $\begin{array}{l}\text { Comparar a mortalidade } \\
\text { entre ente pessoas com } \\
\text { TB e população similar } \\
\text { (diagnosticados com } \\
\text { ILTB) 1993-2002 }\end{array}$ & $\begin{array}{l}\text { A probabilidade de morrer após } \\
\text { tratamento de TB foi } 7 \text { vezes maior do } \\
\text { que a população comparada. Uma em } \\
\text { cada } 5 \text { das pessoas com história de TB } \\
\text { tratada morreram em média } 4,1 \text { anos } \\
\text { depois da conclusão do tratamento. Não } \\
\text { foram identificadas causalidades }\end{array}$ \\
\hline E24 & Wu et al., 2015 & $\begin{array}{l}\text { Comparing the factors } \\
\text { correlated with } \\
\text { tuberculosis-specific and non- } \\
\text { tuberculosis-specific deaths in } \\
\text { different age } \\
\text { groups among tuberculosis- } \\
\text { related deaths in Taiwan. } \\
\end{array}$ & Taiwan & $\begin{array}{l}\text { Coorte } \\
\text { retrospectiva }\end{array}$ & Regressão logística & $\begin{array}{l}\text { Identificar fatores } \\
\text { correlacionados com } \\
\text { mortalidade por TB } \\
\text { comparada com } \\
\text { mortalidade não } \\
\text { específica por TB }\end{array}$ & $\begin{array}{c}\text { Idosos (OR:2,68), residir a oeste } \\
\text { (OR:2.01), escarro positivo (OR:2,54), } \\
\text { comorbidade doença renal crônica }(2,35), \\
\text { AVC (OR:1,74), doença hepática crônica } \\
\text { (OR:1,29) são as prováveis causas das } \\
\text { mortes por TB }\end{array}$ \\
\hline E25 & Field et al., 2014 & $\begin{array}{c}\text { Timing, } \\
\text { rates, and causes of death in a } \\
\text { large South African } \\
\text { tuberculosis programme. }\end{array}$ & $\begin{array}{l}\text { Africa do } \\
\text { Sul }\end{array}$ & Coorte & $\begin{array}{c}\text { Análise de } \\
\text { sobrevida: Kaplan- } \\
\text { Meier }\end{array}$ & $\begin{array}{c}\text { Determinar o tempo e a } \\
\text { causa das mortes que } \\
\text { iniciaram o tratamento } \\
\text { da TB }\end{array}$ & $\begin{array}{l}\text { Encontrou alta mortalidade até um mês } \\
\text { após o início do tratamento (IRR } 0.86 \\
(0.55-1.36 \text { ). Entre os fatores associados: } \\
\text { idade avançada, TB prévia, coinfecção } \\
\text { HIV, TB pulmonar foram significantes }\end{array}$ \\
\hline
\end{tabular}


- continuação -

\begin{tabular}{|c|c|c|c|c|c|c|c|}
\hline & $\begin{array}{c}\text { Autores/ } \\
\text { Ano } \\
\text { Publicação }\end{array}$ & Título & Local & $\begin{array}{l}\text { Tipo de } \\
\text { Estudo }\end{array}$ & Tipo de Análise & Objetivos & Principais resultados \\
\hline E26 & $\begin{array}{l}\text { Mee et al. } \\
\quad 2014\end{array}$ & $\begin{array}{l}\text { Changing use of traditional } \\
\text { healthcare amongst those } \\
\text { dying of HIV related disease } \\
\text { and TB in rural South Africa } \\
\text { from } 2003 \text { - 2011: a } \\
\text { retrospective cohort study. }\end{array}$ & $\begin{array}{c}\text { África do } \\
\text { Sul }\end{array}$ & $\begin{array}{l}\text { Coorte } \\
\text { retrospectiva }\end{array}$ & Regressão & $\begin{array}{c}\text { Analisar a prevalência e } \\
\text { fatores determinantes no } \\
\text { uso de serviços de saúde } \\
\text { tradicionais entre pessoas } \\
\text { que morreram por TB e } \\
\text { HIV }\end{array}$ & $\begin{array}{l}\text { Detectou que o uso de serviços de } \\
\text { saúde tradicionais reduziu no } \\
\text { período e a variável distância entre } \\
\text { domicílio e serviço de saúde mais } \\
\text { próximo apresentou associação } \\
\text { estatisticamente significativa com } \\
\text { os óbitos }\end{array}$ \\
\hline $\mathrm{E} 27$ & Wang et al., 2013 & $\begin{array}{l}\text { Deaths of tuberculosis } \\
\text { patients in urban China: a } \\
\text { retrospective cohort study. }\end{array}$ & China & $\begin{array}{l}\text { Coorte } \\
\text { retrospectiva }\end{array}$ & Regressão de Cox & $\begin{array}{l}\text { Identificar fatores } \\
\text { associados com as mortes } \\
\text { relacionadas com a TB } \\
\text { em todas as mortes } \\
\text { ocorridas por pacientes } \\
\text { anteriormente } \\
\text { diagnosticados com TB } \\
\end{array}$ & $\begin{array}{l}\text { A TB foi responsável por } 17 \% \text { das } \\
\text { mortes, ser do sexo masculino } \\
\text { esteve positivamente associado as } \\
\text { morrer, além de morbidades } \\
\text { (psicopatia, bronquite crônica, } \\
\text { adoecimento por câncer e múltiplas } \\
\text { doenças coexistentes) } \\
\end{array}$ \\
\hline E28 & $\begin{array}{c}\text { Shimazaki } \text { et a., } \\
2013\end{array}$ & $\begin{array}{l}\text { Risk factors for death among } \\
\text { hospitalised tuberculosis } \\
\text { patients in poor urban areas in } \\
\text { Manila, The Philippines. }\end{array}$ & $\begin{array}{l}\text { Manila, } \\
\text { Filipinas }\end{array}$ & Transversal & Modelos de Poisson & $\begin{array}{l}\text { Avaliar a associação } \\
\text { entre TB e outras } \\
\text { covariáveis não } \\
\text { relacionadas a TB entre } \\
\text { pessoas com HIV }\end{array}$ & $\begin{array}{l}\text { Tratamento antirretroviral foi fator } \\
\text { de proteção contra não relacionadas } \\
\text { a TB a contagem de células TCD4 }\end{array}$ \\
\hline E29 & $\begin{array}{c}\text { Podlekareva et } \\
\text { al., } 2013\end{array}$ & $\begin{array}{c}\text { Health care } \\
\text { index score and risk of death } \\
\text { following tuberculosis } \\
\text { diagnosis in HIV-positive } \\
\text { patients. }\end{array}$ & $\begin{array}{l}\text { Oeste } \\
\text { europeu }\end{array}$ & Coorte & Modelo de Cox & $\begin{array}{l}\text { Desenvolver um índice } \\
\text { de saúde para monitorar } \\
\text { o risco de morte entre } \\
\text { pacientes com TB e } \\
\text { TB/HIV }\end{array}$ & $\begin{array}{l}\text { O escore mostrou que a cada } \\
\text { unidade aumentada reduz } 27 \% \text { a } \\
\text { mortalidade HR: } 0,73\end{array}$ \\
\hline
\end{tabular}


- continuação -

\begin{tabular}{|c|c|c|c|c|c|c|c|}
\hline & $\begin{array}{c}\text { Autores/ } \\
\text { Ano } \\
\text { Publicação }\end{array}$ & Título & Local & $\begin{array}{l}\text { Tipo de } \\
\text { Estudo }\end{array}$ & Tipo de Análise & Objetivos & Principais resultados \\
\hline E30 & Yen et al., 2012 & $\begin{array}{l}\text { DOT associated with reduced } \\
\text { all-cause mortality among } \\
\text { tuberculosis patients } \\
\text { in Taipei, Taiwan, 2006-2008. }\end{array}$ & $\begin{array}{l}\text { Taipei, } \\
\text { Taiwan, }\end{array}$ & Coorte & $\begin{array}{l}\text { Regressão logística } \\
\text { multivariada }\end{array}$ & $\begin{array}{l}\text { Determinar se pacientes } \\
\text { que receberam DOT } \\
\text { morreram menos do que } \\
\text { aqueles que auto } \\
\text { administraram os } \\
\text { medicamentos e fatores } \\
\text { associados com } \\
\text { mortalidade } \\
\end{array}$ & $\begin{array}{l}\text { As mortes foram } 40 \% \text { menos } \\
\text { frequentes entre aqueles que } \\
\text { trataram com DOTs, sexo } \\
\text { masculino, idade avançada, } \\
\text { desemprego, doença renal crônica } \\
\text { foram fatores de risco para } \\
\text { mortalidade }\end{array}$ \\
\hline E31 & $\begin{array}{l}\text { Kattan et al., } \\
\quad 2012\end{array}$ & $\begin{array}{l}\text { Tuberculosis mortality: death } \\
\text { from a curable } \\
\text { disease, Connecticut, 2007- } \\
2009 .\end{array}$ & $\begin{array}{l}\text { Connecticut } \\
\text {, EUA }\end{array}$ & Coorte & Análise bivariada & $\begin{array}{l}\text { Analisar as mortes por } \\
\text { TB e perdas de } \\
\text { oportunidade de } \\
\text { diagnosticar a doença }\end{array}$ & $\begin{array}{l}\text { Excesso de uso de álcool (RR:4,4 } \\
\text { IC95\%1,8-11) e idade }>64 \text { anos } \\
\text { foram associados a mortalidade. } 16 \\
(94 \%) \text { dos pacientes que morreram } \\
\text { tiveram uma oportunidade perdida } \\
\text { de diagnóstico }\end{array}$ \\
\hline E32 & $\begin{array}{c}\text { Rodríguez- } \\
\text { Morales; } \\
\text { Castañeda- } \\
\text { Hernández, } 2012\end{array}$ & $\begin{array}{c}\text { Relationships between } \\
\text { morbidity and mortality from } \\
\text { tuberculosis and the human } \\
\text { development index (HDI) in } \\
\text { Venezuela, 1998-2008 } \\
\end{array}$ & Venezuela & Coorte & Regressão linear & $\begin{array}{l}\text { Descrever a relação entre } \\
\text { HDI e seus componentes }\end{array}$ & $\begin{array}{c}\text { Encontrou relação inversa entre a } \\
\text { taxa de mortalidade por TB e HDI } \\
\text { geral }(\mathrm{F}=8.631 ; \mathrm{p}=0.012) \mathrm{a} \\
\text { componente do IDH mais } \\
\text { importante foi educação }\end{array}$ \\
\hline E33 & $\begin{array}{l}\text { Van't Hoog et al., } \\
2012\end{array}$ & $\begin{array}{c}\text { Risk factors for excess } \\
\text { mortality and death in adults } \\
\text { with tuberculosis in Western } \\
\text { Kenya }\end{array}$ & Kenia & Coorte & $\begin{array}{c}\text { Modelo de Regressão } \\
\text { proporcional Hazard }\end{array}$ & $\begin{array}{c}\text { Comparar as taxas de } \\
\text { mortalidade por TB } \\
\text { durante o tratamento com } \\
\text { outras causas }\end{array}$ & $\begin{array}{l}\text { HIV foi fator de risco e ser mulher } \\
\text { ou ter iniciado o tratamento no } \\
\text { último ano foi fator de proteção }\end{array}$ \\
\hline E34 & $\begin{array}{l}\text { Souza; Pinheiro, } \\
2011\end{array}$ & $\begin{array}{l}\text { Óbitos e internações por } \\
\text { tuberculose não notificados no } \\
\text { município do Rio de Janeiro }\end{array}$ & $\begin{array}{c}\text { Rio de } \\
\text { Janeiro, } \\
\text { Brasil }\end{array}$ & Epidemiológico & Regressão logística & $\begin{array}{l}\text { Analisar a subnotificação } \\
\text { de óbitos e internaçôes } \\
\text { por tuberculose no } \\
\text { Sistema de Informação de } \\
\text { Agravos de Notificação } \\
\text { (Sinan) }\end{array}$ & $\begin{array}{c}\text { Os menores de } 15 \text { anos tiveram } 4,8 \\
\text { vezes a chance de não notificação } \\
\text { daqueles entre } 15 \text { e } 59 \text { anos. } \\
\text { Algumas divisões regionais de } \\
\text { saúde apresentaram percentual de } \\
\text { óbitos não notificados acima de } \\
50 \%\end{array}$ \\
\hline
\end{tabular}

- continua - 
- conclusão -

\begin{tabular}{|c|c|c|c|c|c|c|c|}
\hline & $\begin{array}{l}\text { Autores/ } \\
\text { Ano } \\
\text { Publicação }\end{array}$ & Título & Local & $\begin{array}{l}\text { Tipo de } \\
\text { Estudo }\end{array}$ & Tipo de Análise & Objetivos & Principais resultados \\
\hline E35 & $\begin{array}{c}\text { Nigatu et al., } \\
2010\end{array}$ & $\begin{array}{l}\text { Epidemiological analysis of } \\
\text { tuberculosis in Ethiopia: a } \\
\text { ten-year trend analysis }\end{array}$ & Etiópia & Epidemiológico & Série espaço-temporal & $\begin{array}{c}\text { Examinar a tendência } \\
\text { epidemiológica em } \\
\text { período de dez anos da } \\
\text { morbidade e mortalidade } \\
\text { por TB } \\
\end{array}$ & $\begin{array}{l}\text { As taxas de incidência aumentaram } \\
\text { no período estudado. Zonas } \\
\text { agroecológicas foram mais afetadas }\end{array}$ \\
\hline E36 & Silva et al., 2010 & $\begin{array}{c}\text { Factors } \\
\text { associated with mortality in } \\
\text { hospitalized patients with } \\
\text { newly diagnosed } \\
\text { tuberculosis }\end{array}$ & Brasil & Coorte & $\begin{array}{l}\text { Regressão } \\
\text { Multivariada }\end{array}$ & $\begin{array}{c}\text { Identificar fatores } \\
\text { clínicos e } \\
\text { epidemiológicos } \\
\text { associados com a morte } \\
\text { entre pacientes } \\
\text { diagnósticos com TB no } \\
\text { hospital }\end{array}$ & $\begin{array}{c}\text { A ventilação mecânica, } \\
\text { consolidação no RX e escarro } \\
\text { negativos foram preditores de } \\
\text { mortes }\end{array}$ \\
\hline
\end{tabular}


Dentre os 36 artigos analisados na revisão, foram realizados no Brasil 14 (38,8\%) estudos, no continente Africano (África do Sul, Etiópia, Kenia e Camarões) 08; (22,2\%) artigos foram encontrados na China (Taipei, Wenchuan) 03; $(8,1 \%)$ artigos dos EUA foram incluídas duas (5,5\%) pesquisas e de Taiwan mais duas (5,5\%); e ocorreu uma pesquisa em cada um dos seguintes países: Venezuela, México, Omã, Filipinas, Coreia, Oeste europeu e Suíça.

Quanto aos tipos de análises utilizadas pelos estudos, observou-se que $12(33,3 \%)$ artigos realizaram estudo ecológico com análise espacial, 11 (30,5\%) realizaram estudo de coorte com uso de regressão linear ou logística e $13(36,1 \%)$ realizaram estudo de coorte aplicando análise de sobrevida.

Dentre os artigos que utilizaram análise espacial, a análise para detecção de aglomerados de risco foi utilizada por seis autores (ARCOVERDE et al., 2018; SANTOS et al., 2018; BERRA et al., 2017; SANTOS-NETO, et al., 2015; ALVAREZ- HERNANDEZ et al., 2010; HOULIHAN et al., 2010).

As análises espaciais bivariadas por meio do uso de Índice de Moran Global e Local (LISA) foram utilizadas por diversos autores (ARCOVERDE et al., 2018; SANTOS et al., 2018; BERRA et al., 2017; ALVAREZ- HERNANDEZ et al., 2010). Os autores Yamamura et al. (2017) e Santos-Neto et al. (2016) realizaram regressão linear com verificação de dependência espacial do resíduo para posterior aplicação da análise de regressão espacial.

Os determinantes correlacionados com a mortalidade por TB mais comumente encontrados pelos estudos foram aqueles relativos à desigualdade social e econômica, representados por variáveis como Índice de Vulnerabilidade Social-IVS (BERRA et al., 2017), equidade social (YAMAMURA et al., 2017), desigualdade de renda (CECCON et al., 2017; SANTOS-NETO et al., 2016), renda e Índice de Desenvolvimento Humano (IDH) (ARCOVERDE et al., 2018; SANTOS et al., 2018). Outros determinantes identificados pelos estudos foram relativos a condição de moradia, infraestrutura, incluindo características da vizinhança no entorno (BERRA et al., 2017; ARCOVERDE et al., 2018, SANTOS et al, 2018), iluminação da residência, número de janelas no domicílio e o número de pessoas por dormitório ou densidade domiciliar (ZURCHER et al., 2017).

Entre os determinantes correlacionados à mortalidade por TB, por meio dos estudos de abordagem individual e utilizando análises como regressão, foi observado que os principais fatores identificados foram: sexo masculino (OLIVEIRA et al., 2019; YEN et al., 2012), idade avançada (LEE et al., 2017; YEN et al., 2019; WU et al., 2015; YAMAMURA et al., 2015; WANG et al., 2013; YEN et al., 2012; GAIFER et al., 2016), presença de 
comorbidades como doenças do aparelho respiratório, derrame pleural (OLIVEIRA et al., 2019; WANG et al., 2013), doença renal (YEN et al., 2017; YEN et al., 2012).

Alguns estudos (OLIVEIRA et al., 2019; FERREIRA et al., 2018; LEE et al., 2017; PECEGO et al., 2016; BIGNA et al., 2015; FIELD et al., 2014) investigaram as mortes precoces por TB e fatores associados e, dentre aqueles identificados, encontraram a presença de comorbidades como HIV (CECCON et al., 2017; GESESEW et al., 2016; GAIFER et al., 2016; PECEGO et al., 2016; FIELD et al., 2014 ), doenças do aparelho respiratório, derrame pleural (OLIVEIRA et al., 2019; YEN et al., 2017), baixo IMC (GAIFER et al., 2016), ser acamado (GESESEW et al., 2016), doença renal (WU et al., 2015) uso de álcool (KATTAN et al., 2012).

Em um estudo, o diabetes mellitus apareceu como fator protetor para mortalidade por TB, o que foi explanado através do acompanhamento especial em serviços especializados para atendimento destes pacientes (SANTOS FELTRIN et al., 2016) e ainda aplicação da TDO foi correlacionada com menor risco de mortes por TB (YEN et al., 2017).

Verifica-se que a análise espacial tem sido utilizada para correlacionar a mortalidade por TB com variáveis sociais e econômicas das áreas onde os indivíduos viveram; enquanto que estudos que utilizaram técnicas de regressão, buscaram encontrar determinantes de ordem individual (sexo, idade, raça/cor, comorbidades) e sua associação com a mortalidade por TB.

Estudos de base individual, alguns com uso de análise de sobrevida, identificaram que as mortes por TB ocorridas precocemente são um alerta para a questão da evitabilidade da doença. Oliveira et al. (2019) encontraram que 74,6\% dos óbitos ocorreram de maneira precoce, Lee et al. (2017) encontraram uma mediana de sobrevivência após início do tratamento da TB de 21 dias, Pecego et al. (2016) observaram que 48\% dos pacientes com TB/HIV morreram antes de completarem 6 meses de tratamento e Bigna et al. 2015 concluíram que $49 \%$ dos pacientes morreram na fase intensiva do tratamento, isto é, antes de completarem 2 meses.

Diante da literatura analisada, observou-se que determinantes sociais se relacionam com a mortalidade por TB; no entanto, podem ser mensurados de diferentes maneiras e de acordo com as regiões e nível de observação, de forma ecológica (dados agregados) e ou mesmo individual, por meio de um estudo de coorte retrospectiva.

Uma inquietação que emergiu na construção deste trabalho e decorrente da própria revisão da literatura é que as mortes nos territórios não são homogêneas; algumas delas ocorrem de maneira muito precoce, nos primeiros meses do tratamento, o que inquietou os pesquisadores ao verificar este fenômeno no conjunto de dados. Houve uma preocupação de 
verificar os casos que, mesmo depois de diagnosticados pelos serviços de saúde, morreram até 2 meses após o início do tratamento (WAITT et al.; 2011, WHO, 1994, LEE et al.; 2017); por que morreriam, o que foi entendido como mortes precoces; aqueles casos que ocorreram, há uma hipótese, de que talvez a coinfecção pelo HIV esteja relacionada a este evento. Assim, para a pesquisa entendeu-se como necessário mapear as mortes por TB, buscar seus determinantes sociais, de uma análise de seu contexto, e compreender em um nível não agregado se haveriam mortes precoces e quais seriam seus fatores individuais associados.

Neste estudo é assumido que os fatores individuais são as características dos indivíduos como sexo, raça/cor, presença de comorbidades, tipo de tratamento, embora haja conexão destas variáveis com o contexto e do contexto com elas; no estudo foi importante definir estes limites, tendo na tese um momento da abordagem dos determinantes sociais do contexto e do território e num segundo momento concernentes ao indivíduo, como poderá ser observado mais à frente.

Dos estudos levantados na revisão, não se observou algum estudo que tenha realizado análise espacial, sequenciado de um estudo de coorte retrospectiva, com análise de sobrevida, o que evidencia a originalidade e ineditismo do estudo. A combinação destas abordagens dá maior abrangência, profundidade e consistência interna aos achados. 
3 Objetivos 


\subsection{Objetivo Geral}

Investigar aglomerados de risco para as mortes por $\mathrm{TB}$, sua relação com os determinantes sociais, investigar a ocorrência de mortes precoces em pacientes com TB e coinfecção TB/HIV e fatores individuais relacionados.

\subsection{Objetivos Específicos}

1. Estimar as taxas de mortalidade por TB (bruta e bayesiana);

2. Identificar aglomerados de risco para as mortes por TB;

3. Caracterizar as áreas em relação às taxas de mortalidade bruta, bayesiana e risco relativo espacial das mortes por TB;

4. Investigar a dependência espacial da mortalidade por TB (bruta e bayesiana) e do risco relativo espacial das mortes por TB;

5. Investigar a correlação entre as taxas de mortalidade bruta, bayesiana e o risco relativo espacial das mortes por TB;

6. Descrever as variáveis dos determinantes sociais da saúde e avaliá-las;

7. Relacionar as taxas da mortalidade e risco relativo espacial da TB com as variáveis dos determinantes sociais da saúde (comparação metodológica);

8. Identificar os aglomerados de risco espacial das variáveis dos determinantes sociais da saúde;

9. Investigar se as áreas dos aglomerados de risco espacial das variáveis dos determinantes sociais da saúde estão associadas às áreas de aglomerados de risco espacial da mortalidade por TB;

10. Identificar os casos que morreram precocemente por TB e ou TB-HIV;

11. Analisar os determinantes individuais associados às mortes precoces por TB e ou TB/HIV. 
4 Quadro Teórico 
Com vistas à orientação dos procedimentos metodológicos, bem como para a definição de uma matriz teórica que pudesse trazer de forma mais sedimentada o conceito de determinantes sociais e orientar as análises e discussão dos resultados, adotou-se a conceituação de Determinantes Sociais da Saúde (DSS) (SOLAR; IRWIN, 2010) incorporada pela Organização Mundial da Saúde, que entende como determinantes sociais, econômicos, culturais, étnicos/raciais e comportamentais que afetam o posicionamento do indivíduo na sociedade condicionando poder, prestígio, acesso a serviços; estas condições somadas exercem impacto sobre o resultado de saúde no indivíduo (SAN-PEDRO; OLIVEIRA, 2013; RASANATHAN et al., 2011; ZIONI; WESTPHAL, 2007).

Um dos primeiros modelos propostos para explicação dos DSS foi de Dahlgren e Whitehead (1991), que dispôs em camadas cinco estratos com os fatores que influenciam a saúde, de forma que as camadas mais próximas são concernentes ao indivíduo (proximais) e as mais distais (macrodeterminantes) variáveis do contexto e que exercem influência sobre a saúde do indivíduo (FIGURA 3).

Figura 3 - Determinantes Sociais da Saúde: modelo de Dahlgren e Whitehead.

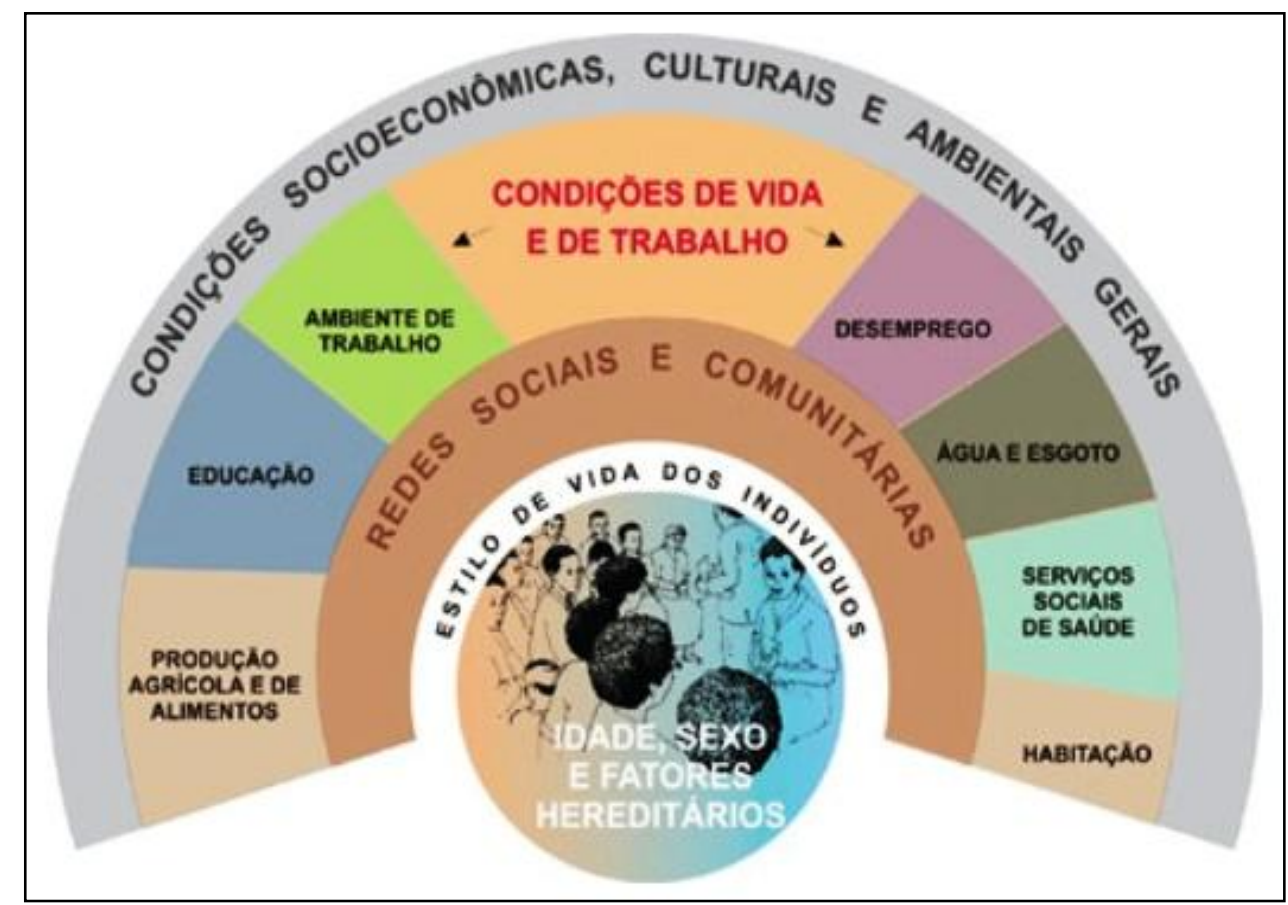

Fonte: CNDSS (2008). 
Em 2010, a OMS definiu seu referencial dos DSS com base no modelo proposto por Solar e Irwin (2010) (FIGURA 4), quando, na Conferência Mundial sobre os determinantes, foi publicado o relatório "Diminuindo diferenças: a prática das políticas sobre determinantes sociais da saúde" (OMS, 2011).

Segundo este relatório, o DSS deveria se apoiar em três pilares fundamentais: 1) ações intersetoriais que busquem melhorar a qualidade de vida e saúde; 2) promoção da autonomia de grupos populacionais mais vulneráveis; 3) Pesquisa com evidência científica, que produza informação e conhecimento sobre as relações entre os determinantes sociais e a saúde (CNDSS, 2008).

Dentre os fatores contextuais (sócio econômico e político) (FIGURA 4) são destacadas as estruturas de governança formais e informais; os mecanismos de participação social da sociedade; as políticas macroeconômicas, políticas fiscais, monetárias, políticas de mercado e a estrutura do mercado laboral; políticas sociais, incluindo as áreas de emprego e habitação; políticas públicas nas áreas de educação, saúde, água e saneamento, e também políticas redistributivas, de seguridade social e de proteção social, e por fim aspectos relacionados com a cultura e com os valores sociais legitimados pela sociedade. Todos estes são considerados os determinantes estruturais das iniquidades em saúde, ou seja, funcionam como um tipo de base ou alicerce sobre o qual as iniquidades são geradas (SOLAR \& IRWIN, 2010; GARBOIS, 2014).

Estes determinantes estruturais, por sua vez, afetam os determinantes intermediários da saúde e dão origem a um conjunto de posições ou estratificações de ordem socio econômica, a partir da renda, educação, ocupação, gênero, raça/etnia do indivíduo. Estas posições dentro das hierarquias sociais têm o poder de determinar maior ou menor vulnerabilidade ao proporcionarem as circunstâncias materiais como moradia, trabalho, disponibilidade de alimentos e que, por sua vez, afetam o comportamento do indivíduo e fatores psicossociais (CDSS, 2010).

A coesão social e capital social ocupam uma posição medial entre os determinantes intermediários (fatores comportamentais, psicossociais) e estruturais (como posição socioeconômica) afetando tanto o sistema de saúde quanto sendo afetados por estes, em uma via de mão dupla. O resultado final sempre impactará sobre a equidade em saúde e bem-estar; todavia, este resultado também retroalimentará os determinantes estruturais e intermediários. 
Figura 4 - Os Determinantes Sociais da Saúde (Solar e Irvan)

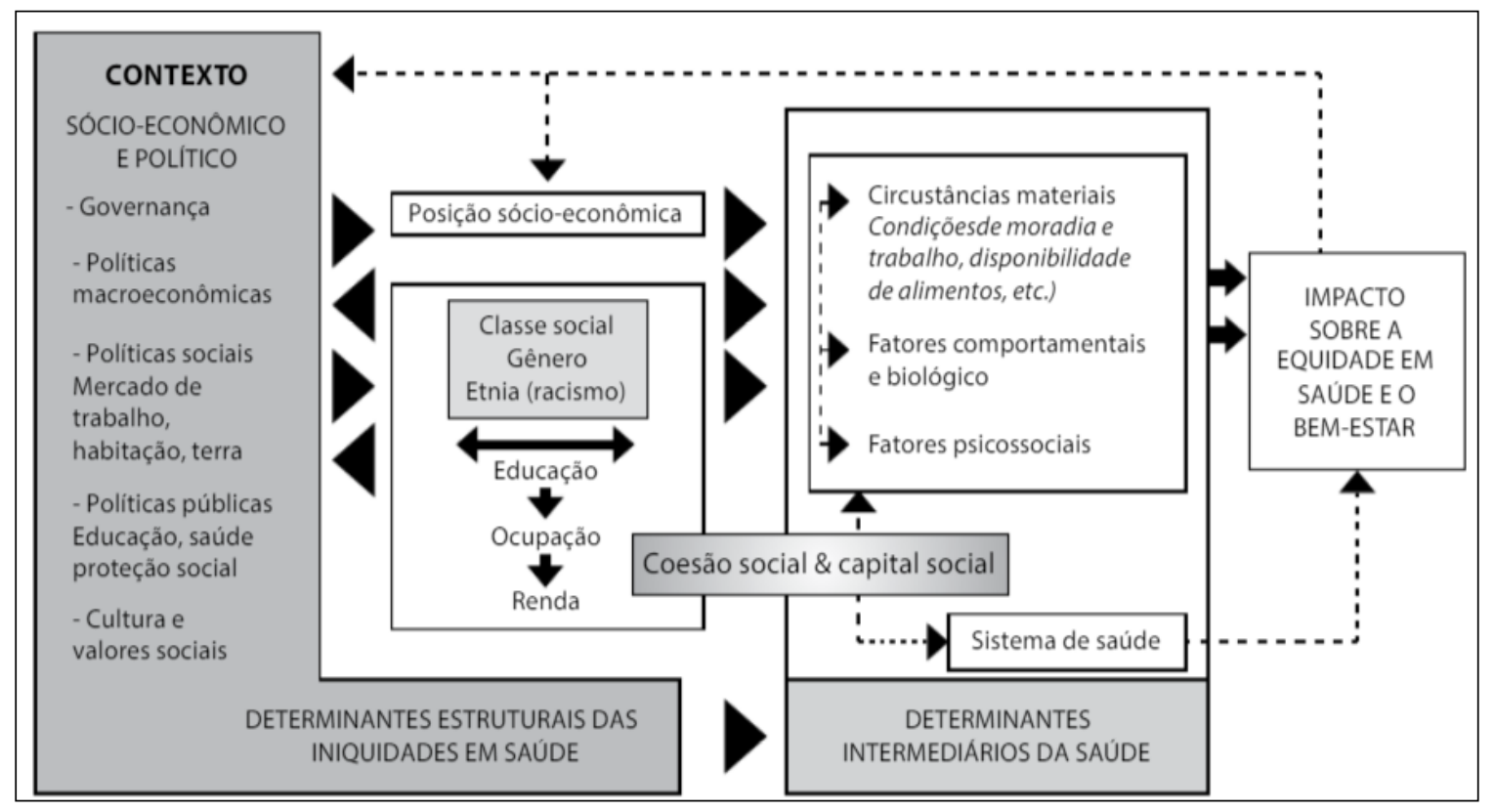

Fonte: WHO (2011).

A abordagem dos DSS significa compreender que a manutenção da saúde tem relação com outros setores da sociedade que não somente a saúde. Reflete também que as iniquidades em saúde não podem ser combatidas sem que as injustiças sociais também o sejam (RASANATHAN et al., 2011; ZIONI; WESTPHAL, 2007).

Os DSS afetam a saúde de diferentes maneiras, não ocupando todos a mesma posição de influência; os fatores ambientais seriam valorizados pela OMS, e poderiam determinarem 25\% da saúde da população, o estilo de vida saudável também tem relevância por aparentemente afetar mais o estado de saúde do indivíduo e os determinantes que causam mais estratificação social também tem importância reconhecida (PELLEGRINI FILHO, 2011; BARROS, 2017).

De acordo com Garbois (2014), muitos estudos, ao abordarem os determinantes sociais, acabam por fragmentar o social em camadas, situações e/ou condições particulares, trazendo o "social” como um "retrato" para explicar o nível de saúde de indivíduos. Torna-se relevante olhar para os diferentes níveis de estrutura e sua relação com o resultado em saúde analisado; neste caso, da mortalidade por TB a compreensão dos DSS está em consonância com a estratégia pelo fim da doença (END TB) (WHO, 2010; RASANATHAN et al., 2011; LONNROTH et al., 2009; WINGFIELD et al., 2016; PELISSARI; DIAZ-QUIJANO, 2017; LO“NNROTH et al., 2009). 


\subsection{Desenho do estudo}

Trata-se de um estudo epidemiológico misto, com duas fases: a primeira, um estudo de abordagem ecológica - Fase 1, utilizando análise espacial com múltiplas técnicas (ROOTHMAN, 2008) e a segunda, um estudo de abordagem individual, do tipo coorte retrospectiva e análise de sobrevida - Fase 2 (MAROCO, 2014).

\subsection{População de estudo, critérios de inclusão e unidades de observação}

\section{Fase 1: Abordagem Ecológica}

Para análise espacial, a população do estudo foi composta de casos que morreram de TB (causa básica) registrada com os códigos CID10: 15.0 a 19.9 (Quadro 2), na Declaração de Óbito (DO) no Sistema de Informação sobre Mortalidade (SIM), ocorridos entre 2008-2015, residentes da zona urbana do município de Curitiba. Foram excluídos os casos de mortes por TB sem logradouro e sem o número de residência por não permitir a etapa de geocodificação dos casos. Para esta etapa, foram consideradas como Unidade de Observação as Unidades de Desenvolvimento Humano (UDH).

As UDH foram elaboradas a partir de uma parceria do Programa das Nações Unidas para o Desenvolvimento (PNUD) com o Instituto de Pesquisa Econômica Aplicada (IPEA), buscando estabelecer regiões com maior homogeneidade socioeconômica. Desta forma, elas são formadas a partir da agregação dos setores censitários (a menor divisão geográfica estabelecida pelo Instituto Brasileiro de Geografia e Estatística - IBGE), que podem ser uma parte de um bairro, um bairro completo ou, em alguns casos, até um município pequeno, atendendo ao critério de no mínimo 400 domicílios por área (PNUD, 2014; IBGE, 2010).

Fase 2: Estudo de base individual, do tipo coorte retrospectiva, com análise de sobrevida

Para responder aos objetivos específicos de identificar os casos que morreram precocemente por TB e ou TB-HIV, e analisar os fatores clínicos individuais associados às mortes precoces por TB e ou TB/HIV, foram considerados os casos com registro de TB (CID10: 15.0 a 19.9) e também coinfecção TB/HIV (CID 10: 20.0) na Declaração de Óbito 
(DO) no Sistema de Informação sobre Mortalidade (SIM) e informações do Sistema de Informação de Agravos de Notificação (SINAN) de pacientes residentes em Curitiba-PR. Para esta etapa, a unidade de observação foram os pacientes com as CID acima referidas. Foram excluídos os casos que apresentassem data de diagnóstico e óbito simultâneas.

Quadro 3 - Formas clínicas consideradas no estudo, segundo a Classificação Internacional de Doenças versão 10 (CID 10).

\begin{tabular}{|c|c|c|}
\hline \multicolumn{2}{|l|}{ CID - 10} & Definição \\
\hline \multirow{10}{*}{$\begin{array}{c}\text { Tuberculose respiratória, } \\
\text { com confirmação } \\
\text { bacteriológica e } \\
\text { histológica }\end{array}$} & A 15.0 & $\begin{array}{l}\text { Tuberculose pulmonar, com confirmação por exame } \\
\text { microscópico de expectoração, com ou sem cultura }\end{array}$ \\
\hline & A 15.1 & $\begin{array}{l}\text { Tuberculose pulmonar, com confirmação somente por } \\
\text { cultura }\end{array}$ \\
\hline & A 15.2 & $\begin{array}{l}\text { Tuberculose pulmonar, com confirmação por meio não } \\
\text { especificado }\end{array}$ \\
\hline & A 15.3 & $\begin{array}{l}\text { Tuberculose pulmonar, com confirmação por meio não } \\
\text { especificado }\end{array}$ \\
\hline & A 15.4 & $\begin{array}{l}\text { Tuberculose dos gânglios intratorácicos, com } \\
\text { confirmação bacteriológica e histológica }\end{array}$ \\
\hline & A 15.5 & $\begin{array}{l}\text { Tuberculose da laringe, da traqueia e dos brônquios, com } \\
\text { confirmação bacteriológica e histológica }\end{array}$ \\
\hline & A 15.6 & $\begin{array}{l}\text { Pleuris tuberculoso, com confirmação bacteriológica e } \\
\text { histológica }\end{array}$ \\
\hline & A 15.7 & $\begin{array}{l}\text { Tuberculose primária das vias respiratórias, com } \\
\text { confirmação bacteriológica e histológica }\end{array}$ \\
\hline & A 15.8 & $\begin{array}{l}\text { Outras formas de tuberculose das vias respiratórias, com } \\
\text { confirmação bacteriológica e histológica }\end{array}$ \\
\hline & A 15.9 & $\begin{array}{l}\text { Tuberculose não especificada das vias respiratórias, com } \\
\text { confirmação bacteriológica e histológica }\end{array}$ \\
\hline \multicolumn{2}{|l|}{ CID - 10 } & Definição \\
\hline \multirow{9}{*}{$\begin{array}{l}\text { Tuberculose das vias } \\
\text { respiratórias, sem } \\
\text { confirmação } \\
\text { bacteriológica ou } \\
\text { histológica }\end{array}$} & A 16.0 & $\begin{array}{c}\text { Tuberculose pulmonar com exames bacteriológico e } \\
\text { histológico negativos }\end{array}$ \\
\hline & A 16.1 & $\begin{array}{l}\text { Tuberculose pulmonar, sem realização de exame } \\
\text { bacteriológico ou histológico }\end{array}$ \\
\hline & A 16.2 & $\begin{array}{l}\text { Tuberculose pulmonar, sem menção de confirmação } \\
\text { bacteriológica ou histológica }\end{array}$ \\
\hline & A 16.3 & $\begin{array}{l}\text { Tuberculose dos gânglios intratorácicos, sem menção de } \\
\text { confirmação bacteriológica ou histológica }\end{array}$ \\
\hline & A 16.4 & $\begin{array}{l}\text { Tuberculose da laringe, da traqueia e dos brônquios, sem } \\
\text { menção de confirmação bacteriológica ou histológica }\end{array}$ \\
\hline & A 16.5 & $\begin{array}{l}\text { Pleurisia tuberculosa, sem menção de confirmação } \\
\text { bacteriológica ou histológica }\end{array}$ \\
\hline & A 16.7 & $\begin{array}{l}\text { Tuberculose respiratória primária sem menção de } \\
\text { confirmação bacteriológica ou histológica }\end{array}$ \\
\hline & A 16.8 & $\begin{array}{l}\text { Outras formas de tuberculose das vias respiratórias, sem } \\
\text { menção de confirmação bacteriológica ou histológica }\end{array}$ \\
\hline & А 16.9 & $\begin{array}{l}\text { Tuberculose respiratória, não especificada, sem menção } \\
\text { de confirmação bacteriológica ou histológica. }\end{array}$ \\
\hline
\end{tabular}


- conclusão -

\begin{tabular}{|c|c|c|}
\hline \multicolumn{2}{|l|}{ CID - 10} & Definição \\
\hline \multirow{3}{*}{$\begin{array}{l}\text { Tuberculose do sistema } \\
\text { nervoso }\end{array}$} & A 17.1 & Tuberculoma meníngeo \\
\hline & A 17.8 & Outras tuberculoses do sistema nervoso \\
\hline & A 17.9 & Tuberculose não especificada do sistema nervoso \\
\hline \multirow{7}{*}{$\begin{array}{l}\text { Tuberculose de outros } \\
\text { órgãos }\end{array}$} & A18.0 & Tuberculose óssea e das articulações \\
\hline & A 18.1 & Tuberculose do aparelho geniturinário \\
\hline & A 18.2 & Linfadenopatia tuberculosa periférica \\
\hline & A 18.3 & $\begin{array}{c}\text { Tuberculose do intestino, do peritônio e dos gânglios } \\
\text { mesentéricos }\end{array}$ \\
\hline & A 18.4 & Tuberculose de pele e do tecido celular subcutâneo \\
\hline & A 18.5 & Tuberculose do olho \\
\hline & A 18.6 & Tuberculose do ouvido \\
\hline \multirow{7}{*}{ Tuberculose miliar } & A 18.7 & Tuberculose das suprarrenais \\
\hline & A 18.8 & Tuberculose de outros órgãos especificados \\
\hline & A 19.0 & $\begin{array}{c}\text { Tuberculose miliar aguda de localização única e } \\
\text { especificada }\end{array}$ \\
\hline & A 19.1 & Tuberculose miliar aguda de múltiplas localizações \\
\hline & A 19.2 & Tuberculose miliar aguda não especificada \\
\hline & A 19.8 & Outras tuberculoses miliares \\
\hline & A 19.9 & A19.9 Tuberculose miliar não especificada \\
\hline $\begin{array}{l}\text { Doença pelo vírus da } \\
\text { imunodeficiência } \\
\text { humana (HIV), } \\
\text { resultando em doenças } \\
\text { infecciosas e parasitárias }\end{array}$ & B20.0 & B20.0 Doença pelo HIV resultando em tuberculose \\
\hline
\end{tabular}

Fonte: Classificação Internacional de Doenças, versão 10 (CID - 10).

\subsection{Local de estudo}

O estudo foi conduzido em Curitiba, capital do estado do Paraná, que conta com 1.751.907 habitantes (IBGE, 2010); está situado nas coordenadas geográficas Latitude, $25^{\circ}$ $25^{\prime} 40^{\prime \prime} \mathrm{S}$, Longitude, $49^{\circ} 16^{\prime} 23^{\prime \prime} \mathrm{W}$ e ocupa uma área de 435,036 $\mathrm{km}^{2}$, com densidade demográfica de 4.027,04 (hab. Km² ${ }^{2}$ (FIGURA 5). 
Figura 5 - Localização geográfica das Unidades de Desenvolvimento Humano no município de Curitiba, Paraná, Brasil.

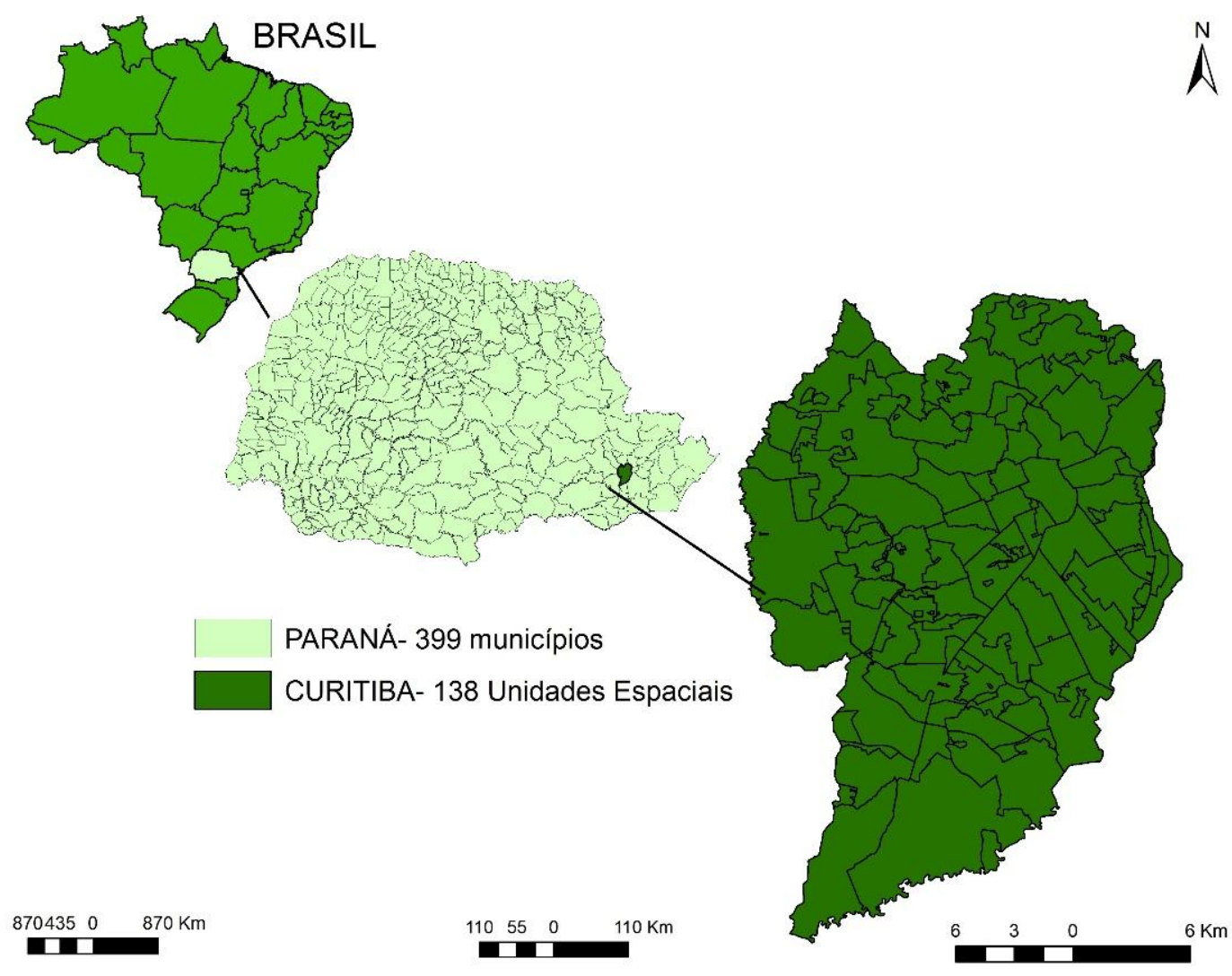

Fonte: elaborado pela própria autora

O Índice de Desenvolvimento Humano (IDH) de Curitiba está na faixa de desenvolvimento muito alto, ocupando a $10^{\mathrm{a}}$ posição entre os municípios brasileiros com melhores IDH Tabela 1 (IBGE, 2010; IPARDES, 2018).

Tabela 1 - Índice de Desenvolvimento Humano de Curitiba, Paraná, Brasil

\begin{tabular}{lc}
\hline Índices & Valores Índices Curitiba \\
\hline IDH & 0,823 \\
IDH longevidade & 0,855 \\
IDH renda & 0,850 \\
IDH educação & 0,768 \\
Índice de GINI & 0,5652 \\
\hline
\end{tabular}

Fonte: elaborado pela própria autora 
Além da divisão em 138 UDH, Curitiba possui outras divisões, sendo elas: 75 bairros agrupados em nove regiões geridas por subprefeituras, e ainda está dividida em 2.395 setores censitários. Possui 5.664 estabelecimentos de saúde, sendo 113 Unidades Básicas de Saúde (UBS) e 28 Núcleos de Apoio à Saúde da Família (NASF) com uma cobertura populacional pela atenção básica de 55,81\% (IPARDES, 2018). Com relação aos dados da TB, detém incidência de 14 casos por 100.000 habitantes em 2017 e mortalidade equivalente a 1,2 mortes para cada 100.000 habitantes (BRASIL, 2018a).

\subsection{Fonte de informação}

Dados obtidos do Sistema de Informações sobre Mortalidade (SIM) e do Sistema de Informação de Agravos de Notificação (SINAN), da Secretaria Estadual de Saúde do Paraná (SESA-PR).

\section{Variáveis sob estudo}

Fase 1: Abordagem ecológica

As variáveis utilizadas para análise dos determinantes sociais da saúde estão expressas no quadro abaixo e foram obtidas do PNUD 2013.

Quadro 4 - Variáveis consideradas para análise dos determinantes sociais da saúde.

\begin{tabular}{|l|l|l|}
\hline \multicolumn{1}{|c|}{ Código } & \multicolumn{1}{|c|}{$\begin{array}{c}\text { Nome da } \\
\text { variável }\end{array}$} & \multicolumn{1}{c|}{ Definição } \\
\hline ESPVIDA & $\begin{array}{l}\text { Esperança de } \\
\text { vida }\end{array}$ & $\begin{array}{l}\text { Número médio de anos que as pessoas deverão viver a } \\
\text { partir do nascimento, se permanecerem constantes ao } \\
\text { longo da vida o nível e o padrão de mortalidade por idade } \\
\text { prevalecentes no ano do Censo (2013) }\end{array}$ \\
\hline SOBRE60 & $\begin{array}{l}\text { Probabilidade de } \\
\text { sobrevivência } \\
\text { até } 60 \text { anos }\end{array}$ & $\begin{array}{l}\text { Probabilidade de uma criança recém-nascida viver até os } \\
60 \text { anos, se permanecerem constantes ao longo da vida o } \\
\text { nível e o padrão de mortalidade por idades prevalecentes } \\
\text { no ano do Censo }\end{array}$ \\
\hline
\end{tabular}


- continuação -

\begin{tabular}{|c|c|c|}
\hline Código & Nome da variável & Definição \\
\hline FB_SUPER & $\begin{array}{l}\text { Frequência bruta ensino } \\
\text { superior }\end{array}$ & $\begin{array}{l}\text { Razão entre o número total de pessoas de } \\
\text { qualquer idade frequentando o ensino superior } \\
\text { (graduação, especialização, mestrado ou } \\
\text { doutorado) e a população na faixa etária de } 18 \text { a } \\
24 \text { anos, multiplicada por } 100\end{array}$ \\
\hline GINI & $\begin{array}{l}\text { Índice de desigualdade } \\
\text { econômica }\end{array}$ & $\begin{array}{l}\text { Mede o grau de desigualdade existente na } \\
\text { distribuição de indivíduos segundo a renda } \\
\text { domiciliar per capita. Seu valor é } 0 \text { quando não } \\
\text { há desigualdade (a renda domiciliar per capita } \\
\text { de todos os indivíduos tem o mesmo valor) e } \\
\text { tende a } 1 \text { à medida que a desigualdade aumenta. } \\
\text { O universo de indivíduos é limitado àqueles que } \\
\text { vivem em domicílios particulares permanentes }\end{array}$ \\
\hline RDPC & Renda per capita & $\begin{array}{l}\text { Razão entre o somatório da renda de todos os } \\
\text { indivíduos residentes em domicílios } \\
\text { particulares permanentes e o número total } \\
\text { desses indivíduos. Valores em reais de } \\
\text { 01/agosto de } 2010\end{array}$ \\
\hline RPOB & $\begin{array}{l}\text { Renda domiciliar per } \\
\text { capita média dos } \\
\text { vulneraveis à pobreza. }\end{array}$ & $\begin{array}{l}\text { Média da renda domiciliar per capita das } \\
\text { pessoas com renda domiciliar per capita igual } \\
\text { ou inferior a } \mathrm{R} \$ 255,00 \text { mensais, a preços de } \\
\text { agosto de } 2010 \text {. O universo de indivíduos é } \\
\text { limitado àqueles que vivem em domicílios } \\
\text { particulares permanentes }\end{array}$ \\
\hline THEIL & Índice de desigualdade & $\begin{array}{l}\text { Mede a desigualdade na distribuição de } \\
\text { indivíduos segundo a renda domiciliar per } \\
\text { capita, excluídos aqueles com renda domiciliar } \\
\text { per capita nula. É o logaritmo da razão entre as } \\
\text { médias aritmética e geométrica da renda } \\
\text { domiciliar per capita dos indivíduos, sendo nulo } \\
\text { quando não existir desigualdade de renda entre } \\
\text { eles e tendente ao infinito quando a } \\
\text { desigualdade tender ao máximo }\end{array}$ \\
\hline T_BANAGUA & $\begin{array}{l}\text { Percentual da população } \\
\text { que vive em domicílios } \\
\text { com banheiro e água } \\
\text { encanada }\end{array}$ & $\begin{array}{l}\text { Razão entre a população que vive em } \\
\text { domicílios particulares permanentes com água } \\
\text { encanada em pelo menos um de seus cômodos e } \\
\text { com banheiro exclusivo e a população total } \\
\text { residente em domicílios particulares } \\
\text { permanentes, multiplicada por 100. A água } \\
\text { pode ser proveniente de rede geral, de poço, de } \\
\text { nascente ou de reservatório abastecido por água } \\
\text { das chuvas ou carro-pipa. Banheiro exclusivo é } \\
\text { definido como cômodo que dispõe de chuveiro } \\
\text { ou banheira e aparelho sanitário }\end{array}$ \\
\hline
\end{tabular}


- conclusão -

\begin{tabular}{|c|c|c|}
\hline Código & Nome da variável & Definição \\
\hline T_DENS & $\begin{array}{c}\text { Densidade por } \\
\text { dormitório }\end{array}$ & $\begin{array}{l}\text { Razão entre a população que vive em } \\
\text { domicílios particulares permanentes com } \\
\text { densidade superior a } 2 \text { e a população total } \\
\text { residente em domicílios particulares } \\
\text { permanentes, multiplicada por } 100 \text {. A } \\
\text { densidade do domicílio é dada pela razão entre } \\
\text { o total de moradores do domicílio e o número } \\
\text { total de cômodos usados como dormitório }\end{array}$ \\
\hline T_LIXO & $\begin{array}{l}\text { Percentual da } \\
\text { população que vive } \\
\text { em domicílios urbanos } \\
\text { com serviço de coleta } \\
\text { de lixo }\end{array}$ & $\begin{array}{l}\text { Razão entre a população que vive em } \\
\text { domicílios com coleta de lixo e a população } \\
\text { total residente em domicílios particulares } \\
\text { permanentes, multiplicada por } 100 \text {. Estão } \\
\text { incluídas as situações em que a coleta de lixo é } \\
\text { realizada diretamente por empresa pública ou } \\
\text { privada, ou o lixo é depositado em caçamba, } \\
\text { tanque ou depósito fora do domicílio, para } \\
\text { posterior coleta pela prestadora do serviço. São } \\
\text { considerados apenas os domicílios particulares } \\
\text { permanentes localizados em área urbana }\end{array}$ \\
\hline AGUA_ESGOTO & $\begin{array}{l}\text { Percentual de pessoas } \\
\text { em domicílios com } \\
\text { abastecimento de água } \\
\text { e esgotamento } \\
\text { sanitário inadequados }\end{array}$ & $\begin{array}{l}\text { Razão entre as pessoas que vivem em } \\
\text { domicílios cujo abastecimento de água não } \\
\text { provém de rede geral e cujo esgotamento } \\
\text { sanitário não é realizado por rede coletora de } \\
\text { esgoto ou fossa séptica e a população total } \\
\text { residente em domicílios particulares } \\
\text { permanentes, multiplicada por 100. São } \\
\text { considerados apenas os domicílios particulares } \\
\text { permanentes }\end{array}$ \\
\hline PAREDE & $\begin{array}{l}\text { Percentual de pessoas } \\
\text { em domicílios com } \\
\text { paredes que não sejam } \\
\text { de alvenaria ou } \\
\text { madeira aparelhada }\end{array}$ & $\begin{array}{l}\text { Razão entre as pessoas que vivem em } \\
\text { domicílios cujas paredes não são de alvenaria } \\
\text { nem de madeira aparelhada e a população total } \\
\text { residente em domicílios particulares } \\
\text { permanentes, multiplicada por } 100 \text {. São } \\
\text { considerados apenas os domicílios particulares } \\
\text { permanentes }\end{array}$ \\
\hline I_ESCOLARI & $\begin{array}{l}\text { Subíndice de } \\
\text { escolaridade da } \\
\text { população adulta - } \\
\text { IDHM Educação. }\end{array}$ & $\begin{array}{l}\text { Subíndice que compõe o Índice de } \\
\text { Desenvolvimento Humano } \\
\text { Educação, representando o nunicipal } \\
\text { escolaridade da população adulta. É obtido a } \\
\text { partir do indicador "\% de } 18 \text { anos ou mais com } \\
\text { fundamental completo" ( } 8 \text { anos de estudo) }\end{array}$ \\
\hline
\end{tabular}

Fonte: Elaborado pela autora a partir do PNUD (2013). 
Fase 2: Estudo de base individual, do tipo coorte retrospectiva, com análise de sobrevida

Quadro 5 - Variáveis individuais analisadas. Curitiba, Paraná, Brasil (2008-2015).

\begin{tabular}{|c|c|c|}
\hline \multirow{11}{*}{$\begin{array}{l}\text { *Características } \\
\text { individuais e } \\
\text { sociais }\end{array}$} & Variáveis independentes & Classes \\
\hline & Data do óbito & Data \\
\hline & \multirow{2}{*}{ Sexo } & Feminino \\
\hline & & Masculino \\
\hline & Idade & Contínua \\
\hline & \multirow{2}{*}{ Raça/cor } & Branca/amarela \\
\hline & & Afrodescendente \\
\hline & \multirow{2}{*}{ Escolaridade } & 8 anos e mais de estudo \\
\hline & & 0-7 anos de estudo \\
\hline & \multirow{2}{*}{ Estado Civil } & Casado / União estável \\
\hline & & Solteiro / viúvo / separado \\
\hline \multirow{12}{*}{ **Comorbidades } & \multirow{2}{*}{ Tipo de Entrada } & Caso novo \\
\hline & & Reingresso/retratamento \\
\hline & \multirow{2}{*}{ Institucionalizado } & Não \\
\hline & & Sim \\
\hline & \multirow{2}{*}{ Exame: radiografia } & Normal \\
\hline & & Sim / suspeito \\
\hline & \multirow{2}{*}{ Forma clínica } & Pulmonar \\
\hline & & Extrapulmonar \\
\hline & \multirow{2}{*}{ Agravo - uso de álcool } & Não \\
\hline & & Sim \\
\hline & \multirow{2}{*}{ Agravo Diabetes Mellitus (DM) } & Não \\
\hline & & Sim \\
\hline \multirow{16}{*}{$\begin{array}{l}* * \text { Operacionais: } \\
\text { exames e } \\
\text { tratamento }\end{array}$} & \multirow{2}{*}{ Exame: baciloscopia } & Negativo \\
\hline & & Positivo \\
\hline & \multirow{2}{*}{ Cultura } & Negativo \\
\hline & & Positivo \\
\hline & \multirow{2}{*}{ Medicamento utilizado: Rifampicina } & Sim \\
\hline & & Não \\
\hline & \multirow{2}{*}{ Medicamento utilizado: Isoniazida } & Sim \\
\hline & & Não \\
\hline & \multirow{2}{*}{$\begin{array}{l}\text { Medicamento utilizado: } \\
\text { Pirazinamida }\end{array}$} & Sim \\
\hline & & Não \\
\hline & \multirow{2}{*}{ Medicamento utilizado: Etambutol } & Sim \\
\hline & & Não \\
\hline & \multirow{2}{*}{$\begin{array}{l}\text { Medicamento utilizado: } \\
\text { Estreptomicina }\end{array}$} & Sim \\
\hline & & Não \\
\hline & \multirow{2}{*}{$\begin{array}{l}\text { Medicamento utilizado: outras } \\
\text { drogas }\end{array}$} & Sim \\
\hline & & Não \\
\hline
\end{tabular}




\begin{tabular}{|l|l|l|}
\hline & \multirow{2}{*}{ Tratamento supervisionado - DOTS } & Sim \\
\cline { 3 - 3 } & & Não \\
\hline
\end{tabular}

Fonte: elaborado pela autora a partir dos dados do *SIM **SINAN

\subsection{Plano de análise}

Os passos metodológicos para análise dos dados da pesquisa estão esquematicamente representados na figura 6, de forma a facilitar a compreensão do estudo.

Figura 6 - Síntese esquemática dos procedimentos analíticos segundo objetivo do estudo. Curitiba, Paraná, Brasil (2008-2015). 


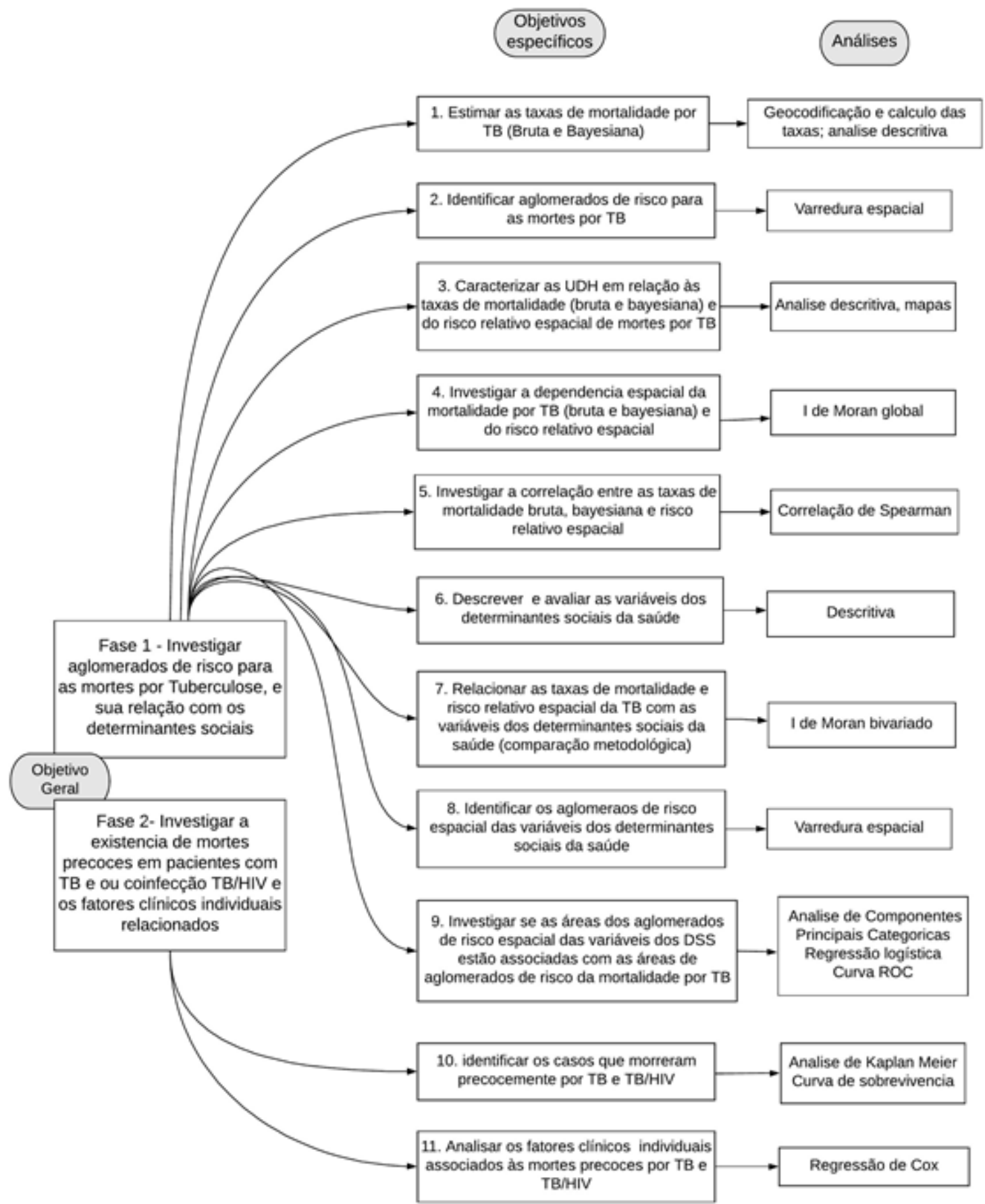

Fonte: Elaborado pela autora

\subsubsection{Fase 1: Abordagem Ecológica}

Para responder ao objetivo geral, foram utilizadas diversas técnicas de análise, como exposto na Figura 6. Como já exposto anteriormente, para consecução dos objetivos da tese foi necessário o desdobramento do estudo em duas fases, sendo que a primeira fase contemplou os objetivos específicos de um a nove e a fase 2 , os objetivos dez e onze.

Para responder ao primeiro objetivo de calcular as taxas de mortalidade por TB (bruta e bayesiana) recorreu-se primeiramente a geocodificação dos casos de óbitos por TB. 
Foram obtidas as coordenadas geográficas (latitude e longitude) dos endereços dos casos de óbitos, com auxílio do software de acesso livre Google Earth. Posteriormente procedeu-se à geocodificação, utilizando o software TerraView versão 4.2.2.

As informações dos casos de óbitos já geocodificadas geraram um arquivo de pontos que foram unidos com o arquivo de polígonos (UDH de Curitiba), resultando em um novo arquivo com os casos distribuídos nas respectivas UDH. O arquivo final dos endereços geocodificados foi definido com a projeção Universal Transversa de Mercator (UTM) e datum Sistema de Referência Geocêntrico para as Américas (SIRGAS) 2000. Foi utilizado o software ArcGis 10.2 para este procedimento.

A taxa bruta de mortalidade (TM) foi calculada considerando a somatória dos óbitos ocorridos em todo o período de estudo (oito anos) pela população de cada UDH, multiplicado por 100.000 e dividida por oito, referente aos anos do período de estudo, conforme fórmula abaixo.

$$
T M=\left(\frac{\sum \text { óbitos por TB }}{\text { população total }}\right) \times 100.000 \times \frac{1}{8}
$$

A taxa bayesiana da mortalidade por TB (TBM) também foi calculada. Trata-se de um método "smoothed" que tem o poder de suavização dos valores, ou redução das flutuações aleatórias. É uma técnica útil quando se pretende estimar os valores de interesse em regiões vizinhas sem casos registrados (zeros), ou ainda, na presença de áreas escassamente povoadas (BEST, 2005; MARSHAL, 1991; TSUTUKAWA, 1985). Pode ser adotado quando se presume que a frequência de óbitos tenha uma distribuição de Poisson com uma média proporcional ao tamanho da população.

Desta forma, as taxas bayesianas suavizam cada taxa, fazendo uma média ponderada da taxa interna e da taxa externa. Essa taxa externa pode ser obtida globalmente por meio do chamado método Bayes Empírico, que considera a média global dos vizinhos. O melhor estimador bayesiano é dado por uma combinação linear entre a taxa observada e a média (CÂMARA, 2004).

Para o cálculo das taxas bayesianas empíricas globais ội, considera-se:

$\hat{o}_{\mathrm{i}}=$ Ciri $+(1-\mathrm{Ci}) \mathrm{m}$

em que $C i=\frac{s^{2}-\frac{\mathrm{h}}{\mathrm{m}} / \mathrm{n}}{s^{2}-\frac{\dot{m}}{\mathrm{n}}+\frac{\dot{m}}{\mathrm{~m}} / n_{i}} \mathrm{~m}$ é a taxa global dos eventos, $\dot{\mathrm{n}}$, o número médio de pessoas em risco, $\mathrm{n}_{\mathrm{i}}$ é o número de pessoas observadas na área $\mathrm{i}, s^{2}=\sum i \frac{n i(r i-\mathrm{m})^{2}}{n}, \mathrm{n}$ é o 
número de pessoas observadas em todas as áreas juntas e $\mathrm{r}_{\mathrm{i}}$ é a taxa observada na área $\mathrm{i}$ (CÂMARA, 2004). O cálculo das taxas foi processado no software TerraView versão 4.2.2 e os mapas coropléticos das TM e TBM foram construídas no software ArcGis 10.2.

Para responder ao segundo objetivo, de identificar aglomerados de risco para mortes por TB, foi aplicada a técnica de varredura espacial (KULLDORFF; NAGARWALLA, 1995) com obtenção do Risco Relativo espacial (RR) da mortalidade por TB. O RR pode ser compreendido como o risco de morrer por TB dentro de uma região em relação ao risco morrer por TB fora dessa região (PRATES; KULLDORF; ASSUNÇÃO, 2014).

O RR é calculado considerando a seguinte fórmula:

$$
R R^{S}=\frac{N_{Z} / E_{z}}{\left(N-N_{Z}\right) /\left(E_{A}-E_{Z}\right)}
$$

Em que o $\mathrm{N}$ é o total número de casos, $\mathrm{N}_{\mathrm{Z}}$ é o número de casos no aglomerado $\mathrm{Z} ; \mathrm{E}_{\mathrm{A}}$ é o número de casos esperados sobre a região sob a hipótese nula; $\mathrm{E}_{\mathrm{Z}}$ é o número de casos na área Z sobre a hipótese nula. Quando o RR resulta em 1 (um), há uma forte evidência de não existência de cluster ou risco; se maior que um, existe risco maior, e menor do que um existe um baixo risco de sofrer o evento na área, que pode ser considerada como proteção (PRATES; KULLDORF; ASSUNÇÃO, 2014).

Mediante a aplicação da técnica de varredura espacial (KULLDORFF; NAGARWALLA 1995), foram obtidos os aglomerados ou cluster de risco dos óbitos por TB e também das variáveis dos DSS selecionadas previamente.

A detecção do aglomerado é feita mediante o posicionamento de um círculo virtual de raio variável em torno de cada centroide que calcula a taxa e o RR do evento no interior de cada círculo. Aglomerado de risco é considerado existente quando o valor observado na região delimitada pelo círculo é maior do que o esperado; se o valor for menor que o esperado, é denominado de aglomerado de baixo risco ou de proteção (KULLDORFF, 1995). Desta forma, as hipóteses assumidas neste estudo foram H0: não há aglomerados de risco e H1: a região z é um aglomerado.

Para a aplicação da técnica, foram criadas planilhas no Excel; a primeira com os casos de óbitos contendo a data da ocorrência, a segunda com as informações sobre coordenadas geográficas dos centroides das UDH gerados a partir do software TerraView versão 4.2.2 e a terceira em que constavam informações populacionais das UDH conforme os dados obtidos do PNUD (PNUD 2013; IBGE, 2010). 
Considerando que a distribuição dos casos é heterogênea e os eventos são raros em relação à população, foi adotado o modelo discreto de Poisson, ao atender algumas condições como a não sobreposição geográfica dos aglomerados, o tamanho máximo do aglomerado igual a 50\% da população exposta, aglomerado com formato circular e 999 replicações.

Após a detecção dos aglomerados de risco, as UDH foram categorizadas em dois tipos (dummy) da seguinte maneira, áreas de risco $=1$ e áreas de não risco $=0 . \mathrm{O}$ mesmo procedimento foi realizado para cada uma das variáveis dos DSS selecionadas, e para estes casos foi adotada uma distribuição normal.

Após a obtenção das taxas (TM e TBM) e do RR foram atendidos os objetivos de comparação metodológica, como caracterizar as UDH de acordo com as respectivas distribuições expostas nos mapas. Foi avaliada a intensidade da correspondência entre as medidas de mortalidade utilizadas no estudo, por meio da correlação entre as TM, TBM e RR das mortes por TB; para isso foi utilizada a correlação de Spearman, que se trata de um coeficiente que mede a intensidade da correlação entre duas variáveis; quanto maior a associação linear entre as variáveis mais próximo de +1 ou -1 , e quanto mais próximo de zero menor a relação entre elas; se o coeficiente foi maior que $70 \%$ considera-se forte relação linear entre elas. (MARTINS, 2010,).

O quarto objetivo específico de investigar a dependência espacial das taxas TM, TBM e do RR recorreu-se a autocorrelação espacial por meio do Índice de Moran Global (I), o qual mensura o grau de associação espacial, cujos resultados podem variar entre $-1 \mathrm{a}+1$, os valores negativos apontam a existência de correlação inversa e os positivos de correlação direta (MEDRONHO; WERNECK, 2009). Foi criada uma matriz espacial do tipo "queen" por contiguidade (Wij), nessa modalidade, as unidades espaciais que possuem fronteiras em comum são consideradas vizinhas e adotou-se a contiguidade de primeira ordem.

O Índice de Moran bivariado foi utilizado para averiguar a correlação espacial entre as variáveis dependentes (TM, TBM e RR) e as variáveis dos determinantes sociais da saúde, (ANSELIN, 2005). Essa análise permitiu comparar quais variáveis dos DSS apresentariam correlação com as medidas de mortalidade (TM, TBM e RR)

Para investigar a relação das áreas de risco dos DSS e das áreas de risco de mortalidade por TB, adotou-se a Análise de Componentes Principais Categóricas (ACP), para que se pudesse alcançar um modelo mais completo, com maior informação possível, trazida do conjunto original de variáveis definidas para a pesquisa (MAROCO, 2014).

Uma vez que os DSS são um conceito subjetivo/abstrato, e, portanto, não simples mensuração, o uso da ACP é justificado até mais que o uso de variáveis originais, pois esta 
técnica constrói componentes ou dimensões, que são composições a partir das variáveis originais, ao reduzir a complexidade dos dados disponíveis, trazendo a informação mais relevante (MAROCO, 2014; MEULMAN, 1992; SPENCER, 2014). Quando se tem valor igual ou superior a $80 \%$ do total das variâncias da população, para um p (variáveis) grande, pode-se atribuir uma ou mais componentes, e na construção destes índices ou componentes é desejável que se tenha a maior variância possível (FERREIRA, 1996). Foi utilizada a função optimal scaling para a análise de dados qualitativos, já que se utilizaram as variáveis categóricas, binarizadas, classificadas de acordo com aglomerados de risco (sim e não). Foi selecionada rotação ortogonal Varimax, que maximiza a variação entre os pesos de cada componente principal. Foram retidas as dimensões ou componentes com base no critério de autovalores (eigenvalues) superiores a 1 e avaliadas pelo Alpha de Cronbach, que é uma medida da fiabilidade de cada componente ou dimensão, que é tanto melhor quanto maior for esta estatística (MAROCO, 2014; MEULMAN, 1992).

As variáveis com maior "peso" ou principais de cada componente foram selecionadas para a construção de um mapa de sobreposição de aglomerados de risco das variáveis dos DSS, que por meio da soma das áreas resultou num Score de sobreposição de aglomerados de risco.

$\mathrm{Na}$ sequência, aplicou-se a regressão logística binária, adotando como variável dependente as UDH que fazem parte do aglomerado de risco (sim ou não) tendo como medida de associação o Odds Ratio, a um nível de confiança de 95\%. O método de ajustamento foi o de Máxima Verosimilhança (Maximum likelihood), que estima os coeficientes de regressão maximizando a probabilidade de encontrar as realizações da variável dependente $\left(\mathrm{y}_{1}, \mathrm{y}_{2}, \ldots\right.$, $\mathrm{y}_{\mathrm{n}}$ ) amostradas e método stepwise para entrada das dimensões. Foram também obtidos os coeficientes de Nagelkerke $\mathrm{R}^{2}$, que reflete a porcentagem das variações ocorridas no Log da razão de chances; também se utilizou o teste de Hosmer and Lemeshow para estimar a qualidade de ajuste do modelo.

Adicionalmente, aplicou-se Receiver Operating Chacarteristic (curva ROC); a interpretação deste teste baseia-se no valor da área sob a curva ROC, que varia entre zero e um; quanto mais próximo de um o valor encontrado maior é a capacidade do modelo para discriminar os indivíduos, sendo a classificação a seguinte: 0,5 , não há poder discriminatório; 0,5-0,7 discriminação fraca; 0,7-0,8 discriminação aceitável, 0,8-0,9, discriminação boa; >0,9 discriminação excelente. Desta forma, um modelo para apresentar boas capacidades preditivas deve ser superior a 80\% (HOSMER; LEMESHOW, 2000; MAROCO, 2014). Fixou-se o erro 
tipo I em 5\% como estatisticamente significativo $(\mathrm{p}<0,05)$. As análises foram realizadas por meio do Software SPSS versão 20.0. Os mapas temáticos foram elaborados por meio do software ArcGis ${ }^{\circledR}$ versão 10.2.

\subsubsection{Fase 2: Análise de sobrevida: estudo de base individual, do tipo coorte retrospectiva}

De forma sequencial, para responder ao objetivo de identificar a ocorrência de mortes precoces em pacientes com TB e coinfecção TB/HIV e fatores individuais relacionados, inicialmente foi realizada análise descritiva para obtenção das frequências absolutas e percentuais das variáveis categóricas clínicas e operacionais (Quadro 4). Para as variáveis contínuas (tempo em dias e idade) foram obtidos os valores mínimo, máximo, média, mediana e desvio-padrão.

A sobrevida no presente estudo foi considerada como sendo o tempo desde o diagnóstico da TB até o óbito por TB e TB/HIV. O evento de interesse ou falha foi considerado o óbito precoce (aquele que ocorreu até 2 meses após o início do tratamento) conforme descrito na literatura (WAITT et al., 2011; WHO, 1994; LEE et al., 2017).

O método de Kaplan-Meier foi utilizado para estimar a probabilidade de sobrevida, com definição da curva de sobrevivência de Kaplan-Meier como a probabilidade de sobreviver em um determinado período de tempo em intervalos de tempo estabelecidos (ALTMAN, 1992). A probabilidade de sobrevivência em qualquer momento específico é calculada pela fórmula dada abaixo (GOEL et al., 2010):

$\mathrm{St}=\underline{\text { número de pacientes vivos no início do período estudado }- \text { número de pacientes mortos }}$ Número de pacientes vivos no início do período estudado

Esta técnica permite a comparação de grupos estatisticamente, testando a hipótese nula, ou seja, não há diferença quanto à sobrevivência entre duas intervenções, ou características (EFRON, 1988; GOEL et al., 2010). O teste log-rank é utilizado para comparar curvas de sobrevida entre grupos (FERREIRA; PATINO, 2016). A hipótese nula é testada estatisticamente, que calcula o número esperado de eventos em cada grupo, ou seja, E1 e E2, enquanto $\mathrm{O} 1$ e $\mathrm{O} 2$ são o número total de eventos observados em cada grupo, respectivamente.

$$
\left.\log -\operatorname{rank}=\underline{\left(\mathrm{O}_{1}\right.}-\underline{\mathrm{E}_{1}}\right)^{2}+\underline{(\mathrm{O}}_{2} \underline{\underline{\mathrm{E}_{2}}} \underline{2}^{2}
$$


$\mathrm{E}_{1} \quad \mathrm{E}_{2}$

O número total de eventos esperados em um grupo (E2) é a soma do número de eventos esperados, no momento de cada evento em qualquer um dos grupos, reunindo os dois grupos. No momento do evento em qualquer grupo, o número esperado de eventos é o produto do risco de evento naquele momento com o número total de indivíduos vivos no início do tempo do evento naquele mesmo grupo.

Para analisar os fatores individuais associados às mortes precoces por TB e TB/HIV, foi realizada análise bivariada para identificar os fatores com $\mathrm{p}<0,10$ ou que foram consideradas clinicamente relevantes. Em seguida, estas variáveis foram analisadas em conjunto através do modelo de Cox, e pode-se obter estimativas dos coeficientes de regressão (hazard ratios) ou razão de riscos (GLANTZ et al., 2011).

O modelo de Cox conhecido também como modelo de riscos proporcionais de Cox, ou regressão de Cox (COX, 1972; COX; OAKES, 1984) apresenta resultados semelhantes ao de modelos paramétricos como a regressão linear múltipla, fornecendo as estimativas das razões de risco dos fatores estudados, podendo-se avaliar o impacto que alguns fatores de risco têm no tempo até a ocorrência do evento estudado (BUSTAMANTE-TEIXEIRA; FAERSTEIN; LATORRE, 2002). A função das razões de risco é dada por:

$$
H R(i)=H R_{i}=\exp \left(\beta_{1} X_{i 1}+\beta_{2} X_{i 2}+\ldots+\beta_{k} X_{i k}\right)
$$

As suposições feitas são as de que diferentes indivíduos têm funções de riscos proporcionais entre si, e que a razão entre essas funções de risco não varia no tempo e de que a relação entre hi (t) e hj (t) é constante ao longo do tempo. O método de estimação é o da máxima verossimilhança parcial (maximum likelihood) e os parâmetros são calculados pela maximização da função likelihood (L).

O HR é definido como o risco de um indivíduo dividido pelo risco para outro indivíduo, sendo distinguidos pelos valores do conjunto de variáveis preditivas $\left(\mathrm{x}_{\mathrm{i}}\right)$. Os resultados foram apresentados na forma de razões de risco (HR) com intervalos de confiança de $95 \%$ (IC). Fixou-se erro tipo I em 5\%, sendo considerado como estatisticamente significativo $(\mathrm{p}<0,05)$ em todos os testes. As análises foram realizadas no software IBM SPSS 24.0

\subsection{Aspectos éticos}


Atendendo aos preceitos da Resolução n466/2012, para realização deste estudo, o projeto foi aprovado pelo Comitê de Ética em Pesquisa envolvendo seres humanos da Escola de Enfermagem de Ribeirão Preto da Universidade de São Paulo sob a CAEE no 53269116.9 .0000 .53 


\section{Resultados}


Na Fase 1 do estudo foram identificados 131 óbitos com registro de TB com causa básica na DO no município de Curitiba, entre 2008-2015, dos quais 126 (96,2\%) foram georreferenciados e os outros cinco $(4,8 \%)$ foram excluídos desta fase do estudo, devido a endereços incompletos. Dentre os casos que foram georreferenciados, quatro deles $(3,6 \%)$ tinham registrado como endereço residencial um abrigo domiciliar para moradores de rua que fica localizado no centro do município.

Quanto ao primeiro objetivo específico, as TM e a TBM estão apresentadas na figura 7; pode-se observar que a TM foi de 1,07/100.000 habitantes; segundo a referida figura, a TM está distribuída mais acentuadamente nas regiões à oeste e sul com cores mais escuras, enquanto que a região central e noroeste apresentam áreas claras com menores valores. Especificamente em relação à TBM, verifica-se o mesmo comportamento, ela se mantém nas mesmas regiões, porém, com maior suavização dos valores.

Figura 7 - Distribuição das taxas de mortalidade por tuberculose. Curitiba, Paraná, Brasil (2008-2015).
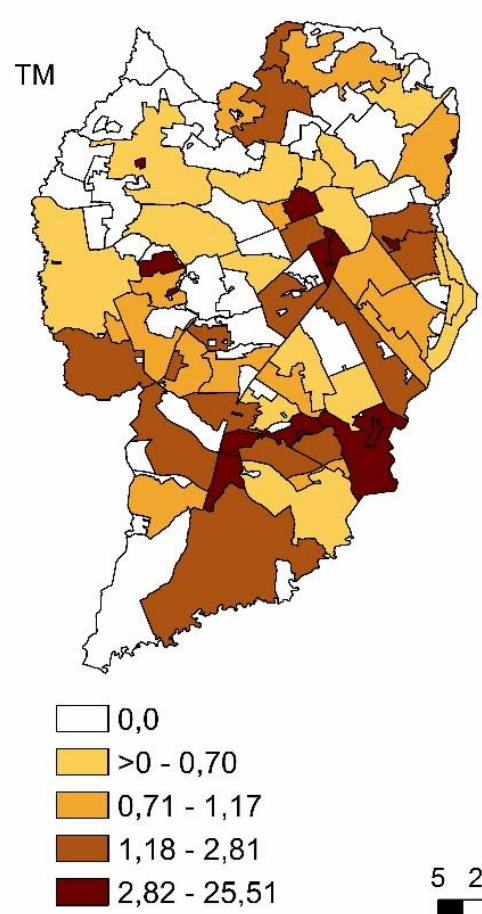
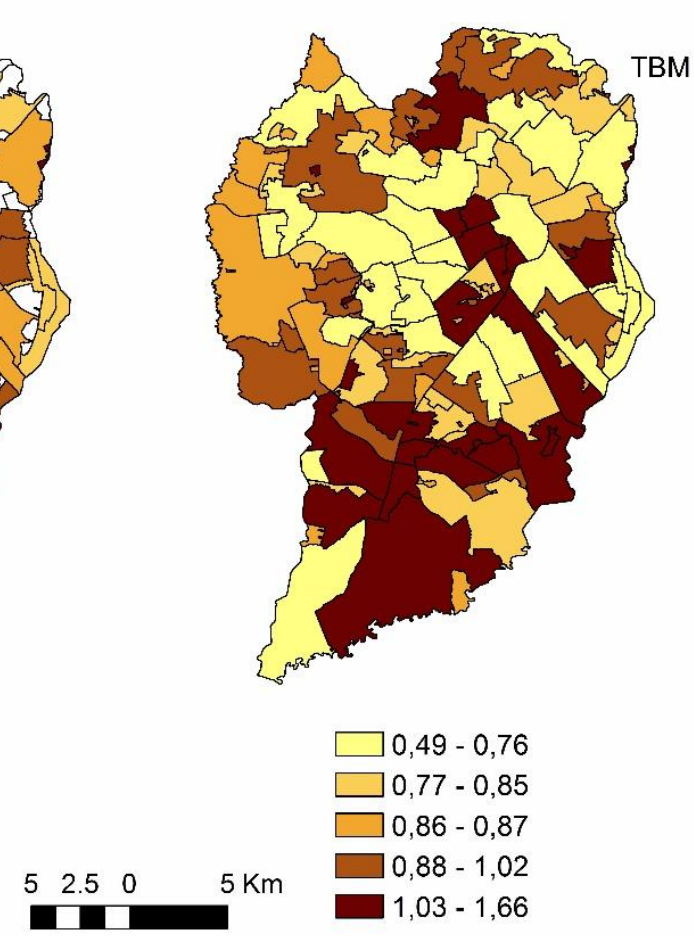

Fonte: próprio autor. Valores adicionais: Taxa bruta de mortalidade $(\mathrm{TM})$ : média $=1,07$; mediana $=0,0$ e DP= 2,70; Taxa bayesiana de mortalidade por TB (TBM): média $=0,89$; mediana $=0,86$ e DP=0,19. 
Um aglomerado de risco para óbitos por TB foi identificado na região sul do município, com um risco-relativo de 2,66 e com 35 casos contidos na área, uma população exposta de 217.420 e uma taxa de 2,0/100.000 habitantes (p-valor=0,01). Os RR obtidos na varredura espacial para cada UDH também foram apresentados na mesma Figura (FIGURA $8)$.

Figura 8 - Aglomerado de risco espacial de mortes por tuberculose e risco relativo espacial atribuídos às unidades de desenvolvimento humano-UDH. Curitiba, Paraná, Brasil (20082015)
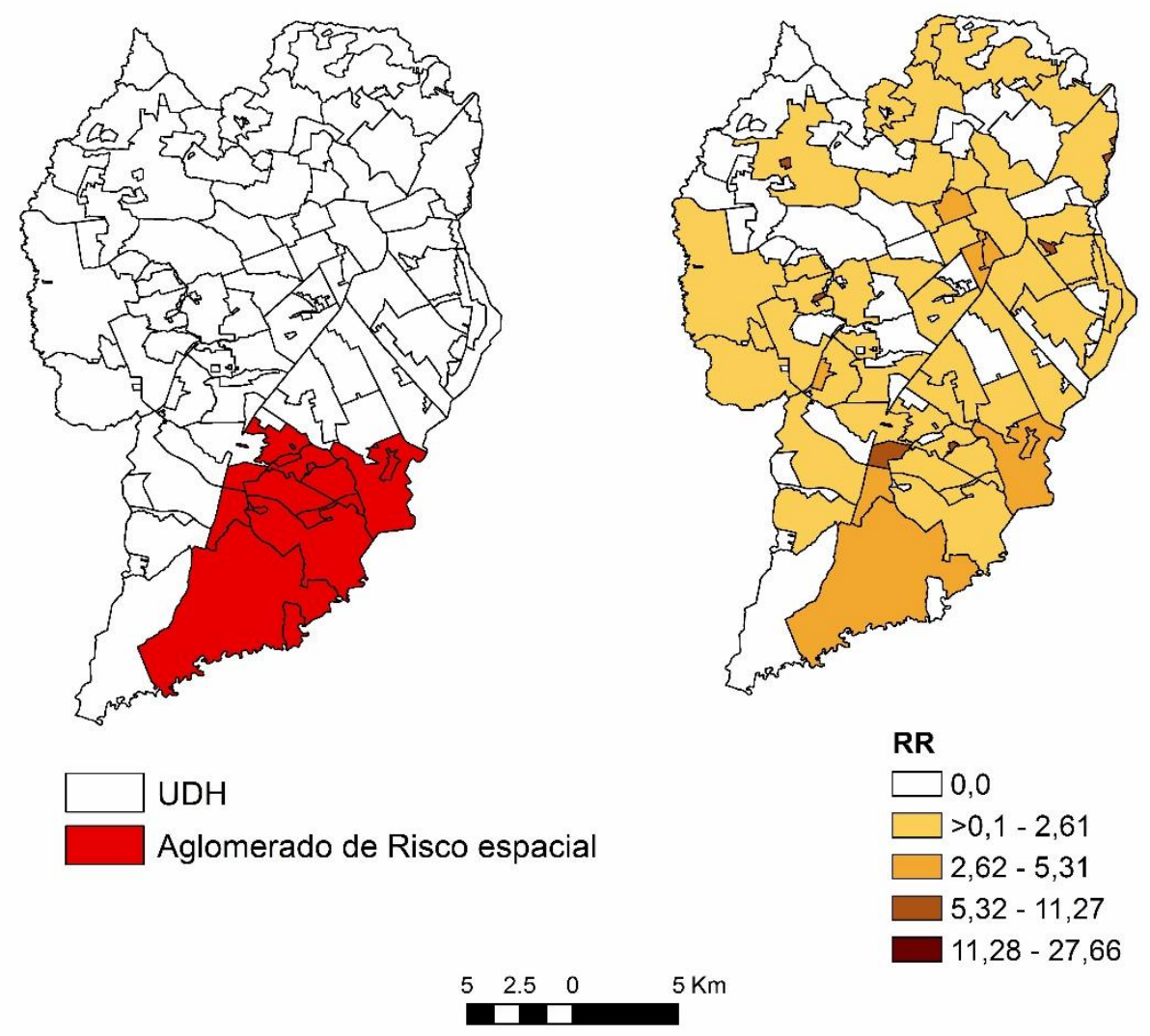

Fonte: próprio autor

Para responder o objetivo específico de investigar a dependência espacial ou autocorrelação espacial foi utilizado I de Moran, sendo que para TM não foi estatisticamente significativa $(p=0,051)$; todavia foi para TBM $(p<0,01)$ e também para o RR $(p=0,048)$.

Para responder ao objetivo específico de investigar a correlação entre TM e TBM foi observado coeficiente de correlação de Spearman =0,667. Entre a TM e o RR, o valor foi de 0,999. Ao considerar as variáveis TBM e RR o correlação de spearman resultou em 0,664 (p $<0,001$ para todos) estatisticamente significativos. 
Os valores das variáveis dos DSS estão distribuídos na tabela 2 e na figura 9.

Tabela 2 - Distribuição dos valores mínimo, máximo, médio, mediano e desvio-padrão das variáveis dos determinantes sociais da saúde analisados. Curitiba, Paraná, Brasil (2008-2015)

\begin{tabular}{lccccc}
\hline $\begin{array}{c}\text { Variáveis dos } \\
\text { determinantes } \\
\text { sociais da saúde }\end{array}$ & Min. & Max. & Média & Mediana & DP \\
\hline ESPVIDA & 69,47 & 81,48 & 76,45 & 76,98 & 3,38 \\
FB_SUPER & 7,86 & 118,74 & 49,63 & 38,05 & 33,33 \\
GINI & 0,33 & 0,63 & 0,42 & 0,41 & 0,05 \\
RDPC & 439,73 & 4645,60 & 1332,56 & 934,40 & 986,40 \\
RPOB & 87,27 & 212,87 & 178,56 & 180,61 & 17,38 \\
THEIL & 0,18 & 0,76 & 0,33 & 0,31 & 0,10 \\
T_DENS & 1,2 & 37,02 & 17,06 & 16,74 & 10,74 \\
I_ESCOLAR & 0,40 & 0,94 & 0,67 & 0,68 & 0,15 \\
SOBRE60 & 75,10 & 09,09 & 85,43 & 86,47 & 4,71 \\
T_BANAGUA & 95,46 & 100 & 98,72 & 99,04 & 1,05 \\
T_LIXO & 99,2 & 100 & 99,83 & 100 & 0,25 \\
AGUA_ESGOTO & 0,0 & 1,76 & 0,09 & 0,0 & 0,21 \\
PAREDE & 0,0 & 13,46 & 2,47 & 1,30 & 3,47 \\
\hline
\end{tabular}

Fonte: próprio autor 
Figura 9 - Distribuição gráfica das variáveis dos determinantes sociais da saúde nas Unidades de desenvolvimento humano-UDH. Curitiba, Paraná, Brasil (2008-2015)

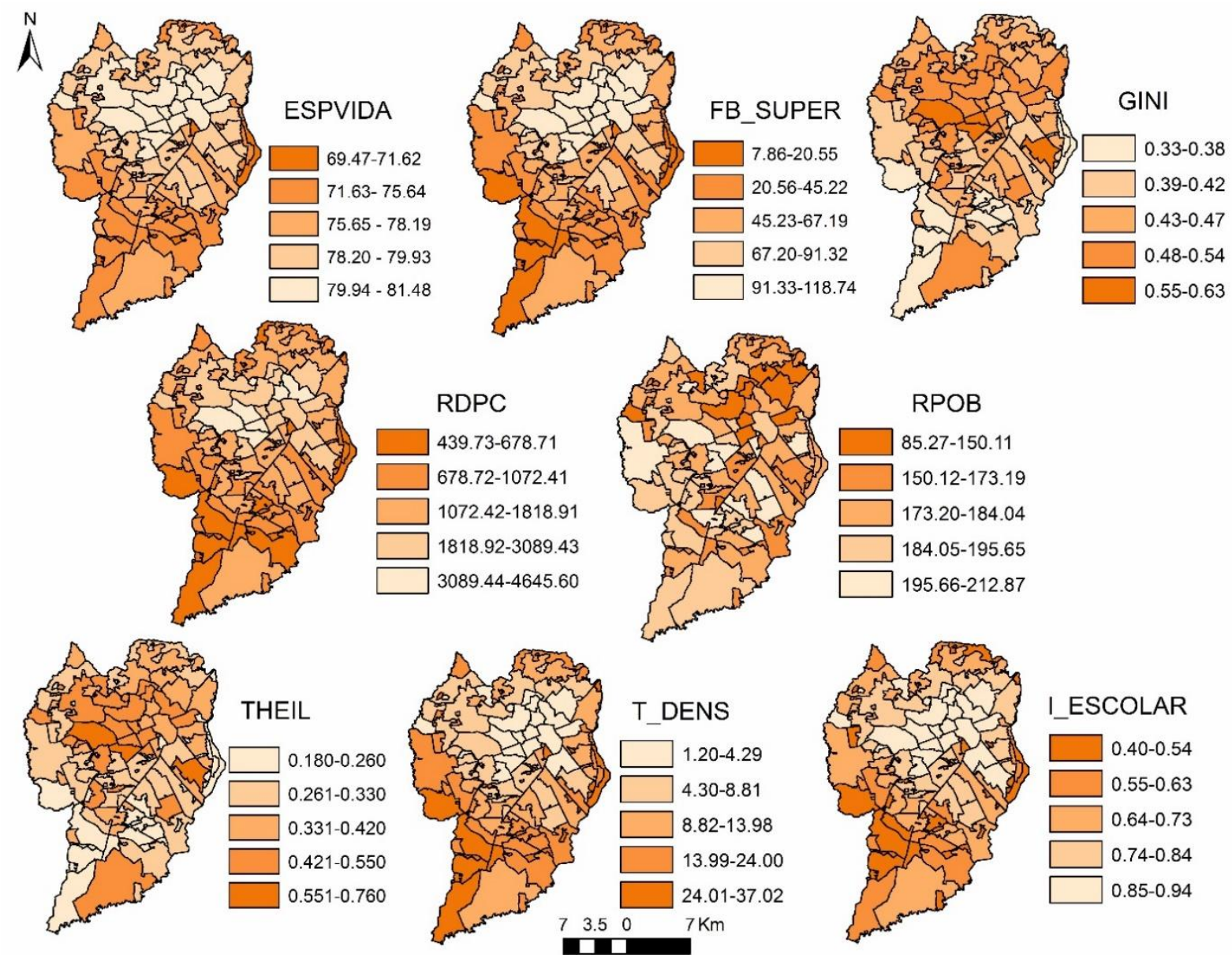




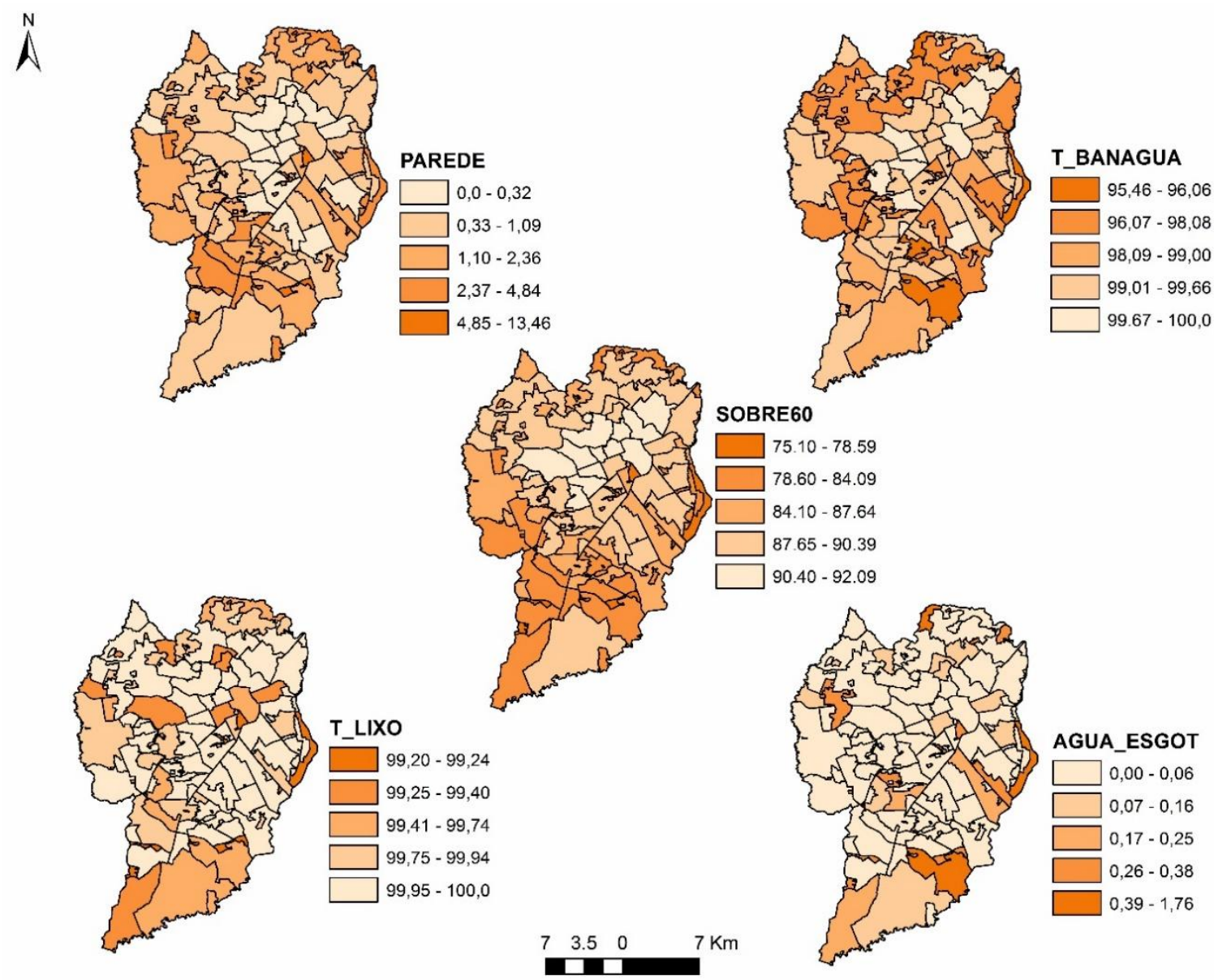

Legenda: ESPVIDA: esperança de vida; FB_SUPER: Frequência bruta ensino superior; GINI: Índice de desigualdade econômica; RDPC: Renda per capita média; RPOB: Renda domiciliar per capita média dos vulneraveis à pobreza; THEIL: Índice de desigualdade; T_DENS: Densidade por dormitório; I_ESCOLAR: Subíndice de escolaridade da população adulta IDHM Educação.

Os mapas construídos das variáveis dos DSS distribuídas nas Unidades de Desenvolvimento Humano estão expostos na figura 9. Segundo esta figura, nota-se que os valores que correspondem à renda, estudo e densidade por dormitório se encontram situados principalmente nas periferias. Nas distribuições das variáveis ESPVIDA, FB_SUPER, RDPC, e I_ESCOLARI, os menores valores representam menos esperança de vida, menor frequência no ensino superior, menor renda média per capita, menor frequência de escolaridade (ensino médio) e estão localizadas principalmente nas regiões periféricas e ao sul do município, e apenas GINI e THEIL tiveram os valores mais elevados concentrados na região central do município, revelando maior heterogeneidade econômica nesta região.

As variáveis PAREDE, T_BANAGUA, T_LIXO, AGUA_ESGOTO representam que as condições de moradia e saneamento disponíveis apresentam os melhores valores de: paredes do domicilio, coleta lixo, água e esgoto na região central, e piores valores nas regiões 
periféricas; desta forma, ao visualizar a distribuição das variáveis dos DSS, nota-se que as piores condições sociais estão localizadas nas periferias e ao sul do município.

Para atender ao objetivo específico de verificar associação dos determinantes sociais da saúde às taxas da mortalidade (TM e TBM) e RR, recorreu-se inicialmente à análise bivariada através do Índice de Moran bivariado, cujos resultados são apresentados na tabela 3.

Tabela 3 - Índice de Moran bivariado da associação dos determinantes sociais da saúde e a mortalidade por TB. Curitiba, Paraná (2008-2018).

\begin{tabular}{lcccccc}
\hline & \multicolumn{2}{c}{ TM } & \multicolumn{2}{c}{ RR } & \multicolumn{2}{c}{ TBM } \\
\hline Variáveis dos DSS & I'Moran & $\begin{array}{c}\text { Sig } \\
\text { (p-valor) }\end{array}$ & I'Moran & $\begin{array}{c}\text { Sig } \\
\text { (p-valor) }\end{array}$ & I'Moran & $\begin{array}{c}\text { Sig } \\
\text { (p-valor) }\end{array}$ \\
\hline ESPVIDA & $-0,004$ & 0,62 & $-0,009$ & 0,53 & $-0,10$ & $\mathbf{0 , 0 4 4}$ \\
FB_SUPER & $-0,003$ & 0,35 & $-0,03$ & 0,24 & $-0,12$ & $\mathbf{0 , 0 2 5}$ \\
GINI & 0,006 & 0,30 & $-0,002$ & 0,59 & $-0,13$ & $\mathbf{0 , 0 2 3}$ \\
RDPC & $-0,03$ & 0,32 & $-0,04$ & 0,20 & $-0,12$ & $\mathbf{0 , 0 2 3}$ \\
RPOB & 0,12 & $\mathbf{0 , 0 2 5}$ & 0,12 & $\mathbf{0 , 0 3 1}$ & $-0,09$ & 0,052 \\
THEIL & $-0,003$ & 0,59 & $-0,012$ & 0,49 & $-0,13$ & $\mathbf{0 , 0 1 9}$ \\
T_DENS & 0,02 & 0,19 & 0,011 & 0,26 & 0,106 & $\mathbf{0 , 0 4 0}$ \\
I_ESCOLAR & $-0,007$ & 0,54 & $-0,016$ & 0,48 & $-0,102$ & $\mathbf{0 , 0 4 0}$ \\
SOBRE60 & 0,005 & 0,33 & $-0,002$ & 0,58 & $-0,095$ & 0,062 \\
T_BANAGUA & 0,04 & 0,11 & 0,04 & 0,12 & $-0,019$ & 0,40 \\
T_LIXO & 0,04 & 0,12 & 0,039 & 0,12 & $-0,00$ & 0,55 \\
AGUA_ESGOTO & $-0,06$ & $\mathbf{0 , 0 5 4}$ & $-0,07$ & $\mathbf{0 , 0 4 5}$ & $-0,008$ & 0,50 \\
PAREDE & 0,002 & 0,32 & 0,004 & 0,30 & 0,034 & 0,21 \\
\hline
\end{tabular}

Fonte: próprio autor

$\mathrm{Na}$ análise bivariada com a TM, apenas duas variáveis (RPOB e AGUA_ESCOTO) dos DSS foram estatisticamente significativa $(p<0,05)$ e apresentaram uma correlação positiva, quando as variáveis foram correlacionadas com o RR mantiveram-se as mesmas, ao serem relacionadas com a TBM resultaram em sete variáveis significativas, referentes a esperança de vida, frequência no ensino superior, Índice de desigualdade GINI, THEIL, densidade por dormitório, escolaridade (ensino médio), todas com correlações inversas.

Para responder ao objetivo de identificar aglomerados de risco para as variáveis dos DSS, as treze (13) anteriormente descritas foram submetidas à técnica de varredura espacial (FIGURA 10), sendo que oito delas apresentaram aglomerados de risco. Os valores referentes aos aglomerados de risco estão apresentados na Tabela 4. 
Figura 10 - Aglomerado de risco espacial das variáveis dos determinantes sociais da saúde. Curitiba, Paraná, Brasil (2008-2015).

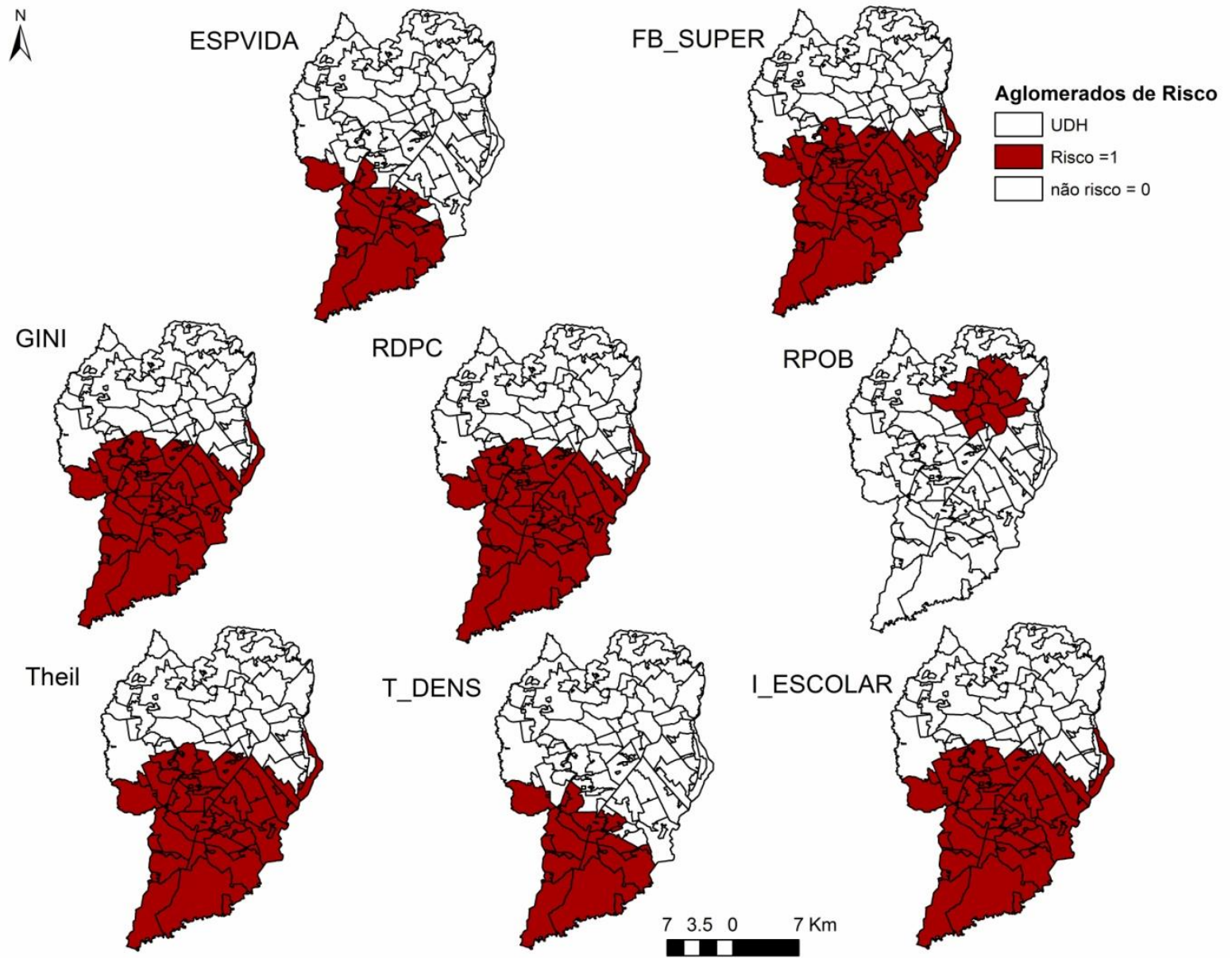

Fonte: Elaborado pela autora

Legenda: ESPVIDA: esperança de vida; FB_SUPER: Frequência bruta ensino superior; GINI: Índice de desigualdade econômica; RDPC: Renda per capita média; RPOB: Renda domiciliar per capita média dos vulneraveis à pobreza; THEIL: Índice de desigualdade; T_DENS: Densidade por dormitório; I_ESCOLAR: Subíndice de escolaridade da população adulta IDHM Educação. 
Tabela 4 - Informações sobre os aglomerados de risco das variáveis dos determinantes sociais da saúde. Curitiba, Paraná, Brasil (2008-2015)

\begin{tabular}{|c|c|c|c|c|c|}
\hline $\begin{array}{c}\text { Variáveis dos } \\
\text { determinantes } \\
\text { sociais da saúde }\end{array}$ & $\begin{array}{l}N^{o} \text { de } \\
\text { UDH }\end{array}$ & $\begin{array}{l}\text { Valor médio } \\
\text { dentro/ valor } \\
\text { médio fora do } \\
\text { aglomerado }\end{array}$ & $\begin{array}{l}\text { Desvio- } \\
\text { Padrão }\end{array}$ & $\begin{array}{c}\text { Log } \\
\text { likelihood }\end{array}$ & p-valor \\
\hline ESPVIDA & 27 & $74.13 / 77.02$ & 3.20 & 8.382 & 0.046 \\
\hline FB_SUPER & 67 & $35.63 / 62.85$ & 30.54 & 12.567 & 0.001 \\
\hline GINI & 68 & $0.41 / 0.45$ & 0.055 & 10.975 & 0.010 \\
\hline RDPC & 68 & $899.82 / 1752.94$ & 892.67 & 14.281 & 0.024 \\
\hline RPOB & 13 & $155.02 / 180.79$ & 15.73 & 14.326 & 0.026 \\
\hline THEIL & 68 & $0.29 / 0.37$ & 0.096 & 17.621 & 0.045 \\
\hline T_DENS & 24 & $25.07 / 15.39$ & 10.14 & 8.562 & 0.032 \\
\hline I_ESCOLAR & 67 & $0.60 / 0.73$ & 0.14 & 13.121 & 0.002 \\
\hline
\end{tabular}

Fonte: Elaborado pela autora

Legenda: ESPVIDA: esperança de vida; FB_SUPER: Frequência bruta ensino superior; GINI: Índice de desigualdade econômica; RDPC: Renda per capita média; RPOB: Renda domiciliar per capita média dos vulneraveis à pobreza; THEIL: Índice de desigualdade; T_DENS: Densidade por dormitório; I_ESCOLAR: Subíndice de escolaridade da população adulta IDHM Educação.

Dentre as oito variáveis com aglomerados de risco espacial detectados, sete delas apresentaram valores menores dentro do aglomerado quando comparado à região externa, exceto a variável T_DENS, que apresentou maior valor dentro do que fora.

No caso dos Índices de GINI e THEIL, os menores valores (mais próximos de zero), que representam mais homogeneidade, foram considerados neste estudo como uma pior condição, devido ao fato de que a homogeneidade encontrada se associa com valores de renda, estudo e moradias piores e mais igualmente distribuída. Desta forma, o aglomerado de risco foi considerado quando os valores foram mais baixos internamente (área dentro do círculo da varredura) do que quando comparadas as áreas externas àquele.

$\mathrm{Na}$ sequência, com as áreas já identificadas de forma binária, (dentro do aglomerado de risco $=1$ e as outras UDH não contidas nos aglomerados $=0$ ), pode-se testar associação entre áreas de mortalidade por TB e áreas de risco das variáveis dos determinantes sociais, sendo aplicado o teste de independência do Qui-quadrado (para variáveis categóricas). 
Tabela 5 - Teste de independência do Qui-quadrado entre as áreas dos aglomerados das variáveis dos determinantes sociais da saúde e áreas de risco de mortes por TB, Curitiba, Paraná, Brasil (2008-2015).

\begin{tabular}{cc}
\hline $\begin{array}{c}\text { Variáveis } \\
\text { dos DSS }\end{array}$ & p-valor \\
\hline ESPVIDA & 0,00 \\
FB_SUPER & 0,00 \\
GINI & 0,00 \\
RDPC & 0,00 \\
RPOB & $\mathbf{0 , 1 4 8}$ \\
THEIL & 0,00 \\
T_DENS & 0,00 \\
I_ESCOLAR & 0,00 \\
\hline
\end{tabular}

Fonte: Elaborado pela autora

Legenda: ESPVIDA: esperança de vida; FB_SUPER: Frequência bruta ensino superior; GINI: Índice de desigualdade econômica; RDPC: Renda per capita média; RPOB: Renda domiciliar per capita média dos vulneraveis à pobreza; THEIL: Índice de desigualdade; T_DENS: Densidade por dormitório; I_ESCOLAR: Subíndice de escolaridade da população adulta IDHM Educação.

Apenas a variável RPOB não foi estatisticamente significativa ( $\mathrm{p}=0,148)$, sendo removida da próxima etapa. As variáveis dos DSS que apresentaram relação significante com as áreas de risco da mortalidade por TB na análise bivariada (teste de qui-quadrado) foram submetidas à Análise de Componentes Principais Categóricas.

Na Análise de Componentes Principais Categóricas e de acordo com a regra do eingenvalue superior a 1, foi possível resumir a informação relacional entre as variáveis em três dimensões ortogonais dos DSS, que explicam 97,38\% da variância total das variáveis originais. Na tabela 6 reproduzem-se os "pesos" das variáveis em cada componente, a percentagem da variância explicada e a consistência interna. 
Tabela 6 - Dimensões dos determinantes sociais da saúde extraídas por meio da Análise de Componentes Principais Categórica. Curitiba, Paraná, Brasil (2008-2015).

\begin{tabular}{|c|c|c|c|c|}
\hline Dimensão & & 1 & 2 & 3 \\
\hline Variáveis & & \multicolumn{3}{|c|}{ Pesos } \\
\hline ESPVIDA & Esperança de vida & 0,794 & 0,092 & 0,570 \\
\hline FB_SUPER & Frequência bruta ensino superior & 0,856 & $-0,375$ & $-0,240$ \\
\hline GINI & $\begin{array}{l}\text { Índice de desigualdade } \\
\text { econômica }\end{array}$ & 0,526 & 0,816 & $-0,241$ \\
\hline RDPC & Renda per capita média & $\mathbf{0 , 8 7 3}$ & $0-, 378$ & $-0,276$ \\
\hline THEIL & Índice de desigualdade & 0,526 & 0,816 & $-0,241$ \\
\hline T_DENS & Densidade por dormitório & 0,760 & 0,076 & 0,620 \\
\hline I_ESCOLAR & $\begin{array}{l}\text { Subíndice de escolaridade da } \\
\text { população adulta }\end{array}$ & 0,869 & $-0,388$ & $-0,257$ \\
\hline \% Variância & & 57,32 & 25,41 & 14,66 \\
\hline Eigenvalue & & 4,01 & 1,77 & 1,02 \\
\hline Alpha de Cro & ach & 0,876 & 0,511 & 0,03 \\
\hline
\end{tabular}

Fonte: Elaborado pela autora. Método de extração: Análise de componentes principais categóricas; Método de rotação: Varimax.

Pode-se observar que as variáveis mais representativas da Dimensão 1 (D1) foram relativas à renda (RDPC) e educação (I_ESCOLAR), sendo considerada como componente de melhor condição social, enquanto que a Dimensão 2 (D2) apresentou os índices de desigualdade social (GINI e THEIL) como variáveis mais representativas, sendo classificada como componente econômico e renda. A terceira Dimensão (D3) foi menos representativa, tanto em termos de variância como de fiabilidade do Alpha de Cronbach, e apresentou a variável densidade por dormitório como mais importante, conceituada como tal.

As estatísticas decorrentes da associação dos determinantes sociais às áreas de risco estão apresentadas na tabela 7; estas estatísticas foram obtidas por meio da regressão logística e segundo os resultados, apenas a D1 foi estatisticamente significativa e inversamente relacionada. O modelo apresentou discriminação excelente de acordo com o valor da área sob a curva $\mathrm{ROC}=0,937 ;$ IC $95 \%=0,897-0,976$. 
Tabela 7- Associação dos determinantes sociais às áreas de risco de mortes por TB, Curitiba, Paraná, Brasil (2008-2015).

\begin{tabular}{ccccccc}
\hline & Coeficiente & $\begin{array}{c}\text { Odds } \\
\text { Ratio }\end{array}$ & (IC 95\%) & $\mathrm{p}$ & $\begin{array}{c}\text { teste de Hosmer } \\
\text { and Lemeshow }\end{array}$ & $\begin{array}{c}\text { Nagelkerke } \\
\mathrm{R}^{2}\end{array}$ \\
\hline C1 & $-2,3$ & 0,093 & $0,34-0,25$ & $\mathbf{0 , 0 0}$ & 0,603 & 0,536 \\
C2 & $-0,47$ & 0,62 & $0,36-1,04$ & 0,07 & & \\
C3 & $-0,31$ & 0,73 & $0,43-1,22$ & 0,23 & & \\
\hline
\end{tabular}

Fonte: Elaborado pela autora

Ao considerar apenas as variáveis mais representativas de cada uma das três Dimensões (RDPC, GINI e T_DENS) e sobrepor seus aglomerados de risco espacial, pode-se observar um mapa de sobreposição destas áreas (Figura 11) que, ao serem somadas, geraram um novo Score. É possível observar que a sobreposição dos aglomerados de risco espacial das três variáveis (RDPC, GINI e T_DENS) mais representativas das Dimensões justapõe-se na mesma região (ao sul) do município, acarretando em um ajuntamento, que somadas suas áreas de risco, resultam num Score igual a dois (minimamente) ou três (no máximo). 
Figura 11 - Sobreposição dos aglomerados de risco espacial das variáveis dos Determinantes sociais da saúde mais representativas e da mortalidade por TB. Curitiba, Paraná, Brasil (20082015).

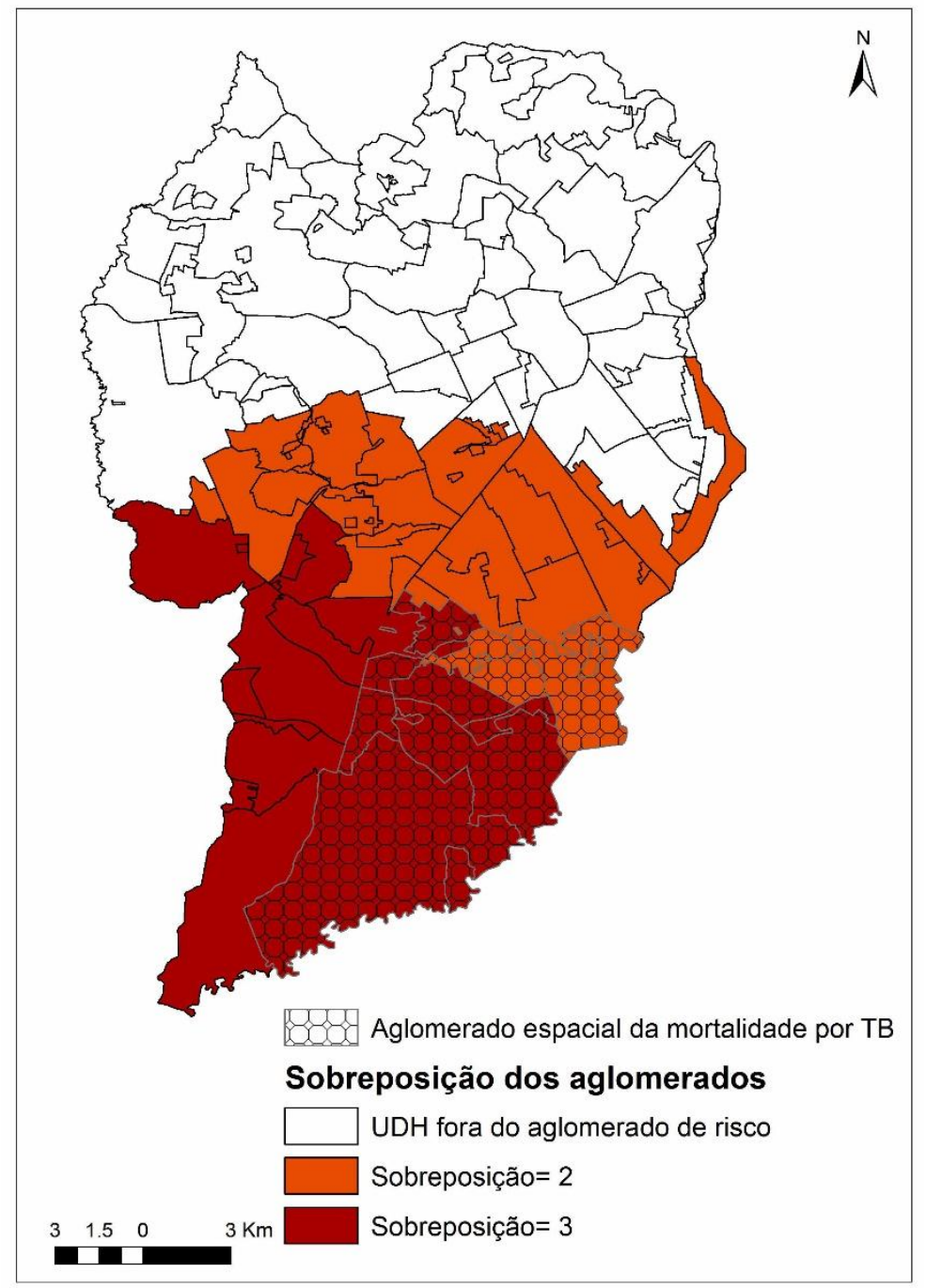

Fonte: Elaborado pela autora

O score obtido com a sobreposição foi submetido à regressão logística, com as áreas de risco espacial das mortes por TB, como variável dependente; os resultados destas estatísticas estão apresentados na Tabela 8. Pode-se observar que há aumento das chances $(\mathrm{OR}=5,98)$ de mortalidade por TB quando relacionadas com as áreas de risco dos DSS. 
Tabela 8 - Regressão logística Score da sobreposição dos aglomerados de risco das variáveis dos Determinantes Sociais da Saúde e as áreas de risco de mortes por TB, Curitiba, Paraná, Brasil (2008-2015)

\begin{tabular}{ccccccccc}
\hline & & & & Curva & (IC 95\%) & teste de & Nagelkerke \\
& Coeficiente & $\begin{array}{c}\text { Odds } \\
\text { Ratio }\end{array}$ & (IC 95\%) & $\mathrm{p}$ & ROC & Rosmer & $\mathrm{R}^{2}$ \\
and & & \\
\hline Score & 1,7 & 5,98 & $\begin{array}{c}2,41- \\
14,49\end{array}$ & 0,00 & 0,865 & $0,796-0,934$ & 0,454 & 0,409 \\
\hline
\end{tabular}

Fonte: Elaborado pela autora

$\mathrm{Na}$ segunda fase, foram identificados 131 casos de óbitos por TB e 74 casos de óbitos com a causa básica TB/HIV, totalizando 205 casos; no relacionamento probabilístico (linkage) entre os bancos SIM e SINAN, 179 (87,3\%) casos entraram para as análises; todavia, 30 casos não possuíam datas adequadas para realização da análise de sobrevida sendo, portanto, excluídos das análises. Na figura 12 são trazidos os casos arrolados para o estudo e exclusões.

Figura 12 - Fluxograma da inclusão dos casos de óbitos por TB e TB/HIV e as análises adotadas. Curitiba, Paraná, Brasil (2008-2015).

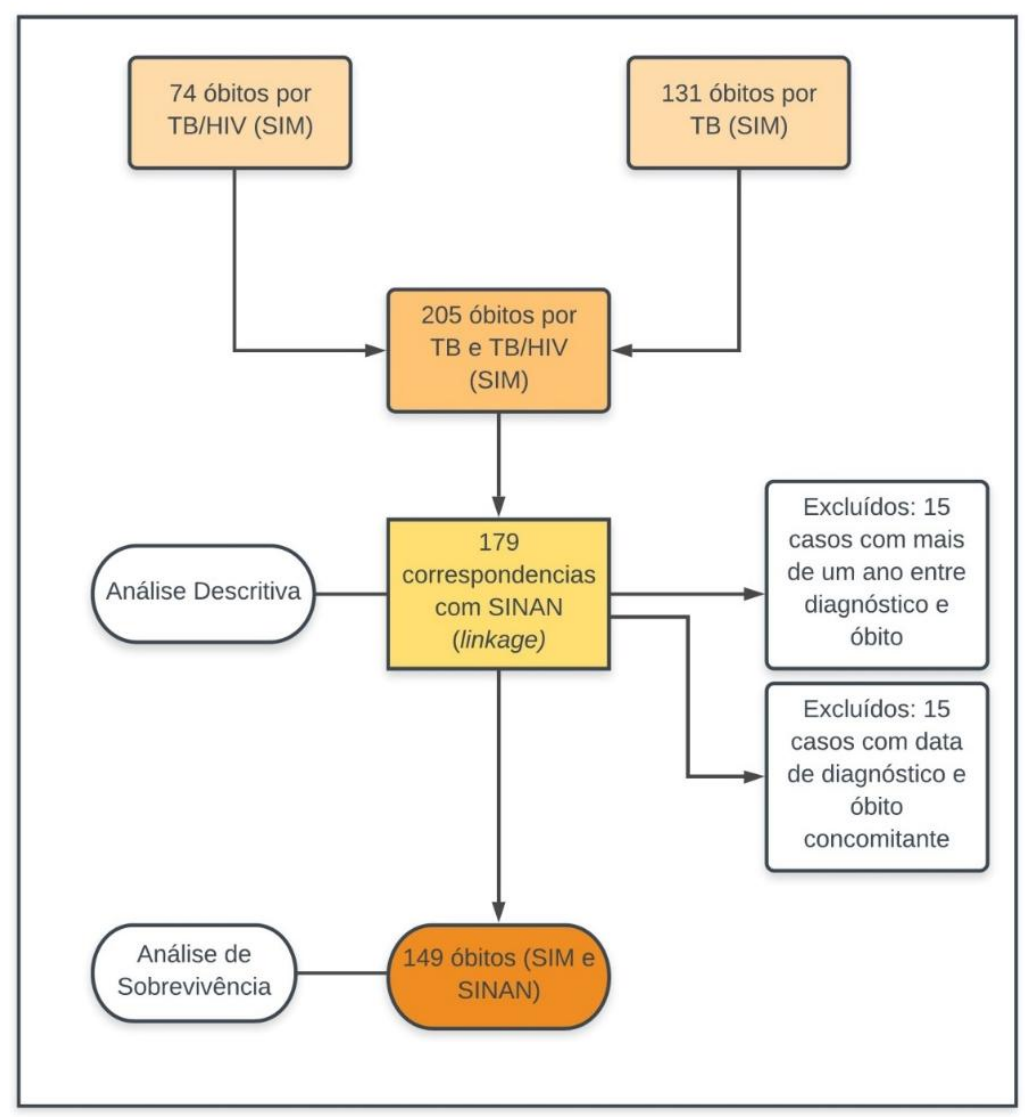


Fonte: Elaborado pela autora

Dentre os 179 óbitos analisados, 105 (58,6\%) tinham diagnóstico de TB (CID 15.019) e $74(41,4 \%)$ a coinfecção TB/HIV (CID 20.0). Os resultados descritivos estão apresentados na tabela 9, em que pode-se observar que a maioria dos casos ocorreu em pessoas do sexo masculino $138(77,1 \%)$, da raça/cor branca predominante $120(67 \%)$ e a média de idade foi de 47 anos (mínimo: 20, máximo: 94, mediana: 44, DP: 14).

A forma clínica mais frequente foi a TB pulmonar $\mathrm{n}=132(73,7 \%), 139(77,7 \%)$ eram de casos novos e 144 (80,4\%) com confirmação diagnosticada por radiografia.

Tabela 9 - Distribuição das características clínica e operacionais dos casos de óbitos. Curitiba, Paraná, Brasil (2008-2015).

\begin{tabular}{|c|c|c|c|}
\hline Variáveis (n=179) & Categorias & $\mathbf{n}$ & $(\%)$ \\
\hline \multirow{2}{*}{ Coinfecção } & Sim TB/HIV & 74 & 41,3 \\
\hline & Não (TB) & 105 & 58,7 \\
\hline \multirow{2}{*}{ Sexo } & Feminino & 41 & 22,9 \\
\hline & Masculino & 138 & 77,1 \\
\hline \multirow{3}{*}{ Raça/Cor } & Branco/amarelo & 120 & 67,0 \\
\hline & Afrodescendente & 45 & 25,1 \\
\hline & Ignorado & 14 & 7,9 \\
\hline \multirow{3}{*}{ Escolaridade } & 0-7 anos de estudo & 104 & 58,1 \\
\hline & 8 anos e mais de estudo & 50 & 27,9 \\
\hline & Ignorado & 25 & 14,0 \\
\hline \multirow{3}{*}{ Estado civil } & Casado/ união estável & 50 & 27,9 \\
\hline & Solteiro/ viúvo / separado & 113 & 63,1 \\
\hline & Ignorado & 16 & 9,0 \\
\hline \multirow{3}{*}{ Tipo de entrada } & Caso novo & 139 & 77,7 \\
\hline & Reingresso/ retratamento & 29 & 16,2 \\
\hline & Ignorado & 11 & 6,1 \\
\hline \multirow{3}{*}{ Institucionalizado } & Não & 141 & 78,8 \\
\hline & Sim & 17 & 9,5 \\
\hline & Ignorado & 21 & 11,7 \\
\hline \multirow{2}{*}{ Raio-X confirmação diagnostica } & Normal & 35 & 19,6 \\
\hline & Sim/suspeito & 144 & 80,4 \\
\hline \multirow{2}{*}{ Forma Clínica } & Pulmonar & 132 & 73,7 \\
\hline & Extrapulmonar & 47 & 26,3 \\
\hline \multirow{3}{*}{ Uso de Álcool } & Não & 108 & 60,3 \\
\hline & Sim & 63 & 35,2 \\
\hline & Ignorado & 8 & 5,0 \\
\hline \multirow{3}{*}{ Agravo DM } & Não & 167 & 93,3 \\
\hline & Sim & 3 & 1,7 \\
\hline & Ignorado & 9 & 5,0 \\
\hline \multirow{3}{*}{ Baciloscopia } & Negativa & 46 & 25,7 \\
\hline & Positiva & 96 & 53,6 \\
\hline & Ignorado & 37 & 20,7 \\
\hline \multirow{3}{*}{ Cultura de escarro } & Negativa & 23 & 12,8 \\
\hline & Positiva & 25 & 14,0 \\
\hline & Ignorado & 131 & 73,2 \\
\hline \multirow{3}{*}{ Rifampicina } & Não & 14 & 7,8 \\
\hline & Sim & 149 & 83,2 \\
\hline & Ignorado & 16 & 8,9 \\
\hline
\end{tabular}


- continua -

- conclusão -

\begin{tabular}{|c|c|c|c|}
\hline Variáveis (n=179) & Categorias & $\mathbf{n}$ & $(\%)$ \\
\hline \multirow{3}{*}{ Isoniazida } & Não & 14 & 7,8 \\
\hline & Sim & 149 & 83,2 \\
\hline & Ignorado & 16 & 8,9 \\
\hline \multirow{3}{*}{ Pirazinamida } & Não & 14 & 7,8 \\
\hline & Sim & 149 & 83,2 \\
\hline & Ignorado & 16 & 8,9 \\
\hline \multirow{3}{*}{ Etambutol } & Não & 51 & 28,4 \\
\hline & Sim & 112 & 62,6 \\
\hline & Ignorado & 16 & 9,0 \\
\hline \multirow{3}{*}{ Estreptomicina } & Não & 159 & 88,8 \\
\hline & Sim & 4 & 2,2 \\
\hline & Ignorado & 16 & 9,0 \\
\hline \multirow{3}{*}{ Etionamida } & Não & 161 & 89,9 \\
\hline & Sim & 1 & 0,6 \\
\hline & Ignorado & 17 & 9,5 \\
\hline \multirow{3}{*}{ Outras drogas } & Não & 148 & 82,7 \\
\hline & Sim & 9 & 5,0 \\
\hline & Ignorado & 22 & 12,3 \\
\hline \multirow{3}{*}{ Tratamento Supervisionado } & Não & 28 & 15,6 \\
\hline & Sim & 133 & 74,3 \\
\hline & Ignorado & 18 & 10,1 \\
\hline
\end{tabular}

Fonte: Elaborado pela autora

Os resultados decorrentes da análise de sobrevida são apresentados na tabela 8; a mediana dos dias sobrevividos do diagnóstico até o óbito entre os indivíduos que morreram por causa básica de TB e TB/HIV foi de 22 dias, sendo que $88(59,1 \%)$ dos pacientes morreram até 30 dias após o diagnóstico e 107 (72,5\%) após 60 dias (mínimo: 1, máximo: 349, D.P: 68,8 e média: 50 dias).

Tabela 10 - Análise de sobrevida: Kaplan-Meier e Cox bivariado entre pacientes que morreram por TB e TB/HIV e os determinantes individuais, Curitiba, Paraná, Brasil (20082015)

\begin{tabular}{|c|c|c|c|c|c|c|c|c|c|}
\hline \multirow[b]{2}{*}{ Variáveis } & \multirow[b]{2}{*}{ Categorias } & \multicolumn{5}{|c|}{ Kaplan-Meier } & \multicolumn{3}{|c|}{ Bivariada } \\
\hline & & $\mathbf{n}$ & Media & DP & IC95\% & $\underset{* *}{\text { p-valor }}$ & HR & IC95\% & p-valor \\
\hline \multirow[b]{2}{*}{ Causa básica } & $\mathrm{TB}^{*}$ & 86 & 19 & 4,6 & $9,9-28,1$ & & & & \\
\hline & TB/HIV & 63 & 28 & 10,7 & $6,8-49,1$ & 0,11 & 0,1 & $0,4-1,1$ & 0,12 \\
\hline \multirow[b]{2}{*}{ Sexo } & Feminino* & 33 & 16 & 6,6 & $2,8-29,1$ & & & & \\
\hline & Masculino & 116 & 23 & 4,1 & $15,1-30,9$ & 0,34 & & & \\
\hline Cor & Branco ou & 98 & 20 & 4,5 & $11,2-28,8$ & 0,28 & & & \\
\hline
\end{tabular}


amarelo

$\begin{array}{lllll}\text { Afrodescen- } & 41 & 33 & 8,9 & 15,4-50,5\end{array}$

dente

- continua -

- conclusão -

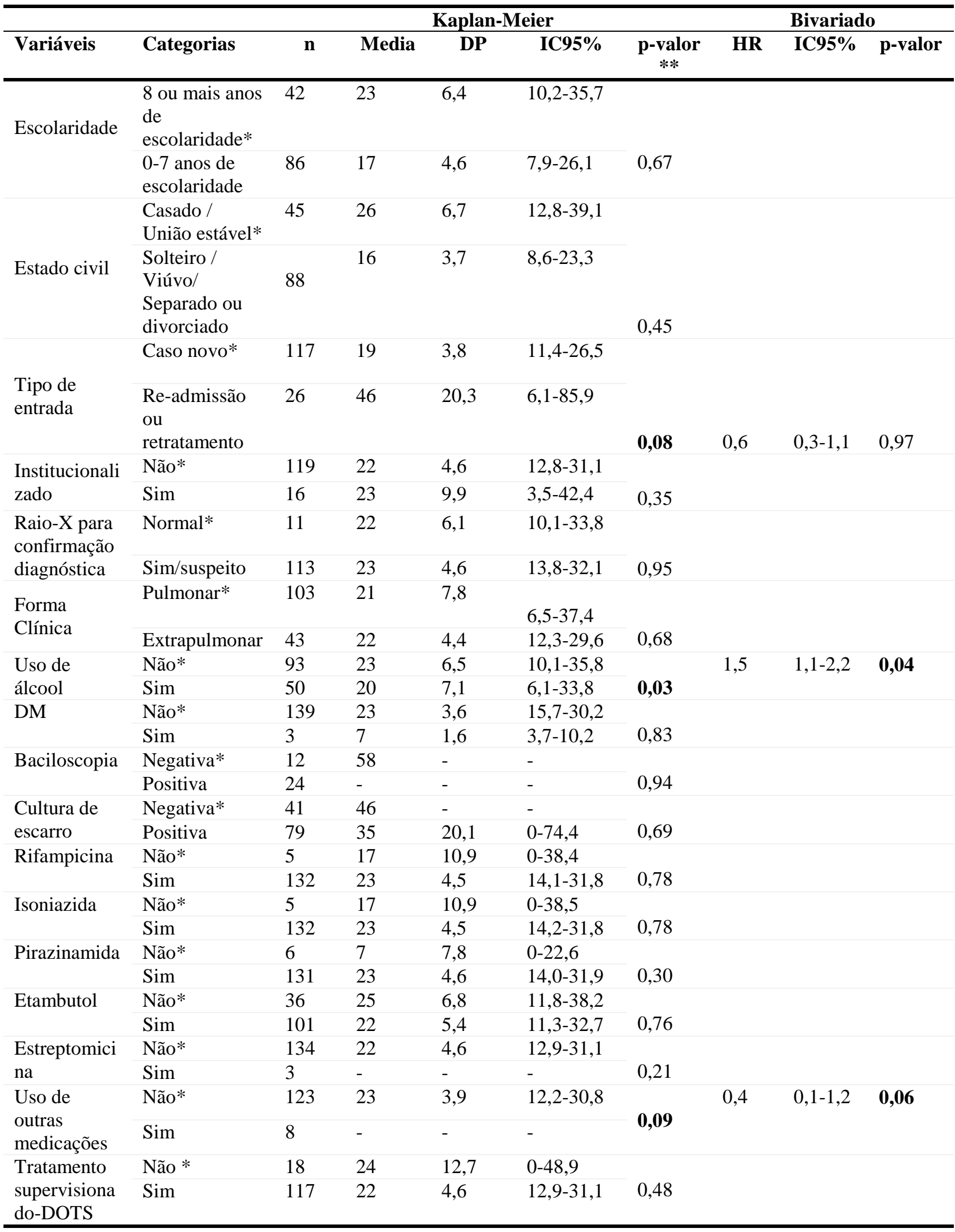

Fonte: Elaborado pela autora 
Tabela 11 - Regressão de Cox multivariada dos determinantes associados às mortes por tuberculose em Curitiba, Paraná, Brasil (2008-2015)

\begin{tabular}{llccc}
\hline Variável & Categorias & HR & IC95\% & p-valor \\
\hline Uso Álcool & Sim & 2,06 & $1,2-3,1$ & $\mathbf{0 , 0 0 2}$ \\
Tipo de entrada & $\begin{array}{l}\text { Readmissão ou } \\
\text { retratamento }\end{array}$ & 0,55 & $0,31-1,03$ & 0,051 \\
$\begin{array}{l}\text { Uso de outras } \\
\text { medicações }\end{array}$ & sim & 0,44 & $0,13-1,4$ & 0,165 \\
\hline
\end{tabular}

Fonte: Elaborado pela autora

Na tabela 8 pode-se observar que o tempo de sobrevivência do grupo na variável coinfecção TB/HIV foi maior do que do grupo com apenas TB, porém sem significância no teste de log-rank, assim como na análise bivariada não houve significância ( $>0,1)$. As variáveis: "Tipo de entrada", "uso de álcool”, e "uso de outros medicamentos" apresentaram p <1,0 e foram inseridas na regressão de Cox. Apenas a variável "uso de álcool" permaneceu no modelo (tabela 9). Na figura 13 é possível observar a curva de sobrevivência de KaplanMeier para a variável uso de álcool.

Figura 13 - As Curvas obtidas pela análise de Kaplan-Meier para sobrevida em relação ao uso de álcool em pacientes que morreram por TB e de TB-HIV. Curitiba, Paraná, Brasil (20082015). 


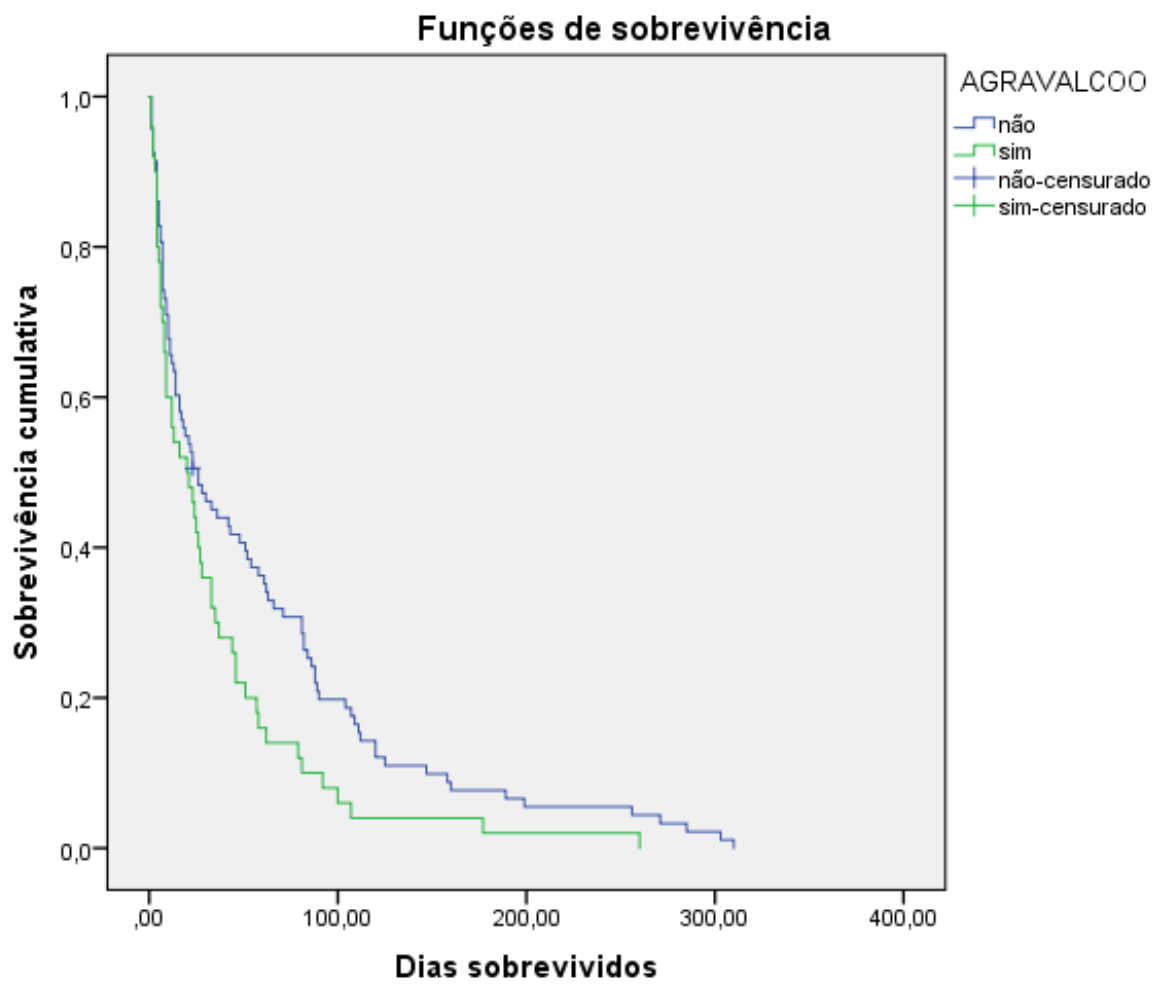


Propôs-se com a tese investigar os DSS associados as áreas de risco para as mortes por TB (fase 1), a ocorrência de mortes precoces em pacientes com TB e coinfecção TB/HIV e fatores individuais relacionados (fase 2). Em relação aos resultados decorrentes da primeira fase, constatou-se a existência de um aglomerado de risco para mortes por TB e dependência espacial, e que os determinantes sociais estavam associados às áreas de risco de mortes por TB; pode-se verificar ocorrência de mortes precoces tanto entre pacientes com TB, como também TB-HIV, verificando que o tempo de sobrevivência do grupo com TB/HIV foi maior que do grupo com apenas TB, porém não houve significância do teste de log-rank; o uso de álcool esteve associado às mortes precoces.

Ao se analisar diferentes medidas da mortalidade por TB (TM, TBM e RR) observou-se forte correlação $(>0,7)$ entre a TM e RR e média correlação entre a TM e TBM; ao considerar que a taxa Bayesiana faz um alisamento em direção a média global, faz sentido que esta medida apresente correlação mais fraca com a taxa bruta, enquanto que o RR proveniente da varredura espacial está mais concatenado aos valores brutos. $\mathrm{Na}$ análise bivariada por meio do I Moran as variáveis referentes a pobreza e saneamento inadequado estiveram positivamente associadas as duas medidas de mortalidade (TM e RR), ou seja, quanto maior estes valores, menor a taxa de mortalidade por TB. Enquanto que outras sete variáveis referentes a maior esperança de vida, mais frequência no ensino superior, maior índice de desigualdade GINI, THEIL, e mais escolaridade (ensino médio), estiveram inversamente correlacionadas com a TBM.

Esta comparação faz perceber que a varredura espacial ao atribuir RR as UDH, é fidedigna a taxa bruta da mortalidade, ao identificar o aglomerado de risco espacial e detectar a região crítica da mortalidade por $\mathrm{TB}$, justificando o uso como categoria de área de risco ou sem risco da mortalidade por TB para análise da relação entre os DSS.

De acordo com as Dimensões extraídas por meio da ACP percebe-se a importância da renda e educação (Dimensão 1) na relação com áreas de mortalidade para TB, sendo que estes fatores reduzem as chances (OR:0,093; IC: 0,34-0,25) da mortalidade por TB; da mesma forma a sobreposição dos aglomerados de risco das variáveis mais representativas mostraram que as regiões com piores renda, índice de desigualdade econômica e maior densidade por dormitório aumentam as chances (OR:5,98; IC: 2,41-14,49) da mortalidade por TB. 
A TB tem sido associada a piores condições sociais há muito tempo, sendo demonstrada na literatura (WINGFIELD et al., 2016; HARLING; CASTRO, 2014; YAMAMURA et al., 2017; LO“NNROTH et al., 2009, ZURCHER et al., 2016). Melhores condições sociais, de moradia, trabalho, alimentação e saúde estão intimamente ligadas com rendas mais elevadas ou maior poder aquisitivo; por sua vez, rendas mais altas estão relacionadas com maiores níveis de educação (WINGFIELD et al., 2016; PELISSARI; DIAZQUIJANO, 2017; LO“NNROTH et al., 2009).

Baixos níveis de educação têm sido frequentemente relacionados com a TB, um estudo (CECCON et al., 2017) concluiu que a mortalidade por TB nas capitais brasileiras esteve mais associada a maior desigualdade de renda, maior taxa de migração, maior proporção de pobres de cor da pele ou raça negra e maiores coeficientes de coinfecção HIV/tuberculose.

Mesmo com a existência de muitos estudos que associaram as condições sociais à TB (PELISSARI; DIAZ-QUIJANO, 2017; CECCON et al., 2017; ZURCHER et al., 2016) poucos estudos se propuseram a construir construtos dos Determinantes Sociais para verificar a relação com as mortes por TB e ainda criar um mapa customizado para o evento (YAMAMURA et al., 2017; BERRA et al., 2017).

Alguns estudos (COUCEIRO; SANTANA; NUNES, 2011) construíram mapa de risco da incidência da TB e puderam confirmar relação com fatores de risco, como HIV/AIDS, habitações superlotadas, domicílios com condições precárias, desemprego, população carcerária e populações imigrantes. Outro estudo (YAMAMURA et al., 2017) construiu indicadores relacionados à mortalidade por TB e constatou que a equidade em termos de renda, escolaridade e ocupação urbana está inversamente associada à mortalidade por TB, ou seja, a equidade, quanto mais presente, reduz a mortalidade por TB.

Foi identificado um aglomerado de risco com renda mais baixa (IPCP) na Região Central do município, ao mesmo tempo apresentando um Índice de GINI mais elevado (mais heterogêneo em termos de distribuição de renda). Este achado pode ser justificado por um fenômeno que tem crescido no Brasil e no mundo, nomeadamente a população em situação de rua (ALBUQUERQUE, 2017; KATZ, 2017). Na cidade de São Paulo foram identificados hotspots de pessoas vivendo nas ruas centrais e em áreas com grande circulação de pessoas, vasto comércio e disponibilidade de serviços sócio assistenciais (ALBUQUERQUE, 2017).

Acresce-se que, nesta pesquisa, alguns casos de óbitos por TB foram incluídos nas análises tendo como endereço de residência um Abrigo Social de Pernoite no cenário de estudo. Pessoas sem moradia ou moradores de rua fazem parte de um grupo de maior 
vulnerabilidade em saúde, que geralmente estão associados com outros problemas sociais e de saúde, como consumo de álcool e drogas, violência e outras comorbidades, vivendo por vezes em habitações improvisadas e em condições insalubres (KATZ, 2017); são, portanto, mais propensos a adoecer por TB e considerados prioridade para o controle da doença (HEUVELINGS et al., 2017).

Há ainda uma outra justificativa que propõe justificar a grande heterogeneidade na distribuição de renda encontrada na região central: a presença de moradias de estudantes de administração própria, que visam atender a alunos da Universidade Federal do Paraná e se localizam nesta região; estes alunos são, por vezes, oriundos de outras cidades do interior e não possuem qualificações profissionais, sendo custeados pelas famílias ou possuindo trabalhos sem exigência de qualificação para obtenção de renda-extra (UFPR, 2018)

Muitos países em desenvolvimento apresentam situação semelhante em termos de distribuição de renda, com heterogeneidade econômica demonstrada pelos índices GINI e THEIL (ATKINSON et al., 2005). Cabe mencionar que o Índice de GINI varia de 0 a 1 , sendo que 1 representa completa desigualdade, em que uma única pessoa concentraria toda a renda disponível e o inverso, mais próximo de zero, representa a distribuição igualitária de toda renda disponível em um determinado local. Desta forma, seria esperado que maior homogeneidade na distribuição de renda estaria associada a melhores condições de vida, enquanto que é suposto que heterogeneidades representem desigualdades e, portanto, uma combinação de situações pobres e ricas na mesma área. Neste estudo, na região central do município foram identificados altos valores de GINI (mais próximo de um, portanto mais desigual) e elevadas rendas per capita (RDPC), e ao mesmo tempo um aglomerado com menores valores de renda entre os mais pobres (RPOB).

Em contraposição a este achado na região central, na região sul do município, onde foi encontrado o aglomerado de risco para óbitos por TB, houve um Índice de GINI homogêneo (valores mais baixos e próximos de zero) o que indica distribuição de renda mais igualitária, porém, com valores mais baixos. O Índice de THEIL é mensurado de maneira diferente do GINI, em que $\mathrm{T}=0$ significa uma distribuição perfeitamente igualitária e indo ao infinito conforme aumenta a concentração da variabilidade média da renda ao longo do tempo; esta variável neste estudo também apresentou aglomerado de risco na região sul.

Por esta razão, neste estudo, optou-se por adotar que os menores valores de Índices de GINI e THEIL compuseram aglomerado de risco e não de proteção, como seria suposto se igualdade representasse uma distribuição de renda mais igualitária e justa; estas interações 
identificadas representam bem o complexo arranjo urbano e a interação com a TB que é justamente de ordem social e econômica para além da biológica (WINGFIELD et al., 2016).

Um estudo realizado no Brasil (PELISSARI; DIAZ-QUIJANO, 2017) encontrou que as variáveis contextuais Índice de GINI, Taxa de incidência da AIDS, taxa de desemprego e proporção de presidiários apresentam associações com a taxa de incidência de tuberculose; porém, por meio de um modelo de regressão multinível, identificou que as variáveis Índice de GINI e renda tiveram o coeficiente de correlação reduzidos a partir da inserção da variável superlotação domiciliar (mais de duas pessoas por dormitório), que permaneceu no modelo (IRR, 1,26; 95\% IC, 1,22-1,31) e concluiu que a desigualdade de renda e a pobreza expressas pela superlotação domiciliar foram os determinantes da incidência da tuberculose, e acrescenta que políticas de moradias adequadas poderiam ser uma solução para minimizar a incidência da TB.

É correto afirmar que a TB contribui para o agravamento da condição econômica do indivíduo e da sociedade, sendo associada aos denominados "gastos catastróficos", que podem comprometer $20 \%$ do orçamento familiar, além dos custos nacionais incorridos especialmente em países de baixa e média renda (WINGFIELD et al., 2016). Siroka et al. (2016) encontraram maior risco de TB relacionado à pobreza domiciliar (Mongólia, Mianmar, Tanzânia e Vietnã).

Como uma das formas de melhoria desta situação, as ferramentas de proteção social aplicadas por meio de programas sociais podem ser adotadas, tendo em vista que buscam trazer alívio da extrema pobreza, o que afeta os determinantes da TB (WINGLFIELD et al., 2016). Carter et al. (2018), ao avaliar o impacto da proteção social e redução da pobreza sobre a incidência global da TB, encontraram que o fim da pobreza extrema resultará em uma redução na incidência global de tuberculose de 33,4\% (95\% IC=15,5-44,5) até 2035 e que a ampliação da cobertura de proteção social resultaria em uma redução na incidência de $76,1 \%$ $(45,2-89,9)$ até 2035 , e ambas as vias juntas poderão resultar em uma redução na incidência de $84,3 \%(54,7-94,9)$. Em primazia, atender o primeiro objetivo do desenvolvimento sustentável produz um efeito importante na carga da TB.

Atualmente, o Brasil perpassa por um período de grandes transformações políticas e econômicas que invariavelmente resvalam em todos os setores, inclusive nas políticas de saúde e sociais. A Emenda Constitucional (EC95) aprovada impõe uma austeridade econômica e tem por intento a redução ou controle da inflação nos próximos 20 anos. A EC95 eliminou a obrigatoriedade de manter gastos federais mínimos com proteção social e saúde, o que anteriormente era regulamentado pela Constituição Nacional de 1988, e ainda estabeleceu 
limites nas despesas federais anuais; isso afetou diretamente os programas sociais, como a cobertura do Programa Bolsa Família (PBF) e a cobertura da Estratégia de Saúde da Família (ESF) (VIEIRA; BENIDES, 2016).

Um estudo abordando a temática de programas sociais como o PBF correlacionou que a redução desta cobertura afetará um dos indicadores de saúde mais sensíveis, nomeadamente a mortalidade infantil, principalmente no quintil da população mais pobre, enquanto nenhuma diferença ocorrerá no quintil mais rico da população (RASELLA et al., 2018).

A variável "densidade por dormitório" também apresentou aglomerado de risco na região sul e foi inserida no mapa de sobreposição de aglomerados de risco espacial das variáveis mais representativas dos DSS. A superlotação favorece as condições para manutenção da cadeia de transmissão da doença (por via respiratória), além das condições da moradia refletirem a qualidade de vida. De acordo com autores (PELISSARI; DIAZQUIJANO, 2017), a variável superlotação domiciliar foi mais importante do que renda e distribuição da renda quando associada com a incidência da TB. Corroborando com este resultado, Harling e Castro (2014) encontraram que a variável "mais de duas pessoas por dormitório" apresentou um RR de 1,13 (IC95\%; 1,37-1,67) em análise de casos notificados de TB no Brasil.

Zurcher et al. (2017) encontraram que a mortalidade por TB esteve positivamente associada ao número de pessoas por dormitório, além ainda de estar associada com características do domicílio como porcentagem de cômodos sem luz do sol, e inversamente relacionado com número de janelas, e concluiu que a melhoria das condições de vida da população de Bern entre 1856-1950 pode ter contribuído significativamente para o declínio da epidemia antes mesmo da disponibilização dos antituberculostáticos após 1950.

Berra et al. (2017) por meio de análise (LISA) encontraram associação entre taxa de mortalidade por TB e as características das residências no entorno, o que confirmou piores condições de habitação e pobreza reveladas pela associação positiva com o índice de vulnerabilidade social no município do nordeste brasileiro.

Cardoso (2008) afirma que as habitações precárias apresentam quatro características predominantes: irregularidade, precariedade, vulnerabilidade e carência social. Em Curitiba, dados apontam que existem 576.290 domicílios no município, dentre estes 47.831 (8,3\%) apresentam mais de 2 pessoas por dormitório, além de 6.975 domicílios serem constituídos de materiais com madeira reaproveitada, palha, taipa e outros materiais ao invés de alvenaria ou 
madeira aparelhada (mais adequadas para construções de moradia) (IBGE, 2010), o que reflete uma pior condição de habitação e menor poder aquisitivo/renda.

De acordo com uma visão crítica sobre o planejamento de Curitiba, houve uma exclusão das camadas sociais mais pobres, que as levou a ocupar áreas periféricas da cidade e seu entorno (IPARDES, 2018; BIALECKI, 2008). Esta afirmação corrobora com os resultados de piores condições de moradia nas regiões periféricas do domicílio

É importante reconhecer que desenvolver um índice-resumo único que catalogue o estado de saúde de um indivíduo ou população pode ser complexo, pois segundo Spassof (1.999) “ao aceitar que a saúde é um fenômeno multidimensional é possível alcançar um grau de desenvolvimento alto em alguma dimensão e baixo em outra simultaneamente" desvelando a complexidade das relações entre os DSS e resultados de saúde

A presente pesquisa não pretende esgotar os DSS associados ao risco da mortalidade por TB, mas propor etapas simples de identificação de áreas de risco e associação com DSS, há que se considerar que existem outros aspectos que não se conseguiu captar na pesquisa; mesmo sendo as UDH unidades espaciais mais homogêneas quanto às características sociais dos territórios, ela tem limites por não conter outras informações relevantes, como coesão social; estudos qualitativos poderiam ser usados em caráter complementar no sentido de maior abrangência dos indicadores.

Em relação aos resultados decorrentes da segunda, não se observaram diferenças entre os grupos de TB e TB-HIV em termos de sexo, idade, condição clínica, esquema de tratamento, aparecendo o uso de álcool como um fator relacionado. Especificamente em relação às mortes precoces, alguns estudos (WAITT et al., 2011; LEE et al., 2017; HARRIER et al., 2001) investigaram este fenômeno também, apresentando resultados muito similares ao da tese, com uma mediana de 21 dias sobrevividos na Coréia (LEE et al., 2017); outro estudo encontrou que $19 \%$ dos pacientes morreram em até 7 dias e $41 \%$ até o primeiro mês após o início do tratamento da TB (HARRIER et al., 2001). Outro estudo, desenvolvido na África, encontrou uma sobrevida média de 2 meses em 53,5\% dos indivíduos que iniciaram o tratamento da $\mathrm{TB}$, sendo que, entre aqueles com sorologia positiva. a mortalidade foi maior do que os pacientes com teste sorológico desconhecido ou negativo (ONYONGO et al., 2017).

A curta sobrevida encontrada (menos de 1 mês) acena para a gravidade da doença no momento do diagnóstico, acenando sua ocorrência em uma fase muito tardia (SCHMALTZ et al., 2012; WAITT et al., 2011;); estes resultados suscitam reflexões acerca das medidas de controle adotadas, como o uso de anti-retroviral, DOTS e a busca ativa, se estão sendo efetivamente empregadas. 
A dificuldade de acesso aos serviços quando do início dos sintomas (LEE et al., 2017), especialmente em grupos em situação de vulnerabilidade ou ainda não qualificação dos serviços para identificação dos sinais de tosse como um sintoma da TB, pode ser uma das explicações para este resultado; um estudo verificou que apenas $42,2 \%$ das pessoas tiveram o diagnóstico da TB feito no seu primeiro acesso ao serviço de saúde (LOUREIRO, et al., 2014). Tal resultado dispara para reflexões sobre a necessidade de um modelo de atenção que valorize a busca ativa dos pacientes nos territórios e rastreio de TB entre a população em geral e nas consultas periódicas dos pacientes com HIV, além da busca de infecção latente da Tuberculose (ILTB) (BRASIL 2013).

Outros aspectos podem estar relacionados com a progressão e pior prognóstico destes casos de tuberculose, podendo envolver questões mais individuais ao doente, tais como a decisão de buscar atendimento de saúde por parte do mesmo, o que perpassa pela tomada de decisão mediante conhecimentos prévios e capacidade de julgamento sobre seu próprio estado de saúde. Um estudo encontrou que 68\% dos pacientes com TB demorou para procurar atendimento de saúde mesmo reconhecendo sintomas da doença e desconfiando estar doente no Zâmbia (MULENGA et al., 2010). A educação em saúde, enquanto tecnologia do cuidado, se volta a melhorar os conhecimentos e sensibilizar a população quanto ao próprio estado de saúde; um estudo randomizado (BISALLAH et al., 2018) encontrou que o grupo que recebeu orientações quanto a TB apresentou melhores conhecimentos, atitudes e práticas após ação educativa de promoção da saúde relacionada a TB desenvolvida com os pacientes.

O Brasil possui um protocolo para vigilância dos óbitos ocorridos com menção de TB como causa, que tem por objetivo investigar as condições individuais e de acesso aos serviços de saúde dos pacientes, além de analisar e corrigir as informações constantes nos diferentes sistemas de informações utilizados, SIM SINAN e Site TB (BRASIL 2017, protocolo). Esta é uma iniciativa estratégica no que se refere à qualificação dos dados; todavia, conforme evidências do próprio estudo, é importante que se verifique a fase em que esse paciente veio a óbito de forma estratificada, se o caso estava em seguimento pelo serviço e se ocorreu na fase inicial ou tardia do tratamento, pois, a depender da fase da ocorrência, as ações também devem ser moduladas, pois a morte precoce faz pensar se as medidas e protocolos adotados têm impactado na TB.

A diferença de sobrevida entre indivíduos com TB e TB/HIV não apresentou significância estatística, embora a mediana entre o grupo com a coinfecção tenha sido maior, ou seja, estes sobreviveram mais dias do que o grupo com apenas TB; uma questão que pode justificar este resultado é o fato que pessoas vivendo com HIV/Aids recebem 
acompanhamento de saúde contínuo de equipe multiprofissional, com consultas, exames e dispensação dos medicamentos periodicamente, o que leva a um contato intermitente com os profissionais de saúde e aumenta as oportunidades de reconhecimento de sinais e sintomas da TB, o que é inclusive recomendado nos protocolos de manejo destes pacientes: a investigação da TB em toda consulta (BRASIL 2013). Outros estudos encontram que a coinfecção com HIV esteve associada a mortes precoces por TB (CECCON et al., 2017; GESESEW et al., 2016; GAIFER et al., 2016; PECEGO et al., 2016).

A maioria das pessoas que morreu de TB e TB/HIV foi do sexo masculino e com menos anos de estudo, o que corrobora com outros resultados (WHO, 2018; BRASIL, 2017; MILLER et al., 2018). A forma clínica pulmonar foi a mais frequente, embora não tenha apresentado associação com a sobrevida neste estudo, além de ser a forma clínica mais comum é epidemiologicamente mais relevante, pois se trata da forma transmissível da doença. Um estudo encontrou que indivíduos com a forma pulmonar apresentaram maior média de sobrevida do que aquelas com a forma extrapulmonar (MILLER et al., 2018).

As evidencias do efeito do álcool na literatura tem demonstrado os efeitos deletérios associados a mais de 200 doenças (WHO, 2013); uma metánalise (IMTIAZ et al., 2017) encontrou que o uso de álcool foi associado a um risco maior RR: 1,35 (IC 95\%: 1,09-1,68) de desenvolver a TB quando comparado àqueles que não usam álcool, e ainda o risco de desenvolver a doença aumentou à medida que o consumo de etanol (em gramas por dia) aumentava.

Ainda outros fatores podem estar ligados ao uso do álcool como desnutrição, moradias com aglomerados de pessoas e uso de outras substâncias, (SILVA et al., 2018). A baixa imunidade já foi documentada como uma explicação que atribua o risco aumentado para desenvolvimento e mortes por TB (MOLINA et al., 2010). Um estudo encontrou que pacientes que morreram por TB, ou com importante piora clínica, apresentaram baixos níveis do fator de necrose tumoral alfa (TNF- $\alpha)$, uma citocina presente na resposta inflamatória, que indicaria uma baixa resposta imune (WAITT et al., 2011), portanto, propiciando evolução e piora da doença.

Um estudo realizado no Brasil encontrou que as mortes por TB ocorridas estiveram associadas a outras infecções bacterianas em PVHIV, o que pode ser combatido com terapias complementares, para além da TB (ESCADA et al., 2017). No Brasil, houve aumento da resistência primária à isoniazida de 4,4\% para 6,0\% e 583 casos de MDRTB (II Inquérito Nacional de Resistência aos Medicamentos Antituberculose), o que leva à necessidade de utilização de outros medicamentos para tratar a TB (RABAHI et al., 2017). A MDRTB é um 
desafio atual e que necessita do desenvolvimento de outros medicamentos eficazes e seguros para o tratamento da doença.

O uso das drogas de primeira linha, rifampicina $(\mathrm{R})$, izoniazida $(\mathrm{H})$ pirazinamida $(\mathrm{Z})$ e etambutol (E) esteve presente na maioria dos casos, apenas o etambutol apareceu ser utilizado em menor frequência, e pode dever-se ao fato deste medicamento ter sido acrescido a partir de 2009 (Nota Técnica 2009: BRASIL, 2011; RABAHI et al., 2017) ao esquema inicial (dois primeiros meses) de tratamento, o que justifica a menor frequência desta droga neste estudo, quando comparado com a frequência de uso do RHZ.

O presente estudo, por meio de uma abordagem ecológica, encontrou que as piores rendas, desigualdade econômica e superlotação domiciliar relacionaram-se às áreas de risco para mortalidade por TB, ao passo que através de uma abordagem individual foi verificado que o uso de álcool se relacionou com as mortes precoces por TB e TB/HIV. O uso do álcool está intimamente ligado a problemas como desnutrição, moradias com aglomerados de pessoas e uso de outras substâncias, de forma que as condições de vida, moradia e renda se interligam aos hábitos individualmente adotados, como é o uso de álcool (SILVA et al., 2018).

A pesquisa buscou integrar a investigação de abordagem ecológica com a abordagem individual, com vistas a dar abrangência e completude aos achados; este é o primeiro estudo feito de forma sequencial, havendo evidências importantes dos DSS que afligem os territórios e, também, das variáveis relacionadas aos indivíduos; havia uma pressuposição que fosse o HIV que levava às mortes precoces por TB, conforme evidenciava a literatura; todavia, $\mathrm{o}$ alcoolismo é o que esteve associado a este desfecho; segundo o referencial adotado pelo estudo, isso tem relação com os hábitos e comportamentos, mas também é decorrente da pobreza e da desigualdade, que são tidos como determinantes estruturais das iniquidades. Percebe-se, segundo este mesmo referencial, que embora os DSS possam ser compreendidos em duas dimensões (estruturais e intermediários), aqueles mais distais (governança, políticas sociais, mercado de trabalho, educação, cultura, valores sociais, classe, social, gênero, etnia, educação, ocupação, renda) e outros mais proximais (biológicos, comportamentais, fatores psicossociais), estão em constante e intensa interação, sendo difícil separar um do outro; o ponto é que, nas duas fases, os DSS estiveram evidenciados, tanto para áreas de risco de mortes e nas mortes precoces.

É importante frisar que a falácia ecológica é um dos principais vieses de um estudo ecológico, sendo que a complementariedade com um estudo de coorte retrospectiva foi importante para avançar nesta limitação, ao trazer informações analisadas dos óbitos de forma 
individual. Outra limitação do estudo refere-se ao uso de dados secundários que, por vezes, não são totalmente preenchidos, gerando falta de informações ou ainda não representar a totalidade dos óbitos ocorridos no período, devido a possível subnotificação.

\section{Pontos-chave do estudo}

\section{Qual é o ganho em conhecimento obtido com este estudo?}

$\mathrm{O}$ estudo realizado permitiu a seleção de um subconjunto potencialmente independente $\mathrm{e}$ complementar, mas poderoso, de variáveis representantes dos DSS (renda, GINI e densidade por dormitório) OR: 1,7 5,98 IC95\%=2,41-14,49; este mapa, muito simples, permitiu correlacionar as áreas de risco espacial para mortalidade por TB, de forma a corroborar com a importância dos DSS para a mortalidade por TB, além ainda de evidenciar que o uso de álcool foi o determinante individual associado às mortes precoces ocorridas por TB e TB/HIV .

\section{Quais são as implicações para o controle da TB?}

Os resultados revelam a necessidade de melhorias múltiplas nas condições de vida da população, enfoque nas regiões mais vulneráveis (áreas de risco) identificadas e políticas específicas para prevenção do uso de álcool, diante da identificação deste fator associado às mortes precoces. Identificar pacientes potenciais para uma evolução para o óbito pode ser uma forma de melhorar este desfecho. Neste mesmo sentido, programas de proteção social e de garantia de emprego seriam mais uma ferramenta no sentido de melhorar a renda do indivíduo e família. As políticas que visem moradias adequadas também têm papel relevante na melhoria das condições de vida da população, o que colabora para que se evite a ocorrência de óbitos por TB. 
O estudo teve como objetivo investigar aglomerados de risco espacial da mortalidade por TB e associar com os DSS, verificando-se que as variáveis renda média per capita, Índice de GINI e densidade por dormitório estiveram associadas a estas áreas, por meio da utilização de uma Dimensão construída pela ACP, além de um mapa de sobreposição das áreas de risco das variáveis mais representativas identificadas, o que corrobora com a importância dos DSS.

Pode-se observar, também, que houve mortes precoces no município, ou seja, ocorridas nos primeiros dois meses do tratamento, dentre os fatores associados a este desfecho, ficou evidenciado o álcool; embora esta tenha sido uma variável individual, ela tem grande relação com o contexto e cenário de privação onde estes pacientes vivem; havia uma hipótese, de que os pacientes com HIV morreriam mais precocemente, todavia isso não se confirmou com o estudo; pelo contrário, eles vivem mais que o paciente com TB somente. Este é o primeiro estudo realizado de forma sequencial na região Sul do Brasil; esta região, embora seja classificada com uma das mais desenvolvidas do país, convive simultaneamente com quadro de grande desigualdade, o que culmina também nas oscilações e variações do risco de mortalidade. O monitoramento das mortes por TB é um dos compromissos firmados pelas autoridades sanitárias no Brasil e, portanto, o estudo traz importantes contribuições nesta direção. Os resultados do estudo confirmam relação dos determinantes sociais com as mortes por TB; portanto, mudanças sociais impactarão positivamente nos indicadores epidemiológicos; todavia, entende-se que as mudanças sociais não ocorrem de forma imediata, seu investimento é gradual e lento; portanto, se há interesse para eliminação da TB até 2050, investimento na área de habitação, renda, trabalho, proteção social é mais que urgente. As políticas de austeridade e os cortes sociais vão na direção contrária à esta política de eliminação da TB.

Estas mortes devem ser evitadas mediante adoção das ações previstas nos programas de controle da TB, como a intensificação da busca ativa e rastreio de potenciais casos com tendência à piora e morte precoce. Identificar pacientes potenciais para uma evolução para o óbito pode ser uma forma de evitar este desfecho. A TB é uma doença antiga e ainda presente, que já foi sinônimo de morte, não sendo admissível que continue a sentenciar vidas em nossa atualidade, principalmente se tratando de pacientes já diagnosticados e que poderiam ter recebido a intervenção necessária e disponível para que o óbito fosse evitado. 


\section{Referências}


ACOSTA, L.M.W.; BASSANESI, S.L. O paradoxo de porto alegre: os determinantes sociais e a incidência da tuberculose. Revista brasileira de epidemiologia suppl. v. 2, p.88-100, 2014

AIDSFree. Strengthening High Impact Interventions for an AIDS-free Generation. 2017. Summary Table of HIV/TB Co-infection Treatment Regimens. Arlington, VA: AIDSFree Project, 2017.

ALBUQUERQUE, T.S. Geografia da população em situação de rua: mudanças na distribuição espacial na cidade de São Paulo nos anos 2009 - 2014. SESSÃO TEMÁTICA 8: técnicas e métodos para análise urbana e regional. XVII ENAMPUR, 2017. Disponível em $<\mathrm{http}$ ///anpur.org.br/xviienanpur/principal/publicacoes/XVII.ENANPUR_Anais/ST_Sessoes_ Tematicas/ST\%208/ST\%208.5/ST\%208.5-05.pdf.> acesso em: 15 de nov. 2018.

ALTMAN, D.G. Analysis of Survival times. In: Practical statistics for Medical research; pp. 365-93 London, UK: Chapman and Hall; 1992.

ALVAREZ-HERNÁNDEZ, G. et al. An analysis of spatial and soocio-economic determinants of tuberculosis in Hermosillo, Mexico, 2000- 2006. International Journal of Tuberculosis and Lung Disease, Paris, v. 14, n. 6, p. 708-713, 2010.

ANDRIES, K. et al. A diarylquinoline drug active on the ATP synthase of Mycobacterium tuberculosis. Science, v. 307, n. 5707, p. 223-227, 2005.

ANSELIN, L. Exploring Spatial Data with GeoDa TM: A Workbook. Centre for Spatially Integrated Social Science. 2005.

ANSELIN, L; SYABRI, I; KHO, Y. GeoDa: An Introduction to Spatial Data Analysis. Geographical Analysis, v.38, p. 5-22, 2006.

ARCÊNCIO, R.A. Análise espacial da relação entre indicadores sociais e mortalidade por tuberculose em dois municípios prioritários para o controle da doença. 104p. Tese (livre Docente) - Escola de Enfermagem de Ribeirão Preto, Universidade de São Paulo, Ribeirão Preto, 2015.

ARCOVERDE, M.A.M. et al. How do social-economic differences in urban areas affect tuberculosis mortality in a city in the tri-border region of Brazil, Paraguay and Argentina. BMC public health, v. 18, n. 1, p. 795, 2018.

ATKINSON, T. et al. Social indicators: EU and the social inclusion. Oxford: OUP, 2005. Banco Mundial. Indicadores. Disponível em: $<$ https://datos.bancomundial.org/indicador/SI.POV.GINI?locations=BR\&view=map $>$, Acesso em 20 de nov. 2018.

BARBOSA, I.R. et al. Análise da distribuição espacial da tuberculose na região Nordeste do Brasil, 2005-2010. Epidemiologia e Serviços de Saúde, Brasília, v.22, n.4, 2013.

BARBOSA, I.R; Costa, I.C.C. Estudo epidemiológico da coinfecção tuberculose-HIV no nordeste do Brasil. Revista de Patologia Tropical, v. 43, n.1, p. 27-38, 2014. 
BARROS, M.B.A. Social inequality in health: revisiting moments and trends in 50 years of publication of RSP. Revista de Saúde Publica. v.51, p.0:17, 2017.

BEM, J. et al. Tuberculosis comorbidity with communicable and non-communicable diseases: integrating health services and control efforts. Lancet Infectious Disease, v.13, p. 436-48, 2013.

BERRA, T.Z. et al. Spatial risk of tuberculosis mortality and social vulnerability in Northeast Brazil. Revista da Sociedade Brasileira de Medicina Tropical, v. 50, n. 5, p. 693-697, 2017.

BERTOLLI FILHO, C. História social da tuberculose e do tuberculoso: 1900-1950 [online]. Rio de Janeiro: Editora FIOCRUZ, 2001. 248p. Disponível em: http://static.scielo.org/scielobooks/4/pdf/bertolli-9788575412886.pdf. Acesso em: 19 ago2015.

BERTOLOZZI, M.R. et al. O controle da tuberculose: um desafio para a saúde pública. Revista Medica. v.93, n.2, p.83-9, 2014.

BEST, N.R.S.; THOMSON, A. A comparison of Bayesian spatial models for disease mapping. Statistical Methods in Medical Research. v. 14, n. 1, p. 35-39, 2005.

BIALECKI, K.R. Planos urbanos e o espaço da habitação: a questão habitacional em Curitiba (1940-2007). 179f. Dissertação (Mestrado) - Programa de Pós-Graduação em Gestão Urbana, Pontifícia Universidade Católica do Paraná-PUC, Curitiba, 2008.

BIGNA, J.J.R. et al. Early Mortality during Initial Treatment of Tuberculosis in Patients CoInfected with HIV at the Yaoundé Central Hospital, Cameroon: An 8-Year Retrospective Cohort Study (2006-2013). PLoS ONE, v. 10, n. 7, p. e0132394, 2015.

BISALLAH, C.I. et al. Effectiveness of health education intervention in improving knowledge, attitude, and practices regarding Tuberculosis among HIV patients in General Hospital Minna, Nigeria - A randomized control trial. PLoS ONE. v. 13, n.2, p. e0192276, 2018.

BRASIL. Boletim Epidemiológico - Departamento de Vigilância, Prevenção e Controle das Infecções Sexualmente Transmissíveis, do HIV/Aids e das Hepatites Virais. Ministério da Saúde - Secretaria de Vigilância em Saúde. v.49, n. 53, 2018 a.

BRASIL. Boletim Epidemiológico - Implantação do Plano Nacional pelo Fim da Tuberculose como Problema de Saúde Pública no Brasil: primeiros passos rumo ao alcance das metas. Ministério da Saúde. Secretaria de Vigilância em Saúde, v. 49, n. 11, mar. 2018b.

BRASIL. Boletim Epidemiológico - Indicadores prioritários para o monitoramento do Plano Nacional pelo Fim da Tuberculose como Problema de Saúde Pública no Brasil. Ministério da Saúde. Secretaria de Vigilância em Saúde. v. 48, n. 8, 2017a.

BRASIL. Ministério da Saúde. Secretaria de Vigilância em Saúde. Departamento de Vigilância das Doenças Transmissíveis. Plano nacional pelo fim da tuberculose. Ministério da Saúde, Secretaria de Vigilância em Saúde, Departamento de Vigilância das Doenças Transmissíveis. - Brasília: Ministério da Saúde, 2017b. 
BRASIL. Ministério da Saúde. Secretaria de Vigilância em Saúde. Departamento de Vigilância das Doenças Transmissíveis. Protocolo de vigilância do óbito com menção de tuberculose nas causas de morte / Ministério da Saúde, Secretaria de Vigilância em Saúde, Departamento de Vigilância das Doenças Transmissíveis. - Brasília: Ministério da Saúde, 2017c.

BRASIL. Boletim Epidemiológico - Perspectivas brasileiras para o fim da tuberculose como problema de saúde pública. Brasília: Ministério da Saúde, v. 47, n. 13, 2016. Disponível em: <http://portalsaude.saude.gov.br/images/pdf/2016/marco/24/2016-009-Tuberculose-001.pdf>. Acesso em: julho de 2017.

BRASIL. Ministério da Saúde. Recomendações para o manejo da coinfecção TB-HIV em serviços de atenção especializada a pessoas vivendo com HIV/AIDS / Ministério da Saúde. Secretaria-Executiva - Brasília: Ministério da Saúde, 2013.

BRASIL. Ministério da Saúde. Secretaria de Vigilância em Saúde. Departamento de Vigilância Epidemiológica. Tratamento diretamente observado (TDO) da tuberculose na atenção básica. Brasília; 2011a. Disponível em: http://bvsms.saude. gov.br/bvs/publicacoes/tratamento_diretamente_observado_ tuberculose.pdf. Acesso em: Outubro, 2018.

BRASIL. Ministério da Saúde. Secretaria de Vigilância em Saúde. Departamento de Vigilância Epidemiológica. Manual de recomendações para o controle da tuberculose no Brasil. Brasília: Ministério da Saúde; 2011b.

BRASIL. Nota técnica sobre as mudanças no tratamento da tuberculose no Brasil para adultos e adolescentes. Ministério da Saúde. Brasília, 2009.

BRASIL. Ministério da Saúde. Secretaria de Vigilância em Saúde. Fundação Oswaldo Cruz. Abordagens espaciais na saúde pública / Ministério da Saúde, Fundação Oswaldo Cruz;.SANTOS, S.M; BARCELLOS,C; (org.). Brasília: Ministério da Saúde, 2006.

BUSTAMANTE-TEIXEIRA, M.T.; FAERSTEIN, E.; LATORRE, M.T. Técnicas de Análise de sobrevida. Cadernos de Saúde Pública. v.18, n.3, p.579-594, 2002.

CÂMARA, G. et al. Análise espacial de áreas. In: Druck $\mathrm{S}$, et al. Análise espacial de dados geográficos. Planaltina: EMBRAPA, 2004.

CARDOSO, A. L. Assentamentos precários no Brasil: discutindo conceitos. Cadernos do CEAS, Salvador: CEAS, n.230, p.51-80, 2008.

CARTER, D.J, et al. The impact of social protection and poverty elimination on global tuberculosis incidence: a statistical modelling analysis of Sustainable Development Goal 1. Lancet Glob Health, v. 6, p. e514-22, 2018.

CARVALHO, F.J.; PATINO, C. M. et al. O que é análise de sobrevida e quando devo utilizála? Jornal Brasileiro de Pneumologia. v.42, n.1, p.77-77, 2016. 
CARVALHO, M.S.; SOUZA-SANTOS, R. Análise de dados espaciais em saúde pública: métodos, problemas, perspectivas. Cadernos de Saúde Pública, Rio de Janeiro, v. 21, n. 2, p. 361-378, 2005.

CATRIONA, J.W. et al. Early Deaths During Tuberculosis Treatment Are Associated With Depressed Innate Responses, Bacterial Infection, and Tuberculosis Progression. Journal Infectious Disease. v.204, n.3, p. 358-362, 2011.

CECCON, R.F. et al. Mortalidade por tuberculose nas capitais brasileiras, 2008-2010. Epidemiologia e Serviços de Saúde, v. 26, p. 349-358, 2017.

CECILIO, H.P. M. et al. Perfil das internações e óbitos hospitalares por tuberculose. Acta Paulista de Enfermagem, São Paulo, v.26, n.3, p.250-255, 2013.

COUCEIRO, L.; SANTANA, P.; NUNES, C. Pulmonary tuberculosis and risk factors in Portugal: a spatial analysis. International Journal of Tuberculosis and Lung Disease, v. 15, n. 11, p. 1445-1454, 2011.

COX, D. Regression models and life tables (with discussion).Journal of the Royal Statistical Society - Series B, v.34, p. 187-220, 1972.

COX, D.; OAKES, D. Analysis of Survival Data. London, UK: Chapman \& Hall; 1984.

CSDH. Final report of the Commission on Social Determinants of Health. Closing the gap in a generation: Health equity through action on the social determinants of health. Geneva: World Health Organization, 2008.

DAHLGREN, G.; WHITEHEAD, M. Policies and Strategies to Promote Social Equity in Health. Stockholm, Sweden: Institute for Futures Studies, 1991.

DARONCO, A. et al. Distribuição espacial de casos de tuberculose em Santa Cruz do Sul, município prioritário do Estado do Rio Grande do Sul, Brasil, 2000 a 2010. Epidemiologia em Serviços de Saúde, v. 21, n. 4, 2012.

EFRON, B. Logistic Regression, Survival Analysis, and the Kaplan-Meier Curve. Journal of the American Statistical Association, v. 83, n. 402, p. 414-425, 1988.

ERAZO, C. et al. Tuberculosis and living conditions in Salvador, Brazil: a spatial analysis. Revista Panamericana de Salud Publica, v.36, n.1, p.24-30, 2014.

ESCADA, R.O.S. et al. Mortality in patients with HIV-1 and tuberculosis co-infection in Rio de Janeiro, Brazil - associated factors and causes of death. BMC Infectious Disease. v.17, p.373, 2017.

FERRAUDO, A.S. Técnicas de análise multivariada - uma introdução. Apostila de Treinamento. Universidade Estadual Paulista (UNESP). 76 p, 2012.

FERREIRA, J.C.; PATINO, C.M. O que é análise de sobrevida e quando devo utilizá-la? Jornal brasileiro de pneumologia. v.42, n.1, p.77-77, 2016.

FERREIRA, M.D. et al. Predictors of mortality among intensive care unit patients coinfected with tuberculosis and HIV. Jornal brasileiro de pneumologia, v. 44, n. 2, p. 118-124, 2018. 
FIELD, N. et al. Timing, rates, and causes of death in a large South African tuberculosis programme. BMC Infectious Disease. v.14, p.3858, 2014.

GAIFER, Z.A. Risk factors for tuberculosis mortality in a tertiary care center in Oman, 20062016. International Journal of Mycobacteriology, v. 6, n. 4, p. 356-359, 2016.

GARBOIS, J.A.; SODRE, F.; DALBELLO-ARAUJO, M. Determinantes sociais da saúde: o "social" em questão. Saúde e sociedade. v. 23, n. 4, p. 1173-1182, 2014 .

GEORGE, F. Sobre determinantes da saúde. set 2011. Disponível em <http://bit.ly/2vZqVke >. Acesso em: 22 maio 2018.

GESESEW, H. et al. Predictors of mortality in a cohort of tuberculosis/HIV co-infected patients in Southwest Ethiopia. Infectious Diseases of Poverty, v.5, n.109, 2016.

GETAHUN, B. et al. Mortality and associated risk factors in a cohort of tuberculosis patients treated under DOTS programme in Addis Ababa, Ethiopia. BMC Infectious Disease. v. 11, n.16, p.127 2011 .

GLANTZ, S.A. How to analyse survival data. In: Glantz SA. Primer in Biostatistics. 7th ed. New York: McGraw-Hill Medical; 2011. p. 229-44.

GOEL, M.K.; KHANNA, P.; KISHORE, J. Understanding survival analysis: Kaplan-Meier estimate. International journal of Ayurveda research. v.1, n.4, p. 274-8, 2010.

GRANT, M.J., BOOTH, A. A typology of reviews: an analysis of 14 review types and associated methodologies. Health Information \& Libraries Journal, v. 26, n. 2, p. 91-108, jun. 2009.

HAIR JR, J.F. et al. Análise Multivariada de dados. 6ed. Porto Alegre: Bookman, 2009, $688 \mathrm{p}$.

HARLING, G.; CASTRO, M.C. A spatial analysis of social and economic determinants of tuberculosis in Brazil. Health \& Place. v.25, p. 56-67, 2014.

HARRIER, A.D. et al. High early death rate in tuberculosis patients in Malawi INT J TUBERC LUNG DIS 5(11):1000-1005, 2001.

HEUVELINGS, C.C. et al. Effectiveness of interventions for diagnosis and treatment of tuberculosis in hard-to-reach populations in countries of low and medium tuberculosis incidence: a systematic review. Lancet Infection Disease, v.17, p. e144-158, 2017

HINO, P. et al. Padrões espaciais da tuberculose e sua associação à condição de vida no município de Ribeirão Preto. Ciências e Saúde Coletiva, v.16, n.12, p. 4795-4802, 2011.

HOSMER, D.W.; LEMESHOW, S. Applied logistic regression. 2nd Edition, John Wiley \& Sons, Inc., New York. 2000.

HOULIHAN, C.F. et al. The tuberculosis challenge in a rural South African HIV programme. BMC Infectious Diseases, v.10, n.23, 2010 
HUANG, C.Y.; HSIEH, W.Y. Efficacy of Mycobacterium vaccae immunotherapy for patients with tuberculosis: a systematic review and meta-analysis. Human vaccines \& immunotherapeutics, v. 13, n. 9, p. 1960-1971, 2017.

INSTITUTO BRASILEIRO DE GEOGRAFIA E ESTATÍSTICA (IBGE). Censo Demográfico 2010. Disponível em: 〈http://www.ibge.gov.br/cidadesat/topwindow.htm?1>. Acesso em:15 de fev. 2018.

Instituto Paranaense de Desenvolvimento Economico e Social (IPARDES). Caderno Estatístico: município de Curitiba., 2018. Disponível em <http://www.ipardes.pr.gov.br/anuario_2016/index.html> Acesso 15 jan. de 2018.

KATTAN, J.A. et al. Tuberculosis mortality: death from a curable disease, Connecticut, 2007-2009. International Journal of Tuberculosis and Lung Disease. v.16, n.12, p.1657$62,2012$.

KATZ, M.H. Homelessness-Challenges and Progress. Journal American Medical Association. v.318, n.23, p.293, 2017.

KAZEMPOUR, D. M. et al. Risk Factors Associated with Survival of Pulmonary Tuberculosis. Iran Journal Public Health. v. 47, n.7, p. 980-987, 2018.

KEBEDE, Y. et al. Tuberculosis and HIV are the leading causes of adult death in northwest Ethiopia: evidence from verbal autopsy data of Dabat health and demographic surveillance system, 2007-2013. Popul Health Metr. v.17, n.1, p.15-27, 2017.

KUBRUSLY, L. S. Um procedimento para calcular índices a partir de uma base de dados multivariados. Pesquisa Operacional, v. 21, n. 1, p. 107-117, 2001. Disponível em:< http://www.scielo.br/pdf/pope/v21n1/a07v21n1.pdf>. Acesso em 15 Novembro de 2017

KULLDORFF, M.; NAGARWALLA, N. Spatial disease clusters: detection and inference. Statistic Medicine. v.14, n.8, p.799-810, 1995.

LEE, J. et al. Comparison of Early and Late Tuberculosis Deaths in Korea. Journal Korean Medicine Science. v.32, p.700-703, 2017.

LIENHARDT, C. et al. Translational research for tuberculosis elimination: priorities, challenges, and actions. PLoS medicine, v. 13, n. 3, p. e1001965, 2016.

LINK, B.G.; PHELAN, J. Social conditions as fundamental causes of disease. Journal of Health and Social Behavior, p. 80-94, 1995.

LIU, Y. et al. Delamanid: From discovery to its use for pulmonary multidrug-resistant tuberculosis (MDR-TB). Tuberculosis (Edinb), v.111, p.20-30, 2018.

LÖNNROTH K., et al. Alcohol use as a risk factor for tuberculosis - a systematic review. BMC Public Health. v.8, p. 289, 2008.

LÖNNROTH, K. et al. Tuberculosis control and elimination 2010-50: cure, care, and social development. The Lancet, v. 375, p. 1814-1829, 2010. 
LONNROTH, K., et al. Drivers of tuberculosis epidemics: the role of risk factors and social determinants. Social Science Medicine, v. 68, p.2240-2246, 2009.

LOUREIRO, R. B. et al. Acesso ao diagnóstico da tuberculose em serviços de saúde do município de Vitória, ES, Brasil. Ciências saúde coletiva, v.19, n.04, p.1233-1244, 2014.

MAGALHÃES, M.A.F.M.; MEDRONHO, R.A. Análise espacial da Tuberculose no Rio de Janeiro no período de 2005 a 2008 e fatores socioeconômicos associados utilizando microdados e modelos de regressão espaciais globais. Ciência \& Saúde Coletiva, v. 22, n.3, p.831-39, 2017.

MANFRÉ, L. A.; LOURENÇO, R.W.; DONALISIO, M.R. Distribuição espacial da tuberculose no município de Sorocaba, São Paulo, Brasil, 2000 - 2007. Revista Caminhos da Geografia, v.11, n. 35, p. 29-43, 2010.

MARINOVA, D. et al. MTBVAC from discovery to clinical trials in tuberculosis-endemic countries. Expert Rev Vaccines. v.16, n. 6, p.565-576, 2017.

MARMOT, M. Social determinants of health inequalities. Lancet; v. 365, p. 1099-104, 2005.

MAROCO J. Análise estatística com utilização do SPSS Statistics. Ed. Report Number, 2014, 990p.

MARSHALL, R.J. Mapping Disease and Mortality Rates Using Empirical Bayes Estimators. Journal of the Royal Statistical Society. Series C (Applied Statistics); v. 40, n. 2, p. 283294, 1991.

MARTINS, G. A. Estatística Geral e Aplicada 3ª Edição. Editora Atlas, 2010.

MATTEELLI, A. et al. Tuberculosis elimination: where are we now? European Respiratory Review, v. 27, n. 148, p. 180035, 2018.

MEDRONHO, R.A. et al. Epidemiologia. $2^{\text {a }}$ Edição. São Paulo: Atheneu, 2009.

MEE, P. et al. Changing use of traditional healthcare amongst those dying of HIV related disease and TB in rural South Africa from 2003 - 2011: a retrospective cohort study. BMC Complementary and Alternative Medicine, v. 14, p. 504, 2014.

MEULMAN, J. Optimal scaling methods for multivariate categorical data analysis. Data Theory Group Faculty of Social and Behavioral Sciences Leiden University, 1992.

MILLER, T. L. et al. Mortality Hazard and Survival After Tuberculosis Treatment. American Journal of Public Health. v.105, n. 5, p. 930-937, 2015.

MILLER, T. L. et al. Mortality Hazard and Survival After Tuberculosis Treatment, American Journal of Public Health. v.105, n. 5, p. 930-937, 2015.

MOLINA, P.E, et al. Focus on: Alcohol and the immune system. Alcohol Res Health, v. 33, v.1, p. 97-108, 2010.

MONKEN, M.; BARCELLOS, C. Vigilância à saúde e território utilizado: possibilidades teóricas e metodológicas. Cadernos de Saúde Pública. v. 21, n. 3, p. 898-906, 2005. 
MULENGA, C. et al. Management of pulmonary tuberculosis patients in an urban setting in Zambia: a patient's perspective. BMC Public Health. v. 10, p.756, 2010.

MUSENGE, E; VOUNATSOU P; KAHN, K. Space-time confounding adjusted determinants of child HIV/TB mortality for large zero-inflated data in rural South Africa Spatial and Spatio temporal. Epidemiology. v.2, p.205-217, 2011.

NG, I.C. et al. Spatial Dependency of tuberculosis incidence in Taiwan. Plos One, v. 7, n. 11, 2012.

NIGATU, T., ABRAHA, M. Epidemiological analysis of tuberculosis in Ethiopia: a ten-year trend analysis. East African Journal Public Health. v.7, n.2, p.182-6, 2010.

NOGUEIRA B.M.F. et al. Factors associated with tuberculosis treatment delay in patients coinfected with HIV in a high prevalence area in Brazil. PLoS One. v.13, n.8, p. e0202292, 2018.

OLIVEIRA, G.P. et al. Uso do sistema de informação sobre mortalidade para identificar subnotificação de casos de tuberculose no Brasil. Revista Brasileira de epidemiologia. v.15, n.3, p.468-477, 2012.

OLIVEIRA, S.P. et al. Early death by tuberculosis as the underlying cause in a state of Southern Brazil: Profile, comorbidities and associated vulnerabilities. International Journal of Tuberculosis and Lung Disease. Supll, n.80S, p.S50-S57, 2019.

ONYANGO, D.O. et al. Reduction of HIV-associated excess mortality by antiretroviral treatment among tuberculosis patients in Kenya. PLoS One. v.12, n.11, p.e0188235, 2017.

PECEGO, et al. Six-month survival of critically ill patients with HIV-related disease and tuberculosis: a retrospective study. BMC Infectious Disease. v.10, n.16, p.270, 2016.

PELISSARI, D.M.; DIAZ-QUIJANO, F.A. Household crowding as a potential mediator of socioeconomic determinants of tuberculosis incidence in Brazil. PLoS One, v.12, n. 4, p:0176116, 2017.

PELLEGRINI FILHO, A. Public policy and the social determinants of health: the challenge of the production and use of scientific evidence. Cadernos de Saúde Pública, v. 27, p. 135140, 2011. Supp. 2.

PEREIRA, A.G.L. et al. Distribuição espacial e contexto socioeconômico da tuberculose, Rio de Janeiro, Brasil. Revista de Saúde Pública, v.49, p. 48; 2015.

PINA, M. F.; SANTOS, S.M. Conceitos básicos de Sistemas de Informação Geográfica e Cartografia aplicados à saúde. Brasília: Organização Panamerica da Saúde -OPAS, 2000.

PODLEKAREVA, et al. Health care index score and risk of death following tuberculosis diagnosis in HIV-positive patients. International Journal of Tuberculosis and Lung Disease. v.17, n.2, p.198-206, 2013.

POETA, P., et al. Tuberculosis in the 21th century: Current status of diagnostic methods. Experimental Lung Research, 2019: 
PRATES, O.M.; KULLDORFF, M.; ASSUNÇÃO, R.M. Relative risk estimates from spatial and space-time scan statistics: Are they biased? Statistical Medicine, v.33, n.15, p. 26342644, 2014.

Programa das Nações Unidas para o Desenvolvimento (PNUD). Atlas do Desenvolvimento Humano nas Regiões Metropolitanas Brasileiras. - Brasília: PNUD, Ipea, FJP, 2013. 120 p.

QUEIROGA, R.P. F. et al. Distribuição espacial da tuberculose e a relação com condições de vida na área urbana do município de Campina Grande - 2004 a 2007. Revista Brasileira de Epidemiologia, v.5, n.1, p.222-32, 2012.

RABAHI, M. F. et al. Tratamento da tuberculose. Jornal brasileiro de pneumologia. v.43, n.6, p.472-486, 2017.

RASANATHAN, K. et al. Primary health care and the social determinants of health: essential and complementary approaches for reducing inequities in health. Journal Epidemioly Community Health. v.65, p. 656-660, 2011.

RASELLA, D. et al. Child morbidity and mortality associated with alternative policy responses to the economic crisis in Brazil: A nationwide microsimulation study. PLoS Medicine, v.15, n.5, p.e1002570, 2018.

REEVES, A. et al. Financing universal health coverage--effects of alternative tax structures on public health systems: cross-national modelling in 89 low-income and middle-income countries. Lancet. v.18, n.386, p. 274-80, 2015.

REHM J., et al. The association between alcohol use, alcohol use disorders and tuberculosis (TB). A systematic review. BMC Public Health. v.9, p. 450, 2009.

RODRÍGUEZ-MORALES， A.J.; CASTAÑEDA-HERNÁNDEZ， D.M. Relationships between morbidity and mortality from tuberculosis and the human development index (HDI) in Venezuela, 1998-2008. International Journal of Infection and Disease, v.16, n.9, p.e704-5, 2012.

ROSA, F.H.F.P., et al. Introdução à Análise de Sobrevivência e Aplicações,

ROTHMAN, K.J. et al. Modern Epidemiology. $3^{\text {a }}$. Ed; Lippincott Williams \& Wilkins (LWW) 2008.

RUFFINO-NETO, A.; VILLA, T.C.S. (Org). Tuberculose: pesquisas operacionais. 1 Edição. Ribeirão Preto, SP : FUNPEC Editora, 2009.

RUFFINO-NETTO, A. Tuberculose: a calamidade negligenciada. Revista da Sociedade Brasileira de Medicina Tropical, v. 35, n. 1, p. 51-58,. 2002.

SÁ, L.D. et al. Implantação da estratégia DOTS no controle da Tuberculose na Paraíba: entre o compromisso político e o envolvimento das equipes do programa saúde da família (19992004). Ciência e Saúde Coletiva, v.16, n.9, p.3917-3924, 2011. 
SAMPAIO, R.F; MANCINI, M.C. Estudos de revisão sistemática: um guia para síntese criteriosa da evidência científica. Revista brasileira de fisioterapia, v. 11, n. 1, p. 83-89, 2007.

SAN PEDRO, A.; OLIVEIRA, R.M. Tuberculose e indicadores socioeconômicos: revisão sistemática da literatura. Revista Panamericana Salud Publica, v. 33, n. 4, p. 294$301,2013$.

SANTOS NETO, M. et al. Pulmonary tuberculosis in São Luis, State of Maranhão, Brazil: space and space-time risk clusters for death (2008-2012). Revista Sociedade Brasileira de Medicina Tropical. v. 48, n. 1, p. 69-76, Feb. 2015.

SANTOS, C.B. et al. Utilização de um Sistema de Informação Geográfica para descrição dos casos de tuberculose. Bol. Pneumol. Sanit., v.12, n.1, p.07-12, 2004.

SANTOS, D. T. et al. Is there association between human development index and tuberculosis mortality risk? Evidence from a spatial analysis study in the south of Brazil. Epidemiology \& Infection, v. 146, n. 14, p. 1763-1770, 2018a.

SANTOS, D.T. et al. Human Development Index and its associations with tuberculosis mortality in a Brazilian municipality: an ecological study. Poster discussion sessions, 49th Union World Conference on Lung Health, v.22, n.11, supp.2, p. S211, nov. 2018 b.

SANTOS, D. T. et al. Social risk and its association with tuberculosis mortality in a context of high inequality in South Brazil: a spatial analysis. BMC Pulmonary Medicine. PULM-D18-00467R1. Artigo submetido.

SANTOS, D. T. et al. Survival analysis, precocious deaths and their determinants in tuberculosis patients in a municipality of Southern Brazil. BMC Public health. PUBH-S-1901211. Artigo submetido.

SANTOS, D.T. et al. Infecção latente por tuberculose entre pessoas com HIV/AIDS, fatores associados e progressão para doença ativa em município no Sul do Brasil. Cadernos de Saúde Pública. v.33, n.8, p. e00050916. 2017.

SANTOS-FELTRIN, A.F. et al. Death in patients with tuberculosis and diabetes: Associated factors dos Santos. Diabetes Research and Clinical Practice, v.120, p.111-116, 2016.

SANTOS-NETO, M. et al. Análise espacial dos óbitos por tuberculose pulmonar em São Luís, Maranhão. Jornal brasileiro de pneumologia, v. 40, n. 5, p. 543-551, 2014.

SANTOS-NETO, M. et al. The Impact of Social Inequities on Mortality Due to Pulmonary Tuberculosis in São Luis, Maranhão, Brazil. International archives of medicine section: epidemiology, v. 9, n. 219, 2016.

SCHMALTZ, C.A. et al. Factors impacting early mortality in tuberculosis/HIV patients: differences between subjects naïve to and previously started on HAART. PLoS One.v.7, n.9, p:e45704, 2012.

SEID, A.; METAFERIA, Y. Factors associated with treatment delay among newly diagnosed tuberculosis patients in Dessie city and surroundings, Northern Central Ethiopia: a crosssectional study. BMC Public Health. v.18, n.1, p. 931, 2018. 
SHIMAZAKI, et al. Risk factors for death among hospitalised tuberculosis patients in poor urban areas in Manila, The Philippines. International Journal of Tuberculosis and Lung Disease, v.17, n.11, p.1420-6, 2013.

SILVA, A.P.S.C.; SOUZA, W.V.; ALBUQUERQUE, M.F.P.M. Two decades of tuberculosis in a city in Northeastern Brazil: advances and challenges in time and space. Revista da Sociedade Brasileira de Medicina Tropical. v. 49, n. 2, p. 211-221, 2016.

SILVA, et al. Factors associated with mortality in hospitalized patients with newly diagnosed tuberculosis. Lung. v.188, n.1, n.33-41, 2010.

SIROKA, A.; PONCE, N. A.; LÖNNROTH, K. Association between spending on social protection and tuberculosis burden: a global analysis. The Lancet Infectious Diseases, v. 16, n. 4, p. 473-479, 2016.

SOLAR O, IRWIN A. A conceptual framework for action on the social determinants of health. Social Determinants of Health Discussion Paper 2 (Policy and Practice). Geneva; World Health Organization, 2010.

SOUSA, L. M. O.; PINHEIRO, R. S. Óbitos e internações por tuberculose não notificados no município do Rio de Janeiro. Revista de Saúde Pública. v.45, n.1, p.31-9, 2011.

SPASOFF, R.A. Epidemiologic methods for health policy. Oxford University Press; New York, 1999.

SPENCER, N.H. Essentials of Multivariate data Analysis. CRC PRESS: Taylor \& Francis Group, 2014.186p.

STIGLITZ, J.E,; SEM, A.; FITOUSSI, J.P. Report by the Commission on the Measurement of Economic Performance and Social Progress. 2009

STOP TB. THE GLOBAL PLAN TO STOP TB 2011-2015. Disponível em <http://www.stoptb.org/assets/documents/global/plan/TB_GlobalPlanToStopTB20112015.pdf> Acesso em 18 de abril de 2013.

SUN, W. et al. A spatial, social and environmental study of tuberculosis in China using statistical and GIS technology. International Journal of environmental research and public Health, v. 12, p. 1425-1448, 2015.

TOURAY, K. et al. Spatial analysis of tuberculosis in an urban West African setting: is there evidence of clustering? Tropical Medicine International Health.v.15, n.6, p.664-672, 2010.

TSUTAKAWA, R.K. Estimation of Cancer Mortality Rates: A Bayesian Analysis of Small Frequencies. Biometrics; v.41, n.1: 69-79, 1985.

Universidade Federal do Paraná (UFPR). Pró-reitora de assuntos estudantis: casas estudantis. Disponível em <http://www.prae.ufpr.br/prae/vida-academica/casas-estudantis/>, acesso em 20 de nov. 2018.

VAN'T HOOG, et al., 2012 Risk factors for excess mortality and death in adults with tuberculosis in Western Kenya. International Journal of Tuberculosis and Lung Disease, v.16, n.12, p.1649-56, 2012. 
VENÂNCIO, J. (org). O território e a vigilância em saúde. Série: Material didático do Programa de Formação de Agentes Locais de Vigilância em saúde Escola Politécnica de Saúde, Rio de Janeiro : FIOCRUZ/EPSJV/PROFORMAR, 2004. 80p.

VENDRAMINI, S.H.F. et al. Análise espacial da co-infecção tuberculose/HIV: relação com níveis socioeconômicos em município do sudeste do Brasil. Revista da Sociedade Brasileira de Medicina Tropical. v. 43, n.5, p.536-541, 2010

VIACAVA, F. et al. Avaliação de Desempenho de Sistemas de Saúde: um modelo de análise. Ciências e saúde coletiva. v. 17, n. 4, p. 921-934, 2012.

VIEIRA, F.S.; BENEVIDES, R.P.S. O Direito à Saúde no Brasil em Tempos de Crise Econômica, Ajuste Fiscal e Reforma Implícita do Estado. Revista de Estudos e Pesquisas sobre as Américas. v.10, n.3, p.1-28, 2016.

WAITT, C.J.; SQUIRE, S.B. A systematic review of risk factors for death in adults during and after tuberculosis treatment. International Journal of Tuberculosis and Lung Disease. v.15, p. 871-85, 2011.

WANG, et al. Deaths of tuberculosis patients in urban China: a retrospective cohort study. International Journal of Tuberculosis and Lung Disease, v.17, n.4, p.493-8, 2013.

WINGFIELD, T. et al., Beyond pills and tests: addressing the social determinants of tuberculosis. Clinical Medicine, v.16, n. 6, p.79-91, 2016.

WORLD HEALTH ORGANIZATION (WHO). Global Health Risks: Mortality and burden of disease attributable to selected major risks. Geneva: World Health Organization; 2009 70p. Available from: http://www.who.

int/healthinfo/global_burden_disease/GlobalHealthRisks_report_full.pdf

WORLD HEALTH ORGANIZATION (WHO). A conceptual framework for action on the social determinants of health. Geneva, 2010. Disponível em: http://apps.who.int/iris/bitstream/handle/10665/44489/9789241500852_eng.pdf;jsessionid=A 549A6436C810B2BC96726B671DB4F36? sequence=1. Acesso em: 23 de setembro de 2018.

WORLD HEALTH ORGANIZATION (WHO). Definitions and reporting framework for tuberculosis - 2013 Revision; 2013.

WORLD HEALTH ORGANIZATION (WHO). Global Tuberculosis Programme: Framework for Effective Tuberculosis Control. Geneva, World Health Organization, 1994.

WORLD HEALTH ORGANIZATION (WHO). Global tuberculosis report 2018. Geneva: World Health Organization, 2018. Disponível em: < http://apps.who.int/iris/bitstream/handle/10665/274453/9789241565646-eng.pdf?ua=1>.

Acesso em 30 de novembro de 2018.

WORLD HEALTH ORGANIZATION (WHO). The end TB strategy. Implementing the end TB strategy: the essentials. Geneva, 2015. Disponível em: $<$ http://www.who.int/tb/publications/2015/end_tb_essential.pdf?ua=1>. Acesso em: $23 \mathrm{de}$ junho de 2017. 
WORLD HEALTH ORGANIZATION (WHO). The End TB Strategy: Global strategy and targets for tuberculosis prevention, care and control after 2015. WHO/HTM/TB/2015.19. Geneva, Switzerland: WHO, 2015.

WORLD HEALTH ORGANIZATION (WHO). What is DOTS? A guide to understanding the WHO-recommended Tb control strategy known as DOTS. WHO/cds/cpc/tb/99.270, 1999.

WORLD HEALTH ORGANIZATION (WHO). WHO Global Tuberculosis Programme: Framework for Effective Tuberculosis Control. Geneva, World Health Organization, 1994.

WORLD HEALTH ORGANIZATION (WHO): Stop TB Partnership: Reach the 3 million. Find. Treat. Cure TB. Geneva: WHO; 2014a.

WU, et al. Comparing the factors correlated with tuberculosis-specific and non-tuberculosisspecific deaths in different age groups among tuberculosis-related deaths in Taiwan. PLoS One. v.3, n.10, p.e0118929, 2015.

WUBULI, A. et al. Socio-Demographic Predictors and Distribution of Pulmonary Tuberculosis (TB) in Xinjiang, China: A Spatial Analysis. PLoS One. v.7, n.10, 2015.

XIMENES A, R. A. et al. Is it better to be rich in a poor area or poor in a rich area? A multilevel analysis of a case-control study of social determinants of tuberculosis. International journal of epidemiology, v. 38, n. 5, p. 1285- 1296, 2009.

XIN-XU L. et al. Spatial variations of pulmonary tuberculosis prevalence co-impacted by socio-economic and geographic factors in People's Republic of China 2010. BMC Public Health. v.14, p:257, 2014.

YAMAMURA, M. et al.; Características epidemiológicas dos casos de óbito por tuberculose e territórios Vulneráveis. Revista Latino-Americana de Enfermagem, v. 23, n. 5, p.910918, 2015.

YANG, X.; LIU, Q.; ZHANG, R. Epidemiology of pulmonary tuberculosis in Wenchuan earthquake stricken area: population-based study. Journal Evidence Based Medicine. v.6, n.3, p. 149-56, 2013.

YEN, Y.F. et al. Determinants of mortality in elderly patients with tuberculosis: a populationbased follow-up study. Epidemiology \& Infection, v. 145, n. 7, p. 1374-1381, 2017.

YEN, Y.F. et al. DOT associated with reduced all-cause mortality among tuberculosis patients in Taipei, Taiwan, 2006-2008. International Journal of Tuberculosis and Lung Disease, v.16, n.2, p.178-84, 2012.

ZERBINI, et al. Risk factors associated with tuberculosis mortality in adults in six provinces of argentina. Medicina (Buenos Aires). v.77, p. 267-273, 2017.

ZHANG, S. et al. DOT associated with reduced all-cause mortality among tuberculosis patients in Taipei, Taiwan, 2006-2008. Antimicrobial Agents and Chemotherapy. v.60, n.4, p.2542-2544, 2016.

ZHAO, F. et al. Space-time clustering characteristics of tuberculosis in China, 2005-2011.

PLoS One. v.19, p.9-12, 2013. 
ZHOU, L. et al. Spatial epidemiology and risk factors of pulmonary tuberculosis morbidity in Wenchuan earthquake-stricken area. Journal of Evidence-Based Medicine. v.9, p. 69-76, 2016.

ZIONI, F.; WESTPHAL, M.F. O enfoque dos determinantes sociais de saúde sob o ponto de vista da teoria social. Saúde Sociedade São Paulo. v. 16, n.3, p.26-34, 2007.

ZUMLA, et al. New antituberculosis drugs, regimens, and adjunct therapies: needs, advances, and future prospects. Lancet Infectious Disease. v.14, n.4, p.327-40, 2014.

ZÜRCHER K., et al. Drug susceptibility testing and mortality in patients treated for tuberculosis in high-burden countries: a multicentre cohort study. Lancet Infectious Disease.v.193, p.298-307, 2019. 
Anexos 
ANEXO 1

República Federativa do Brasil Ministério da Saúde - VIA-SECRETARIA DE SAUDE

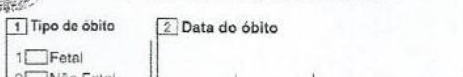

\section{Declaração de Óbito}

Hora [3] Cartåo Sus

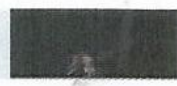

ه Naturalidade

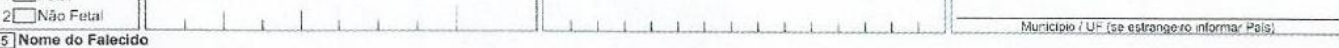

\section{西}

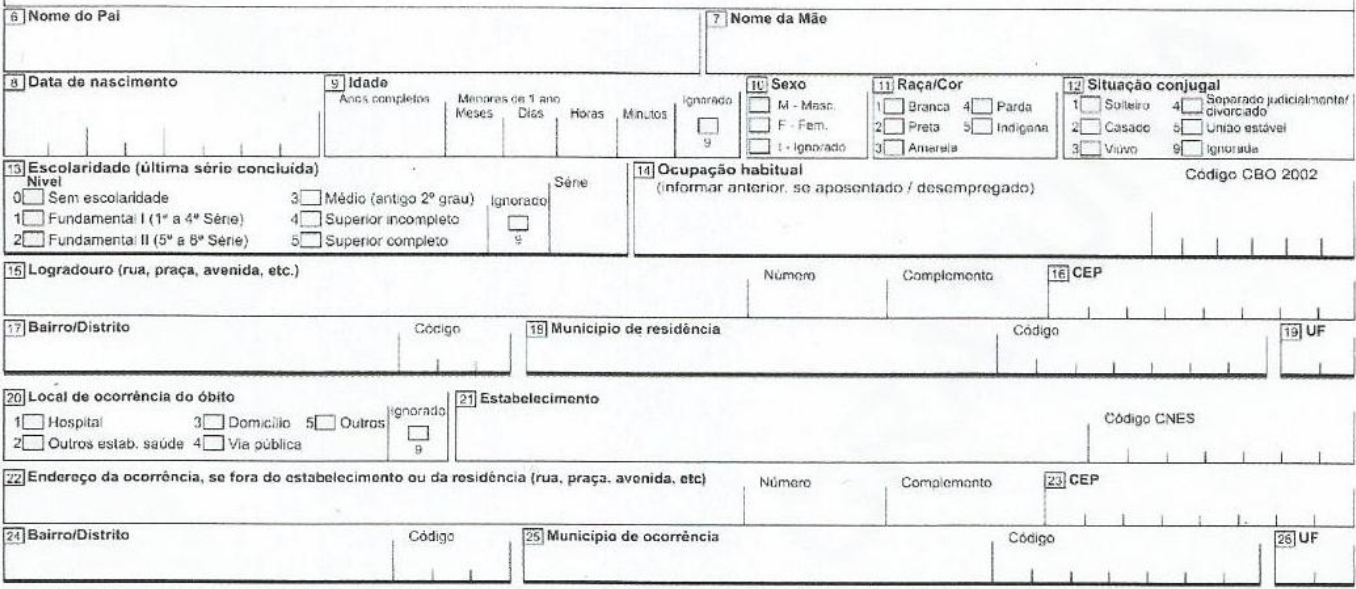

PREENCHIMENTO EXCLUSIVO PARA OBITOS FETAIS E DE MENORES DE 1 ANO - INFORMACCOES SOBRE AMAE

$\begin{aligned} & \text { 27] Idade } \\ & \text { (anos) }\end{aligned}$
2a] Esvel

IV

$0 \square$ Sem escolaridade $\quad 3 \square$ Mededio (antigo $2^{2}$ graul

$1 \square$ Fundamental I (1. a 4. Série) $4 \square$ Superior incompieto

$12 \square$ Fundamental II ( $5^{2}$ a $8^{3}$ Sorie) $5 \square$ Superior compiato

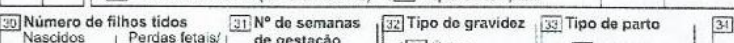

Perdas letais' de gestaçăo

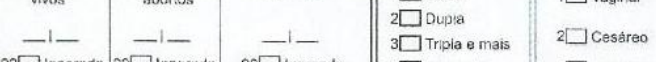

$99 \square$ ignorado $99 \square$ Ignorado $99 \square$ ignerado $9 \square$ ignorada $9 \square$ ignorado

OBITO DE MULHER EM IDADE FERTIL

7 A morte ocorreu

$1 \square$ Na gravidez $3 \square$ No aborti

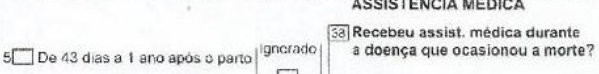

Morte em relaçao ao parto

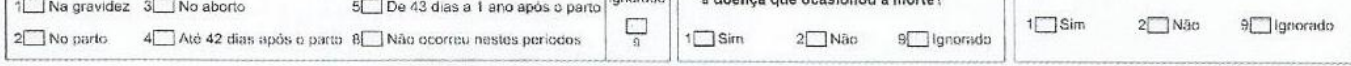

40 CAUSAS DA MORTE

PARTE I
Doença ou estado mórtidida que causou diretamanta a a|

CAUSAS ANTECEDENTES

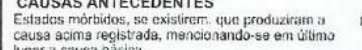

ANOTE SOMENTE UM DIAGNOSTICO POR LINHA

$1 \square$ Antes $2 \square$ Durante

Devico ou coma consequencia de:

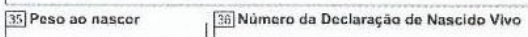

Devico su momo consequéncia de:

- Devico ou como consequência de: d

PARTE II

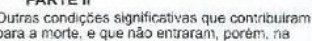

cadoia acima. eque nås entrarant, porém, ne

4] Nome do Médico
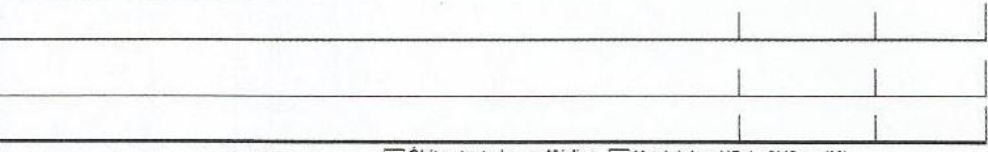

PROVAVEIS CIRCUNSTÃNCIAS DE MORTE NĀO NATURAL (Informaçōes do caráter estrtamente opidomiológico)

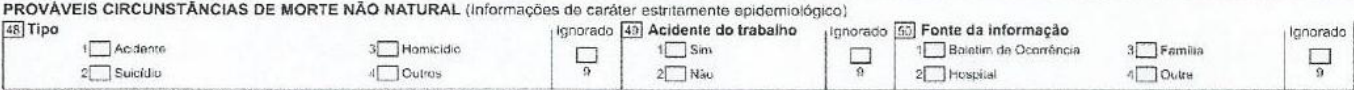

5]. Descriçāo sumaria do evento, incluindo o tipo de locai de ocorrência

$4 \sqrt{43}$ Obito atestado por Médico $\sqrt{44}$ Municipio e UF do SVO ou IML $\begin{array}{ll}10 \text { Assistente } & 4 \square \text { Svo } \\ 2 & \text { Substituto } \\ 5\end{array}$

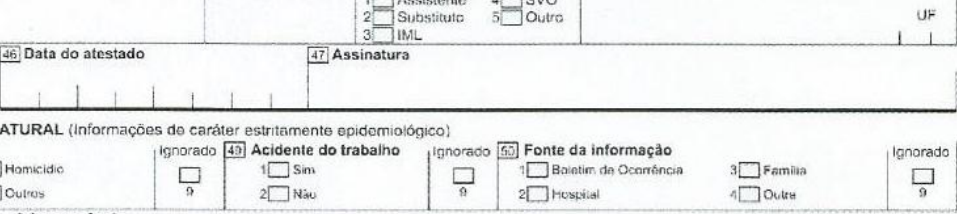
SEA OCORRENCIA FOR EM VIA PULBLICA, ANOTAR O ENDERECCO
TO2 Logradouro (rua, praça, avenida, etc.)

3) Cartório

[5] Registro

Codilgo 


\section{ANEXO 2}

República Federativa do Brasil Ministério da Saúde
SINAN

SISTEMA DE INFORMAÇÃO DE AGRAVOS DE NOTIFICAÇÃO FICHA DE NOTIFICAÇÄ̃O / INVESTIGAÇÃO TUBERCỦlOSE

CRITERIO LABOTORIAL - $\theta$ todo caso que, Independentemente da forma clinica, apresenta pelo menos uma amostra positiva de baclloscopla, ou de cultura,

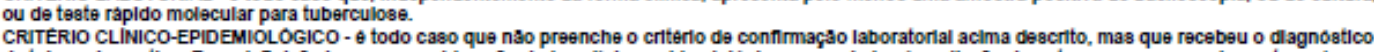
de tuberculose ativa. Essa denniç̧å leva em consideraçà dados clinico-epidemiologicos assoclados a avallaç̧a de outros exames complementares (como 08 de Imagem, histologicos, entre outros).

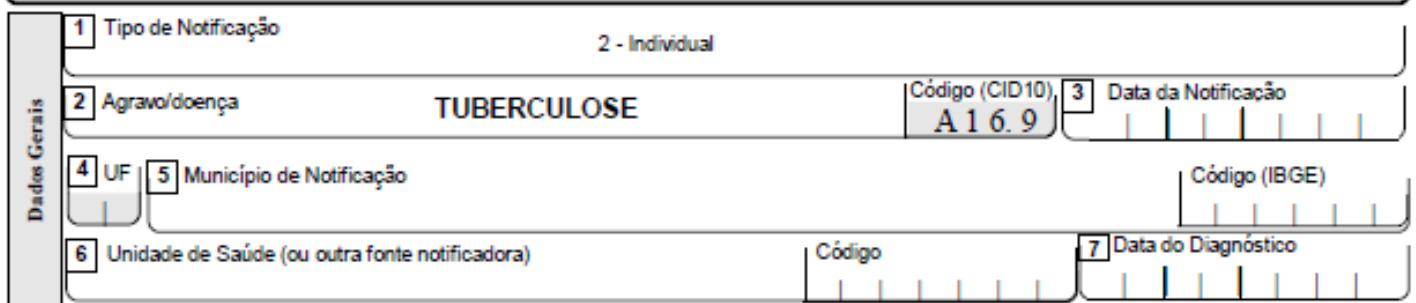

8 Nome do Paciente

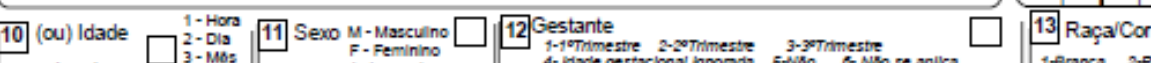

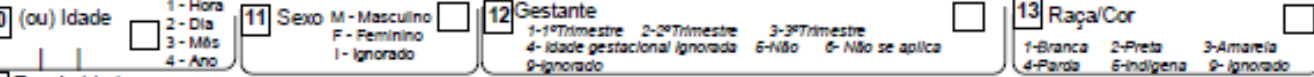
14. Escolaridade

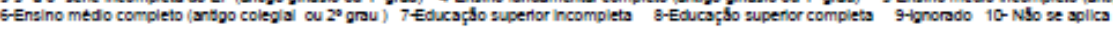

15 Número do Cartão SUS 16 Nome da mãe

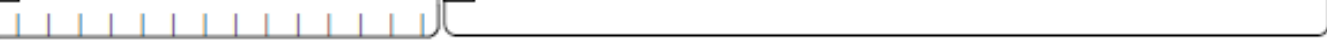
17 UF 18 Municipio de Residencia 1

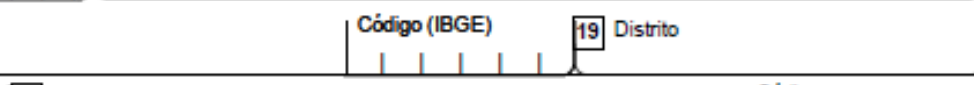
20. Bairr 21 Logradouro (rua, avenida,...)

22 Número 223 Complemento (apto., casa, ...)

$\mid$\begin{tabular}{ccccc|c|} 
Código & & & \\
\hline & & & & & \\
\hline
\end{tabular}
25 Geo campo 02

$+1+1+1$

29 Ponto de Referéncia

29 Zonạ - Urbana 2-Rural 1- Urbana 2 - Rural
3 - Periurbana 9 -Ignorado

Dados Complementares do Caso

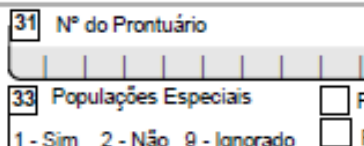

32 Tipo de Entrada 2 - Recidiva

3 - Reingresso Após Abandono

4 - Não Sabe

1 - Sim 2 - Näo 9 - lgnorado

Populaçäo Privada de Liberdade

Populaçäio em Situação de Rua

Profissional de Saúde

24 Beneficiário de programa de ransferéncia de renda do governo $\square$

35 Forma 1 - Pulmonar 2- Extrapulmonar $\square, 36$ Se Extrapulmonar 3 - Pulmonar + Extrapulmonar

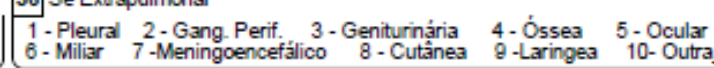
37 Doençass e Agravos Associados

1 - Sim 2 - Näo 9 - lgnorado

$\square$ Aids

\section{DAlcoolismo $\square$ Diabetes $\square$ Doença Menta} $\square$ Uso de Drogas llicitas $\square$ Tabagismo $\square$ Outras

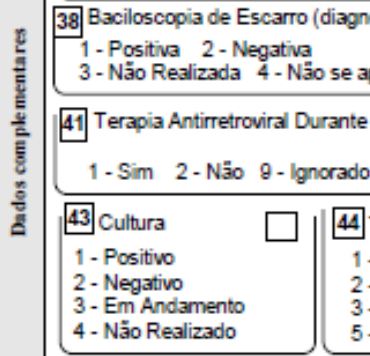
agnóstico) 口. 39 Radiografia do Tórax Nä̊ se aplica 1 - Suspeito 2 - Normal 3 - Outra Patologia 4 - Näo Realizado

1-Positiv

1 - Positivo 3 - Em Andamento

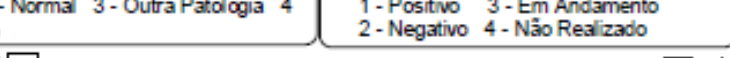
\begin{tabular}{l|l}
42 & Histopatologia \\
1 - Baar Positivo 2
\end{tabular} 1 - Baar Positivo 2 - Sugestivo de TB 3 - Näo Sugestivo de TB 4 - Em Andamento 5 - Năo Realizado

46 Data de Inicio do Tratamento Atual 47 Total de Contatos Identificados

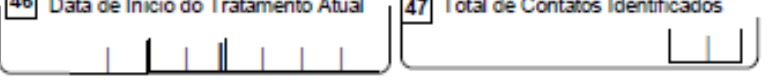

Municipio/Unidade de Sajide

$\underbrace{\text { Função }}_{\text {Sinan NET }}$




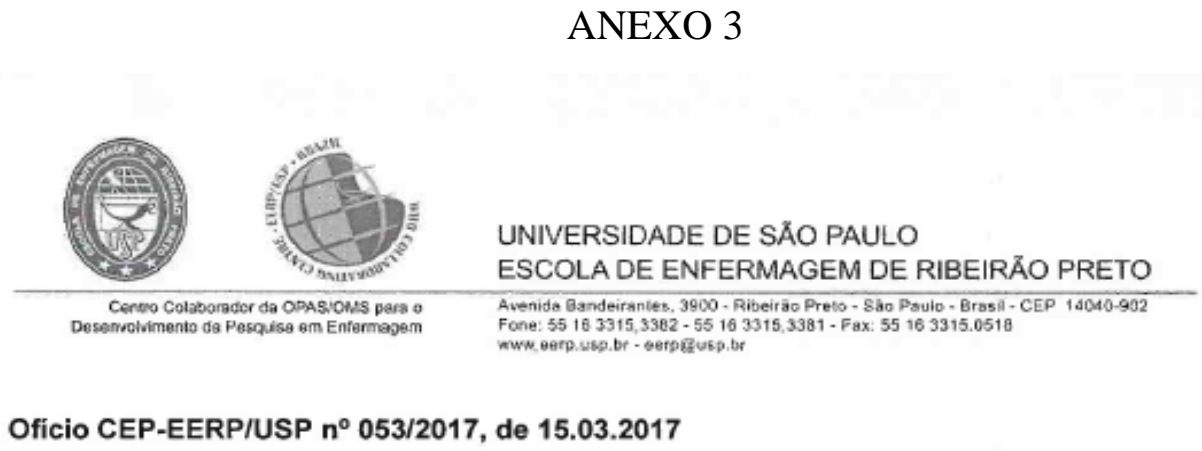

Prezado Senhor,

Comunicamos que o projeto de pesquisa abaixo especificado foi analisado e considerado aprovado pelo Comitê de Ética em Pesquisa da Escola de Enfermagem de Ribeirăo Preto da Universidade de São Paulo (CEP-EERP/USP) em sua 224a Reunião Ordinária, realizada em 15 de março de 2017.

Protocolo CAAE: 64515717.9 .0000 .5393

Projeto: ANÁLISE ESPACIAL DA MORTALIDADE POR TUBERCULOSE E SEUS DETERMINANTES SOCIAIS DA SAÜDE: PROCURANDO EVIDÊNCIAS EM MUNICIPIOS DO PARANÁ

Pesquisadores: Danielle Talita dos Santos

Ricardo Alexandre Arcêncio (orientador)

Em atendimento à Resoluçaào 466/12, deverá ser encaminhado ao CEP o relatório final da pesquisa e a publicaçăo de seus resultados, para acompanhamento, bem como comunicada qualquer intercorrência ou a sua interrupção.

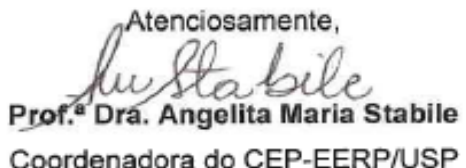

IImo. Sr.

Prof. Dr. Ricardo Alexandre Arcêncio

Departamento de Enfermagem Materno-Infantil e Saúde Pública Escola de Enfermagem de Ribeirăo Preto - USP 